Cochrane Database of Systematic Reviews

\title{
Antidepressants for treating depression in dementia (Review)
}

Dudas R, Malouf R, McCleery J, Dening T

Dudas R, Malouf R, McCleery J, Dening T.

Antidepressants for treating depression in dementia.

Cochrane Database of Systematic Reviews 2018, Issue 8. Art. No.: CD003944.

DOI: 10.1002/14651858.CD003944.pub2.

www.cochranelibrary.com 
TABLE OF CONTENTS

HEADER

ABSTRACT

PLAIN LANGUAGE SUMMARY

SUMMARY OF FINDINGS

BACKGROUND

OBJECTIVES

METHODS

RESULTS

Figure 1.

Figure 2.

Figure 3.

Figure 4.

Figure 5.

Figure 6.

Figure 7.

Figure 8.

DISCUSSION

AUTHORS' CONCLUSIONS

ACKNOWLEDGEMENTS

REFERENCES

CHARACTERISTICS OF STUDIES

DATA AND ANALYSES

Analysis 1.1. Comparison 1 Antidepressant versus placebo, Outcome 1 Depression endpoint mean scores at 6-13 weeks. ......

Analysis 1.2. Comparison 1 Antidepressant versus placebo, Outcome 2 Cornell Scale for Depression in Dementia (CSDD). ......

Analysis 1.3. Comparison 1 Antidepressant versus placebo, Outcome 3 Hamilton Depression rating Scale (HDRS). ..................

Analysis 1.4. Comparison 1 Antidepressant versus placebo, Outcome 4 Number of responders (ITT) at 6-12 weeks. ...............

Analysis 1.5. Comparison 1 Antidepressant versus placebo, Outcome 5 Number of responders (ITT) at 24 weeks. ...................

Analysis 1.6. Comparison 1 Antidepressant versus placebo, Outcome 6 Number of patients with remission (ITT) at 6-12 weeks.

Analysis 1.7. Comparison 1 Antidepressant versus placebo, Outcome 7 Number of patients with remission (ITT) at 24 weeks. ..

Analysis 1.8. Comparison 1 Antidepressant versus placebo, Outcome 8 Cognitive function endpoint mean scores.

Analysis 1.9. Comparison 1 Antidepressant versus placebo, Outcome 9 Change in MMSE mean scores.

Analysis 1.10. Comparison 1 Antidepressant versus placebo, Outcome 10 Activities of daily living, endpoint values at 6-13 weeks.

Analysis 1.11. Comparison 1 Antidepressant versus placebo, Outcome 11 Activities of daily living at 6-9 months. .................. Analysis 1.12. Comparison 1 Antidepressant versus placebo, Outcome 12 Tolerability: Number of dropouts at 6-13 weeks. ..... Analysis 1.13. Comparison 1 Antidepressant versus placebo, Outcome 13 Tolerability: Number of dropouts at 6-9 months. .... Analysis 1.14. Comparison 1 Antidepressant versus placebo, Outcome 14 Safety: number experiencing at least one adverse event.

Analysis 1.15. Comparison 1 Antidepressant versus placebo, Outcome 15 Safety: $\mathrm{N}$ experiencing at least one event of dry mouth.

Analysis 1.16. Comparison 1 Antidepressant versus placebo, Outcome 16 Safety: $N$ experiencing at least one event of fatigue. .

Analysis 1.17. Comparison 1 Antidepressant versus placebo, Outcome 17 Safety: $\mathrm{N}$ experiencing at least one event of constipation.

Analysis 1.18. Comparison 1 Antidepressant versus placebo, Outcome 18 Safety: $\mathrm{N}$ experiencing at least one event of dizziness.

ADDITIONAL TABLES

APPENDICES

WHAT'S NEW

HISTORY

CONTRIBUTIONS OF AUTHORS

DECLARATIONS OF INTEREST

SOURCES OF SUPPORT

1

1

2

4

6

6

7

9

10

13

14

15

16

17

17

18

19

20

21

22

28

48

50

51

52

52

52

53

53

54

54

55

55

55

56

Antidepressants for treating depression in dementia (Review)

Copyright $\odot 2018$ The Cochrane Collaboration. Published by John Wiley \& Sons, Ltd. 
[Intervention Review]

\title{
Antidepressants for treating depression in dementia
}

\author{
Robert Dudas ${ }^{1,2}$, Reem Malouf 3 , Jenny McCleery 4 , Tom Dening 5
}

1Department of Psychiatry, University of Cambridge, Cambridge, UK. 2Older People's Mental Health Service, Cambridge and Peterborough NHS Foundation Trust, Cambridge, UK. ${ }^{3}$ National Perinatal Epidemiology Unit (NPEU), University of Oxford, Oxford, UK. ${ }^{4}$ Oxford Health NHS Foundation Trust, Banbury, UK. ${ }^{5}$ Division of Psychiatry \& Applied Psychology, The University of Nottingham, Nottingham, UK

Contact address: Robert Dudas, Department of Psychiatry, University of Cambridge, Addenbrooke's Hospital, Hills Road, Cambridge, CQ22QQ, UK.rbd21@cam.ac.uk.

Editorial group: Cochrane Dementia and Cognitive Improvement Group.

Publication status and date: New search for studies and content updated (conclusions changed), published in Issue 8, 2018.

Citation: Dudas R, Malouf R, McCleery J, Dening T. Antidepressants for treating depression in dementia. Cochrane Database of Systematic Reviews 2018, Issue 8. Art. No.: CD003944. DOI: 10.1002/14651858.CD003944.pub2.

Copyright ( 2018 The Cochrane Collaboration. Published by John Wiley \& Sons, Ltd.

\section{A B S T R A C T}

\section{Background}

The use of antidepressants in dementia accompanied by depressive symptoms is widespread, but their clinical efficacy is uncertain. This review updates an earlier version, first published in 2002.

\section{Objectives}

To determine the efficacy and safety of any type of antidepressant for patients who have been diagnosed as having dementia of any type and depression as defined by recognised criteria.

\section{Search methods}

We searched ALOIS, the Cochrane Dementia and Cognitive Improvement Group's Specialised Register, on 16 August 2017. ALOIS contains information on trials retrieved from databases and from a number of trial registers and grey literature sources.

\section{Selection criteria}

We included all relevant double-blind, randomised trials comparing any antidepressant drug with placebo, for patients diagnosed as having dementia and depression.

\section{Data collection and analysis}

Two review authors selected studies for inclusion and extracted data independently. We assessed risk of bias in the included studies using the Cochrane 'Risk of bias' tool. Where clinically appropriate, we pooled data for treatment periods up to three months and from three to nine months. We used GRADE methods to assess the overall quality of the evidence.

\section{Main results}

We included ten studies with a total of 1592 patients. Eight included studies reported sufficiently detailed results to enter into analyses related to antidepressant efficacy. We split one study which included two different antidepressants and therefore had nine groups of patients treated with antidepressants compared with nine groups receiving placebo treatment. Information needed to make 'Risk of bias' judgements was often missing.

We found high-quality evidence of little or no difference in scores on depression symptom rating scales between the antidepressant and placebo treated groups after 6 to 13 weeks (standardised mean difference (SMD) $-0.10,95 \%$ confidence interval (CI) -0.26 to $0.06 ; 614$ participants; 8 studies). There was probably also little or no difference between groups after six to nine months (mean difference (MD) 0.59 
point, $95 \% \mathrm{Cl}-1.12$ to 2.3, 357 participants; 2 studies; moderate-quality evidence). The evidence on response rates at 12 weeks was of low quality, and imprecision in the result meant we were uncertain of any effect of antidepressants (antidepressant: $49.1 \%$, placebo: $37.7 \%$; odds ratio (OR) $1.71,95 \% \mathrm{Cl} 0.80$ to $3.67 ; 116$ participants; 3 studies). However, the remission rate was probably higher in the antidepressant group than the placebo group (antidepressant: 40\%, placebo: $21.7 \%$; OR 2.57, $95 \% \mathrm{Cl} 1.44$ to 4.59 ; 240 participants; 4 studies; moderatequality evidence). The largest of these studies continued for another 12 weeks, but because of imprecision of the result we could not be sure of any effect of antidepressants on remission rates after 24 weeks. There was evidence of no effect of antidepressants on performance of activities of daily living at weeks 6 to 13 (SMD $-0.05,95 \% \mathrm{Cl}-0.36$ to $0.25 ; 173$ participants; 4 studies; high-quality evidence) and probably also little or no effect on cognition (MD 0.33 point on the Mini-Mental State Examination, $95 \% \mathrm{Cl}-1.31$ to 1.96; 194 participants; 6 studies; moderate-quality evidence).

Participants on antidepressants were probably more likely to drop out of treatment than those on placebo over 6 to 13 weeks (OR $1.51,95 \%$ $\mathrm{Cl} 1.07$ to 2.14; 836 participants; 9 studies). The meta-analysis of the number of participants suffering at least one adverse event showed a significant difference in favour of placebo (antidepressant: $49.2 \%$, placebo: 38.4\%; OR 1.55, 95\% $\mathrm{Cl} 1.21$ to $1.98,1073$ participants; 3 studies), as did the analyses for participants suffering one event of dry mouth (antidepressant: 19.6\%, placebo: 13.3\%; OR 1.80, 95\% Cl 1.23 to $2.63,1044$ participants; 5 studies), and one event of dizziness (antidepressant: $19.2 \%$, placebo: $12.5 \%$; OR 2.00, $95 \% \mathrm{Cl} 1.34$ to $2.98,1044$ participants; 5 studies). Heterogeneity in the way adverse events were reported in studies presented a major difficulty for meta-analysis, but there was some evidence that antidepressant treatment causes more adverse effects than placebo treatment does.

\section{Authors' conclusions}

The available evidence is of variable quality and does not provide strong support for the efficacy of antidepressants for treating depression in dementia, especially beyond 12 weeks. On the only measure of efficacy for which we had high-quality evidence (depression rating scale scores), antidepressants showed little or no effect. The evidence on remission rates favoured antidepressants but was of moderate quality, so future research may find a different result. There was insufficient evidence to draw conclusions about individual antidepressant drugs or about subtypes of dementia or depression. There is some evidence that antidepressant treatment may cause adverse events.

\section{PLAIN LANGUAGE SUMMARY}

\section{Antidepressants for treating depression in dementia}

\section{Review question}

We reviewed the evidence about the effect of antidepressants on depression in people with dementia.

\section{Background}

Depression can be hard to recognise in people with dementia, but there is evidence that it is common and associated with increased disability, poorer quality of life, and shorter life expectancy. Many people with dementia are prescribed antidepressants to treat depression, but there is uncertainty about how effective this is.

This review updates an earlier version, first published in 2002.

\section{Search date}

We searched up to August 2017 for relevant studies.

\section{Study characteristics}

We found ten studies with 1592 people to include in the review. On average, the studies lasted only 12 weeks, although one study ran for nine months. Each of them used a set of formal criteria to diagnose both depression and dementia and compared an antidepressant against a dummy pill (placebo).

The older studies used more old-fashioned antidepressants (imipramine, clomipramine, and moclobemide) and the newer studies used more modern ones, such as venlafaxine, mirtazapine and so-called SSRI antidepressants (sertraline, fluoxetine, citalopram and escitalopram).

The people taking part in the studies had an average age of 75 and they had mild or moderate dementia. With the exception of two studies, they were being treated as outpatients.

\section{Key results}

We found that there was little or no difference in scores on depression rating scales between people treated with antidepressants and those treated with placebo for 12 weeks. The evidence to support this finding was of high quality, which suggests that further research is unlikely to find a different result. There was probably also little or no difference after six to nine months of treatment. 
Another way to assess the effect of antidepressants is to count the number of people in the antidepressant and placebo groups who show significant clinical improvement (response) or who recover from depression (remission). There was low-quality evidence on the number of people showing a significant clinical improvement and the result was imprecise so we were unable to be sure of any effect on this measure. People taking an antidepressant were probably more likely to recover from depression than were those taking placebo (antidepressant: 40\%, placebo: $21.7 \%$ ). There was moderate-quality evidence for this finding, so it is possible that further research could find a different result.

We found that antidepressants did not affect the ability to manage daily activities and probably had little or no effect on a test of cognitive function (which includes attention, memory, and language).

People taking an antidepressant were probably more likely to drop out of treatment and to have at least one unwanted side effect.

\section{Quality of the evidence}

The quality of the evidence varied, mainly due to poorly conducted studies and problems with the relevance of the outcome measures used. This should be taken into consideration when interpreting the different results on depression rating scales and recovery rates, as evidence was of a higher quality for the former than for the latter.

Another major problem is that side effects are very rarely well-reported in studies.

Therefore, further research will still be useful to reach conclusions that are more reliable and can better help doctors and patients to know what works for whom. 
SUMMARY OF FINDINGS

Summary of findings for the main comparison. Antidepressant treatment compared with placebo for depression in dementia

Antidepressant treatment compared with placebo for depression in dementia

Patient or population: patients with depression and dementia

Settings: outpatient (except Roth 1996, which was mixed in- and outpatients)

Intervention: antidepressant treatment

Comparison: placebo treatment

\begin{tabular}{|c|c|c|c|c|c|c|}
\hline \multirow[t]{3}{*}{ Outcomes } & \multicolumn{2}{|c|}{ Illustrative comparative risks $(95 \% \mathrm{CI})$} & \multirow{3}{*}{$\begin{array}{l}\text { Relative effect } \\
(95 \% \mathrm{Cl})\end{array}$} & \multirow{3}{*}{$\begin{array}{l}\text { No of Partici- } \\
\text { pants } \\
\text { (studies) }\end{array}$} & \multirow{3}{*}{$\begin{array}{l}\text { Quality of the } \\
\text { evidence } \\
\text { (GRADE) }\end{array}$} & \multirow[t]{3}{*}{ Comments } \\
\hline & Assumed risk & Corresponding risk & & & & \\
\hline & Placebo & Antidepressant & & & & \\
\hline $\begin{array}{l}\text { Depression end- } \\
\text { point mean scores } \\
\text { at } 6 \text { to } 13 \text { weeks }\end{array}$ & & $\begin{array}{l}\text { The standardised depression } \\
\text { ratings scale endpoint mean } \\
\text { score in the antidepressant } \\
\text { group was } \mathbf{0 . 1 0} \text { points lower } \\
\text { ( } 0.26 \text { lower to } 0.06 \text { higher) }\end{array}$ & & $\begin{array}{l}614 \\
(8)\end{array}$ & $\begin{array}{l}\oplus \oplus \oplus \oplus \\
\text { high }\end{array}$ & $\begin{array}{l}\text { No evidence of an effect of antide- } \\
\text { pressants on depression in dementia }\end{array}$ \\
\hline $\begin{array}{l}\text { Number of respon- } \\
\text { ders (ITT) at } 6 \text { to } 12 \\
\text { weeks }\end{array}$ & 377 per 1000 & $\begin{array}{l}\mathbf{5 0 9} \text { per } \mathbf{1 0 0 0} \\
\text { (326 to } 690)\end{array}$ & $\begin{array}{l}\text { OR } 1.71(0.80 \text { to } \\
3.67)\end{array}$ & $\begin{array}{l}116 \\
\text { (3 studies) }\end{array}$ & $\begin{array}{l}\oplus \oplus \odot \odot \\
\text { low1 }\end{array}$ & $\begin{array}{l}\text { No evidence of an effect of antide- } \\
\text { pressants regarding response to } \\
\text { treatment for depression in demen- } \\
\text { tia }\end{array}$ \\
\hline $\begin{array}{l}\text { Number of patients } \\
\text { with remission (ITT) } \\
\text { at } 6 \text { to } 12 \text { weeks }\end{array}$ & 217 per 1000 & $\begin{array}{l}\mathbf{4 1 5} \text { per } \mathbf{1 0 0 0} \\
\text { (285 to } 559)\end{array}$ & $\begin{array}{l}\text { OR 2.57 [1.44, } \\
4.59]\end{array}$ & $\begin{array}{l}240 \\
(4)\end{array}$ & $\begin{array}{l}\oplus \oplus \oplus \ominus \\
\text { moderate }^{2}\end{array}$ & $\begin{array}{l}\text { Evidence of a positive effect of anti- } \\
\text { depressants on remission of depres- } \\
\text { sion in dementia }\end{array}$ \\
\hline $\begin{array}{l}\text { Cognitive function } \\
\text { endpoint mean } \\
\text { scores at } 6 \text { to } 12 \\
\text { weeks }\end{array}$ & & $\begin{array}{l}\text { The MMSE endpoint mean } \\
\text { score in the antidepressant } \\
\text { group was } 0.33 \text { points higher } \\
\text { [1.31 lower to } 1.96 \text { higher }]\end{array}$ & & $\begin{array}{l}(194) \\
(5)\end{array}$ & $\begin{array}{l}\oplus \oplus \oplus \ominus \\
\text { moderate }^{3}\end{array}$ & $\begin{array}{l}\text { No evidence of an effect of antide- } \\
\text { pressants on cognitive function in } \\
\text { patients with depression and de- } \\
\text { mentia }\end{array}$ \\
\hline $\begin{array}{l}\text { Activities of daily } \\
\text { living, endpoint val- } \\
\text { ues at } 6 \text { to } 13 \text { weeks }\end{array}$ & & $\begin{array}{l}\text { The standardised mean differ- } \\
\text { ence in } A D L \text { endpoint mean } \\
\text { scores in the antidepressant }\end{array}$ & & $\begin{array}{l}173 \\
(4)\end{array}$ & $\begin{array}{l}\oplus \oplus \oplus \oplus \\
\text { high }\end{array}$ & $\begin{array}{l}\text { No evidence of an effect of antide- } \\
\text { pressants on ADLs in patients with } \\
\text { depression and dementia. }\end{array}$ \\
\hline
\end{tabular}




\begin{tabular}{|c|c|c|c|c|c|c|}
\hline $\begin{array}{l}\text { Number of dropouts } \\
\text { at } 6 \text { to } 13 \text { weeks }\end{array}$ & 179 per 1000 & $\begin{array}{l}\mathbf{2 4 8} \text { per } \mathbf{1 0 0 0} \\
\text { (189 to } 318 \text { ) }\end{array}$ & $\begin{array}{l}\text { OR 1.51 } \\
\text { (1.07 to } 2.14)\end{array}$ & $\begin{array}{l}836 \\
(9)\end{array}$ & $\begin{array}{l}\oplus \oplus \oplus \ominus \\
\text { moderate }^{\mathbf{4}}\end{array}$ & $\begin{array}{l}\text { Evidence of a negative effect of anti- } \\
\text { depressants on staying in treatment } \\
\text { in patients with depression in de- } \\
\text { mentia }\end{array}$ \\
\hline $\begin{array}{l}\text { Number of patients } \\
\text { experiencing at } \\
\text { least one adverse } \\
\text { event }\end{array}$ & 384 per 1000 & $\begin{array}{l}492 \text { per } 1000 \\
\text { (430 to } 553)\end{array}$ & $\begin{array}{l}\text { OR } 1.55 \\
(1.21 \text { to } 1.98)\end{array}$ & $\begin{array}{l}1073 \\
(5)\end{array}$ & $\begin{array}{l}\oplus \oplus \oplus \ominus \\
\text { moderate }^{5}\end{array}$ & $\begin{array}{l}\text { Evidence of a negative effect of an- } \\
\text { tidepressants related to side effects } \\
\text { in patients with depression and de- } \\
\text { mentia. }\end{array}$ \\
\hline
\end{tabular}

*The basis for the assumed risk (e.g. the median control group risk across studies) is provided in footnotes. The corresponding risk (and its $95 \%$ confidence interval) is

based on the assumed risk in the comparison group and the relative effect of the intervention (and its $95 \% \mathrm{Cl}$ ).

CI: Confidence interval; OR: Risk Ratio; ITT: intention-to-treat; MMSE: Mini-Mental State Examination

A SMD of 0.2 is often considered to represent a small effect size, 0.5 a moderate effect size and 0.8 a large effect size.

GRADE Working Group grades of evidence

High quality: we are very confident that the true effect lies close to that of the estimate of the effect

Moderate quality: we are moderately confident in the effect estimate: the true effect is likely to be close to the estimate of the effect, but there is a possibility that it is substantially different

Low quality: our confidence in the effect estimate is limited: the true effect may be substantially different from the estimate of the effect

Very low quality: we have very little confidence in the effect estimate: the true effect is likely to be substantially different from the estimate of effect

${ }^{1}$ The quality of the evidence was downgraded due to indirectness (the definitions of "response" were different in the studies and some could be considered surrogate measures, e.g. "best clinical judgement") and imprecision (comparison was underpowered due to low number of total number of participants).

2The quality of the evidence was downgraded due to indirectness (the definitions of "remission" were different in the studies and some could be considered surrogate measures, e.g. "best clinical judgement").

3The quality of the evidence was downgraded due to imprecision (relatively low number of participants and wide confidence intervals).

4 The quality of the evidence was downgraded due to imprecision (the analysis is underpowered; also, the $95 \% \mathrm{Cl}$ around the pooled or best estimate of effect include both little effect and appreciable harm).

5 The quality of evidence was downgraded due to selective reporting. 


\section{B A C K G R O U N D}

\section{Description of the condition}

People with dementia are commonly afflicted with depression (Bennet 2014; Leyhe 2017) and depression is associated with increased disability, impaired quality of life, and higher mortality (Black 2012; Diniz 2013; Vaughan 2015).

However, both depression and dementia are concepts with nebulous boundaries. Depressive illness has been conceptualised in dimensional and categorical terms with no consensus about its fundamental nature. When conceptualised dimensionally, depression's various presentations are explained by their position on a continuum of increasing severity. When conceptualised categorically, depressive illness is sub-grouped into discrete entities such as melancholic or non-melancholic depression and anxious depression (Parker 2000). Dementia is a syndrome that may arise from a variety of underlying pathologies, the most common of which are Alzheimer's disease, vascular dementia, and dementia with Lewy bodies.

Given the complex nature of both depression and dementia, understanding the relationship between the two is difficult. Depressive illness in older people can present as 'pseudodementia' and be difficult to distinguish from a dementing illness (Raskind 1998). On the other hand, depression is often associated with deterioration in cognitive functioning which is sometimes not completely reversible with treatment (Abas 1990). Moreover, in older people a history of depression in later life may be associated with an increased risk of subsequently developing a dementing illness (Naismith 2010; Byers 2011; Barnes 2012; Heser 2013; Diniz 2013). Both disorders are common in older people and may therefore be expected to occur together solely by chance.

Because of these complexities, diagnosing depression in patients with dementia can be difficult. Denial and cognitive impairment may compromise self-report of depressive symptoms by people with dementia. As the dementing illness progresses, the presentation of depression may alter, with nonverbal manifestations (e.g. demanding behaviour, clinging) being more apparent than cognitive features (Vida 1994). Moreover, neurovegetative (autonomic) symptoms such as poor concentration and anhedonia (reduction in or complete lack of ability to enjoy activities the person usually finds enjoyable) are features of both depression and dementia. Not surprisingly, there is no consensus on how best to diagnose depression in demented patients. Depression symptom scales may overestimate, whereas structured diagnostic interviews may underestimate, the prevalence of depression in people with dementia. Only one instrument - the Cornell Scale for Depression in Dementia (CSDD, Alexopoulos 1988) - has been specifically developed for use in a population with dementia. Given the complexity of the issues impinging on accurate diagnosis, it is not surprising that estimates of the incidence and prevalence rates of depression in patients with dementia vary between $0 \%$ and $86 \%$. Larger studies using standardised criteria for major depressive disorder in Alzheimer's disease provide estimates of prevalence at $10 \%$ to $20 \%$ (Loreck 1993).

\section{Description of the intervention}

Drugs licensed as antidepressants are a heterogeneous group. They are commonly described as falling into a number of classes with different mechanisms of action, although the various classes are generally reported to be of similar efficacy (Anderson 2000; Williams 2000). However, different drugs or classes of drugs may vary in their efficacy or safety in the depression of dementia, or may be preferentially effective in particular subtypes of dementia.

The oldest class of antidepressants is the tricyclic antidepressants (TCAs), including drugs such as amitriptyline, imipramine, clomipramine and nortriptyline. As a class, they are associated with side effects that are potentially more problematic for older than for younger patients. In particular, their anticholinergic properties are associated with a negative impact on cognition (Settle Jr 1998). Other problematic anticholinergic effects would include increased intra-ocular pressure, urinary retention, dry mouth, and constipation. Due to their anti-adrenergic side effects, they can also cause postural hypotension (Glassman 1981), and dizziness, thereby increasing the risk of falls. A second class of antidepressants, the selective serotonin reuptake inhibitors (SSRIs), is now more widely used for older people. SSRIs include fluoxetine, paroxetine, sertraline, citalopram, and escitalopram. These drugs have a different range of side effects, most notably nausea and vomiting, agitation, anxiety, indigestion, diarrhoea or constipation, loss of appetite and weight loss, dizziness, blurred vision, dry mouth, excessive sweating, insomnia or drowsiness, headaches, and sexual side effects. However, they have less marked anticholinergic and anti-adrenergic properties and therefore may be less likely to cause confusion or falls (Avorn 1998). Other antidepressant drug classes include selective serotonergic and noradrenergic reuptake inhibitors (SNRIs) such as venlafaxine and duloxetine, tetracyclic anti-depressants such as trazodone and maprotiline, and the reversible monoamine oxidase inhibitors (MAOIs), such as moclobemide. Another often used example of the newer antidepressants is the alpha2-antagonist mirtazapine.

\section{Why it is important to do this review}

Dementia with depression is a common and important clinical problem. A recent Cochrane Review of psychological treatments for depression in dementia found evidence for benefit, but it was poor-quality, heterogeneous evidence (Orgeta 2014). The use of antidepressants for patients with dementia accompanied by depressive symptoms is widespread, but their clinical efficacy is uncertain. This uncertainty is due in part to the difficulties of interpreting the results of clinical trials. Many of the individual trials of antidepressants have been too small to provide precise estimates of the benefits that might realistically be expected. Combining the information from all appropriate trials may provide a better estimate of the likely effects of treatment.

\section{OBJECTIVES}

To determine the efficacy and safety of any type of antidepressant for patients who have been diagnosed as having dementia of any type and depression as defined by recognised criteria. 


\section{METHODS}

\section{Criteria for considering studies for this review}

\section{Types of studies}

We considered all identified relevant double-blind, randomised, placebo-controlled trials of longer than four weeks' duration. Trials in which the allocation to treatment or placebo was not random, or in which treatment allocation was not concealed, were excluded (Altman 1999).

\section{Types of participants}

\section{Inclusion criteria}

To ensure participants of included trials were comparable, subjects were required to meet accepted diagnostic criteria. We included trials involving participants with dementia as diagnosed by accepted criteria such as DSM (APA 1987), NINCDS-ADRDA (McKhann 1984) and ICD-10 (WHO 1992), with a coexisting depressive illness as diagnosed by similarly accepted criteria. Participants could be of either sex and of any age.

\section{Exclusion criteria}

We excluded studies of patients with dementia suffering from emotional disorders or behavioural problems, but falling short of a diagnosis of depression (as diagnosed by recognised criteria).

\section{Types of interventions}

\section{Inclusion criteria}

Any antidepressant medication listed in the British National Formulary number 73, 2017 (see Electronic searches for list of antidepressants) compared with placebo. There was no minimum dose requirement for inclusion.

\section{Exclusion criteria}

We excluded trials of euphoriants (e.g. amphetamines), adjuvants (e.g. lithium), combination treatments (e.g. 'Motipres'), studies of other drug classes not generally regarded primarily as antidepressants (e.g. antipsychotics), and agomelatine, which is contra-indicated in dementia.

\section{Types of outcome measures}

The outcomes of interest were as follows (Table 1 summarises the outcome measures analysed in this paper).

\section{Primary outcomes}

Effect on depression (measured by rating scales, and by rates of response or remission defined according to clear criteria).

\section{Secondary outcomes}

1. Effect on cognitive function (measured by validated psychometric tests).

2. Effect on activities of daily living (measured by validated rating scales).

3. Effect on quality of life (measured by validated rating instruments).

4. Tolerability (measured by withdrawal from trial).

5. Safety (measured by the incidence of adverse effects).

\section{Search methods for identification of studies}

\section{Electronic searches}

We searched ALOIS (www.medicine.ox.ac.uk/alois), the Cochrane Dementia and Cognitive Improvement Group's Specialized Register on 16 August 2017. The search was done on a tag used in ALOIS for studies in which the following antidepressant terms have been used: antidepressant, amitriptyline, lentizol, tryptizol, triptafen, amoxapine, asendis, clomipramine, anafranil, dothiepin, perothiaden, doxepin, sinequan, imipramine, tofranil, lofepramine, gamanil, nortriptyline, allegron, protriptyline, concordin, trimipramine, surmontil, maprotiline, ludiomil, mianserin, mirtazapine, zispin, trazodone, molipaxin, viloxazine, vivalan, phenelzine, nardil, isocarboxazid, tranylcypromine, parnate, moclobemide, manerix, fluoxetine, prozac, citalopram, cipramil, fluvoxamine, faverin, paroxetine, seroxat, sertraline, lustral, nefazadone, dutonin, venlafaxine, efexor, flupenthixol, depixol, fluanxol, reboxetine, edronax, tryptophan, optimax, escitalopram, cipralex, dosulepin, dothapex, prepadine, and vortioxetine.

ALOIS is maintained by the Information Specialist for the Cochrane Dementia and Cognitive Improvement Group and contains studies in the areas of dementia prevention, dementia treatment and cognitive enhancement in the healthy. The studies are identified from:

1. monthly searches of a number of major healthcare databases: MEDLINE, Embase, Cinahl, PsycINFO and Lilacs;

2. monthly searches of a number of trial registers: UMIN (Japan's Trial Register); ICTRP/the WHO portal (which covers ClinicalTrials.gov; ISRCTN; the Chinese Clinical Trials Register; the German Clinical Trials Register; the Iranian Registry of Clinical Trials and the Netherlands National Trials Register, plus others);

3. quarterly search of the Cochrane Library's Central Register of Controlled Trials (CENTRAL);

4. six-monthly searches of a number of grey literature sources: ISI Web of Knowledge Conference Proceedings; Index to Theses; Australasian Digital Theses.

To view a list of all sources searched for ALOIS, see About ALOIS on the ALOIS website.

Details of the search strategies used for the retrieval of reports of trials from the healthcare databases, CENTRAL and conference proceedings can be viewed in the 'methods used in reviews' section within the editorial information about the Dementia and Cognitive Improvement Group.

Additional searches were performed in many of the sources listed above to cover the timeframe from the last searches performed for ALOIS to ensure that the search for the review was as up-to-date and as comprehensive as possible. The search strategies used can be seen in Appendix 1.

\section{Searching other resources}

We consulted a number of experts in old age psychiatry. We also asked the medical information departments of major pharmaceutical companies to search databases and their records for trials involving their products. In addition, we searched reference lists of retrieved studies and review articles. 


\section{Data collection and analysis}

\section{Selection of studies}

A single review author (for the first edition: JB [see Contributions of authors for full names], for the current revision: RD) discarded irrelevant citations identified by searches, based on the title of the publication and its abstract. If there was any suggestion that an article could be relevant, it was retrieved for further assessment. Two review authors (first edition: JB and JSB, current revision: RD and TD) then independently selected the trials for inclusion in the review from the culled citation list.

\section{Data extraction and management}

For the original review, data were independently extracted by two review authors (JB, JSB) and cross-checked. Any discrepancies were discussed and adjudicated by a third reviewer (TD). For the current revision, data were extracted by the first author (RD). Data were sought on every participant for each outcome measure. To allow an intention-to-treat analysis, we sought data irrespective of compliance, whether or not the participant was subsequently deemed ineligible, or otherwise excluded from treatment or followup.

If ordinal scale data appeared to be approximately normally distributed, or if the analysis that the investigators performed suggested that parametric tests were appropriate, then we treated the outcome measures as continuous data. Where the outcome measure was a continuous variable or ordinal variable (such as psychometric test scores, clinical global impression scales, functional and quality of life scales) we extracted summary statistics, including means, standard deviations (SDs) and number in each treatment group, for the final assessment score (corrected for baseline) and the change in score from baseline (i.e. prerandomisation or randomisation) to the final assessment for each study. For dichotomous outcomes, the statistics extracted from each study were the numbers in each treatment group and the numbers in each endpoint category for each treatment group. Where dichotomous data were missing, the participants were assumed to have suffered the least favourable outcome. In studies where a cross-over design was used, only data from the first treatment period were included.

If trial results were reported as medians and interquartile ranges, we calculated SDs using the interquartile range (IQR) to provide the appropriate data to combine the study with other studies.

When two different antidepressants were compared against placebo (Banerjee 2011), we divided the control group where relevant into two groups approximately evenly among the comparisons, with the means and SDs left unchanged. Where it was the only option, we merged the two treatment groups into one (antidepressant efficacy at three to nine months).

\section{Assessment of risk of bias in included studies}

We assessed included trials for risk of bias using the tool in theCochrane Handbook for Systematic Reviews of Interventions, version 5.1.0 (Higgins 2011). We judged whether each trial was at high, low or unclear risk of bias in each of six domains: sequence generation, concealment of allocation, blinding, completeness of outcome data, selective reporting, and funding source.

\section{Measures of treatment effect}

For binary outcome data, we calculated the odds ratio for each trial, and then a pooled odds ratio across appropriate groups of trials (using Mantel-Haenszel methods). For continuous variables, we calculated the mean difference between treatment and control when each study in the meta-analysis used the same outcome measure, or the standardised mean difference when the studies used a variety of outcome measures. We used hazard ratios for time-to-event data.

\section{Unit of analysis issues}

If a trial included multiple treatment groups, then we combined active treatment groups into one group and control treatment groups into one group to allow a single pairwise comparison.

Some studies assessed outcomes at multiple time points, so we pooled data in ranges (e.g. 6 to 13 weeks and 3 to 9 months) to achieve the best match of time points when combining results with similar data from different studies.

\section{Dealing with missing data}

For each study, we noted what approach had been taken to missing data, e.g. imputation, data assumed to be missing at random. We considered how each method may have contributed to a risk of bias. We contacted authors of extracted papers for clarification as required.

\section{Assessment of heterogeneity}

We tested for heterogeneity of the treatment effect between the trials in a meta-analysis using the $\mathrm{Chi}^{2}$ statistic. We quantified inconsistency using $\mathrm{I}^{2}$ and considered that an $\mathrm{I}^{2}$ value of more than $40 \%$ might represent moderate heterogeneity.

\section{Assessment of reporting biases}

If we had been able to include more than 10 studies in any metaanalysis, then we would have performed a test for funnel plot asymmetry, looking for small study effects which might indicate publication bias.

\section{Data synthesis}

We pooled data from different trials if we considered that the trials were sufficiently similar and it was clinically meaningful to do so. In our primary analyses, we pooled trials of all dementia subtypes and all types of antidepressants. We also preformed a separate analysis of antidepressant efficacy at six to nine months.

For dichotomous efficacy outcomes, we used the Mantel-Haenszel method, as the study sizes were small. For our tolerability outcomes, we used the Peto odds ratio method, as for these outcomes we had larger samples, the intervention effects were relatively small, and the events were not particularly common. If a $\mathrm{Chi}^{2}$ test and $\mathrm{I} 2$ indicated little heterogeneity, we used a fixed-effect model for meta-analysis. If there was evidence of heterogeneity of the treatment effect between trials, we either pooled only homogeneous results, or used a random-effects model (in which case the confidence intervals would be broader than those of a fixed-effect model). 
When combining data provided as median and 95\% confidence interval $(\mathrm{Cl})$, we used the generic inverse variance method. We used standard error and median difference.

\section{Subgroup analysis and investigation of heterogeneity}

Five of the included studies used an SSRI antidepressant (Petracca 2001; Lyketsos 2003; Rosenberg 2010; Banerjee 2011; An 2017), one mirtazapine (Banerjee 2011), and one venlafaxine (de Vasconcelos 2007). These are more modern antidepressants commonly used in this patient group (as opposed to tricyclic antidepressants), so we performed a meta-analysis on these subgroups. Where it made clinical sense (e.g. when examining tolerability), we also looked at data by antidepressant group, where possible.

\section{Sensitivity analysis}

When looking at treatment efficacy as reflected by depression symptom rating scale scores, we also performed a sensitivity analysis only looking at studies that used the Cornell Scale for Depression in Dementia (Lyketsos 2003; Rosenberg 2010; Banerjee 2011; An 2017), an instrument specifically developed to measure depressive symptoms in dementia. As in our main treatment efficacy comparison, some studies only reported completer data, so we carried out a sensitivity analysis looking at intention-totreat data only. We also performed a sensitivity analysis when the majority of individual studies reported results pointing toward the opposite of the result of the meta-analysis, or when excluding a study was considered to reduce imprecision or inconsistency.

\section{Summary of findings}

We used the GRADE system to assess the overall quality of evidence behind the effect estimates for each outcome (Ryan 2016). We downgraded the evidence from 'high-quality' by one, two, or three levels after considering imprecision in the effect estimate, risk of bias in the included studies, inconsistency between studies, indirectness of evidence, and publication bias. Two review authors (RD and TD) assessed the quality of evidence independently and resolved any disagreements.

We presented the amount and quality of evidence in a 'Summary of findings' table for the following outcomes: depression (symptom score), depression (response rate), depression (remission rate), cognitive function, activities of daily living, dropout rate and incidence of adverse events.

\section{RE S U L T S}

\section{Description of studies}

\section{Results of the search}

Searches carried out in the previous version of the review can be viewed in Appendix 2.

The searches performed for this update, run in November 2010, May 2012, March 2013, December 2013, March 2014, November 2014, October 2015, July 2016, and August 2017 retrieved a total of 827, $1233,456,495,599,620,520,859$, and 1304 results, respectively (Figure 1). The Information Specialist performed a first assessment to discard obviously non-relevant records and duplicates. This left the author team with 43 (November 2010), 49 (May 2012), 27 (March 2013), 36 (December 2013), 31 (November 2014), 22 (October 2015), 40 (July 2016), and 60 (August 2017) results to further assess, from the last two rounds of which three additional trials were identified (DIADS, Banerjee 2011, and An 2017). 
Figure 1. Study flow diagram.

Included studies: studies
included in the previous
version of the review
$n=7$ RCTs

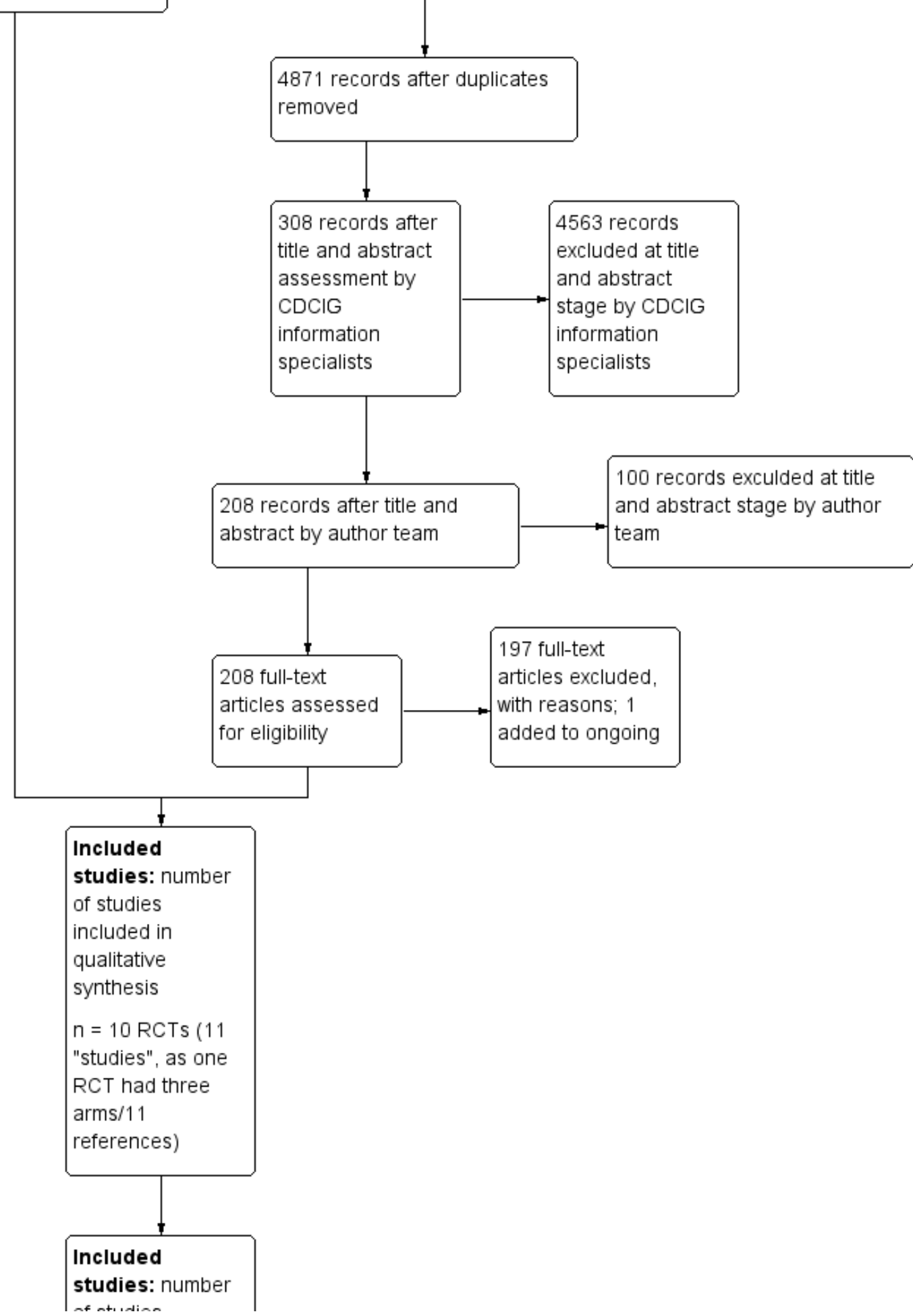

6913 records identified through database searching 
Figure 1. (Continued)

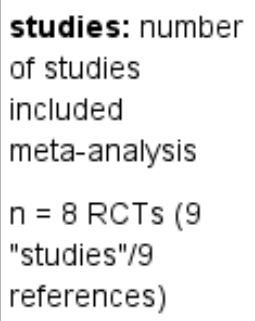

\section{Included studies}

See: Characteristics of included studies (Table 2).

Ten studies with a total of 1592 participants met the inclusion criteria. The studies were generally of short duration (mode: 6 weeks; mean: 12.7 weeks), although the largest study ran for nearly 10 months (Banerjee 2011). The findings from one study (DIADS-2) were reported in separate publications, giving results at 12 weeks (Rosenberg 2010), and also after an extension phase at 24 weeks (Weintraub 2010).

All 10 studies stated that the participants met DSM criteria for dementia or NINCDS-ADRDA criteria for probable Alzheimer's disease. The dementia diagnoses in the trial participants were described in a variety of ways:

1. An 2017: "Alzheimer's disease";

2. Banerjee 2011: "probable Alzheimer's disease";

3. de Vasconcelos 2007: "Alzheimer's disease, vascular dementia, and mixed dementia";

4. DIADS-2 (Rosenberg 2010 and Weintraub 2010): "DSM-IV dementia due to Alzheimer's disease";

5. Fuchs 1993: "primary degenerative dementia";

6. Lyketsos 2003: "probable Alzheimer's disease";

7. Petracca 1996: "Alzheimer's disease";

8. Petracca 2001: "probable Alzheimer's disease";

9. Reifler 1989: "primary degenerative dementia of the Alzheimer's type";

10. Roth 1996: "dementia".

The mean age of participants who met inclusion criteria in the studies, excluding one study which only reported the median age of 80 years (Fuchs 1993), was between 70.8 and 79.3 years, with an overall mean of 75.37 years.

One Austrian study was conducted among inpatients and nursing home residents (Fuchs 1993). One multinational study included both inpatients and outpatients (Roth 1996). The other studies were conducted in single countries and included only outpatients. The outpatient settings varied, including neurology outpatient clinics in Argentina, specialist memory and other outpatient clinics in the USA and Brazil, and community mental health teams in the UK.

The severity of dementia in the studies varied. The mean Mini Mental State Examination (MMSE) score prior to treatment in those participants who met inclusion criteria for the review was between 16.9 to 23.2 (mean score 19.65). One study, de Vasconcelos 2007, only reported a range of MMSE scores of 10 to 24 , and another, Fuchs 1993, reported a median of 20 and no mean scores.

Six studies stated that the participants met DSM criteria for major depression, with one study stating subjects met DSM criteria for either major or minor depression (Petracca 2001). One study required the presence of depression of at least four weeks' duration, assessed as potentially needing antidepressants and scoring eight or more on the Cornell Scale for Depression in Dementia (CSDD), prior to inclusion (Banerjee 2011). In most studies, participants were diagnosed clinically, whereas two studies used a structured clinical interview schedule (Petracca 1996; Petracca 2001). The DIADS-2 study used specifically adapted Major Depression Criteria. The papers reporting on this study (Rosenberg 2010; Weintraub 2010), do not provide validity data regarding the Major Depression Criteria, but a relevant study, Teng 2008, reported for the criteria set $100 \%$ sensitivity and $66 \%$ specificity for major and $94 \%$ sensitivity and $85 \%$ specificity for minor depression, measured against the DSM-IV diagnosis, which is acceptable.

The older studies used tricyclic antidepressants (TCAs) or related compounds; four used a selective serotonin reuptake inhibitor (SSRI); one used a reversible monoamine oxidase inhibitor; and one a serotonin/noradrenaline reuptake inhibitor. One study had two active treatment arms, an SSRI and a noradrenergic and specific serotonergic antidepressant (NaSSA) one (Banerjee 2011). The doses used in seven studies were within the therapeutic range for the specific medication. However, three studies used lower dose medication (Fuchs 1993; de Vasconcelos 2007; Banerjee 2011, for mirtazapine).

The studies used a variety of outcome measures. Four studies used the Hamilton Depression Rating Scale, and four used the more specific Cornell Scale for Depression in Dementia to measure changes in depression symptom levels after treatment. One study used the Montgomery-Asberg Depression Rating Scale and another used the Geriatric Depression Scale. All included studies used the Mini-Mental State Examination to assess changes in cognitive functioning. Only five studies deployed one of four different standardised measures of activities of daily living.

Table 1 summarises the outcome measures included in this review.

\section{Excluded studies}

We excluded studies identified by the searches if their subjects did not have both depression and dementia diagnosed by formal criteria, the intervention was not an antidepressant or it was given in combination with another drug, the study was not a treatment 
trial or a randomised controlled trial, or change in depression was not measured.

\section{Ongoing studies}

We are not aware of any ongoing studies.

\section{Risk of bias in included studies}

See our 'Risk of bias' assessment of included studies in Figure 2 and Figure 3. 
Figure 2. Risk of bias summary: review authors' judgements about each risk of bias item for each included study.

\begin{tabular}{|c|c|c|c|c|c|c|c|}
\hline & 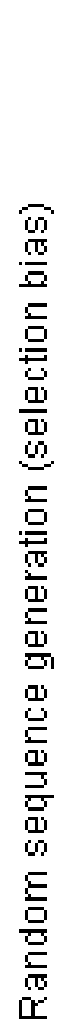 & 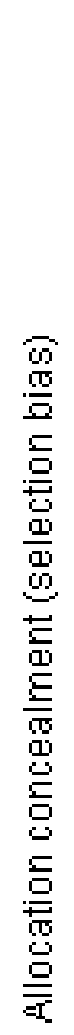 & 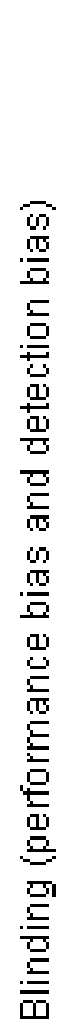 & 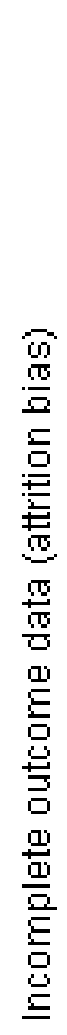 & 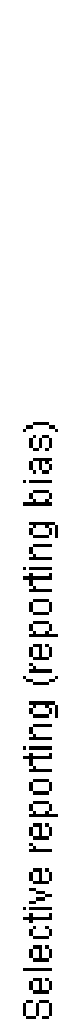 & 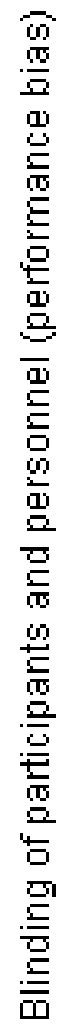 & 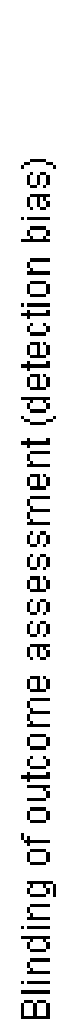 \\
\hline An 2017 & $?$ & $?$ & $?$ & & 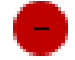 & $?$ & $?$ \\
\hline Banerjee 2011 & + & + & $?$ & & $?$ & $?$ & $?$ \\
\hline de Vasconcelos 2007 & $?$ & $?$ & $?$ & & $?$ & $?$ & $?$ \\
\hline Fuchs 1993 & $?$ & $?$ & $?$ & & - & $?$ & ? \\
\hline Lyketsos 2003 & + & + & $?$ & & + & $?$ & $?$ \\
\hline Petracca 1996 & $?$ & $?$ & + & & + & $?$ & + \\
\hline Petracca 2001 & $?$ & $?$ & & & + & $?$ & ? \\
\hline Reifler 1989 & $?$ & $?$ & $?$ & & $?$ & $?$ & $?$ \\
\hline Rosenberg 2010 & $?$ & $?$ & & & $?$ & & $?$ \\
\hline Roth 1996 & $?$ & $?$ & $?$ & & & $?$ & $?$ \\
\hline Weintraub 2010 & $?$ & $?$ & & & $?$ & $?$ & $?$ \\
\hline
\end{tabular}


Figure 3. Risk of bias graph: review authors' judgements about each risk of bias item presented as percentages across all included studies.

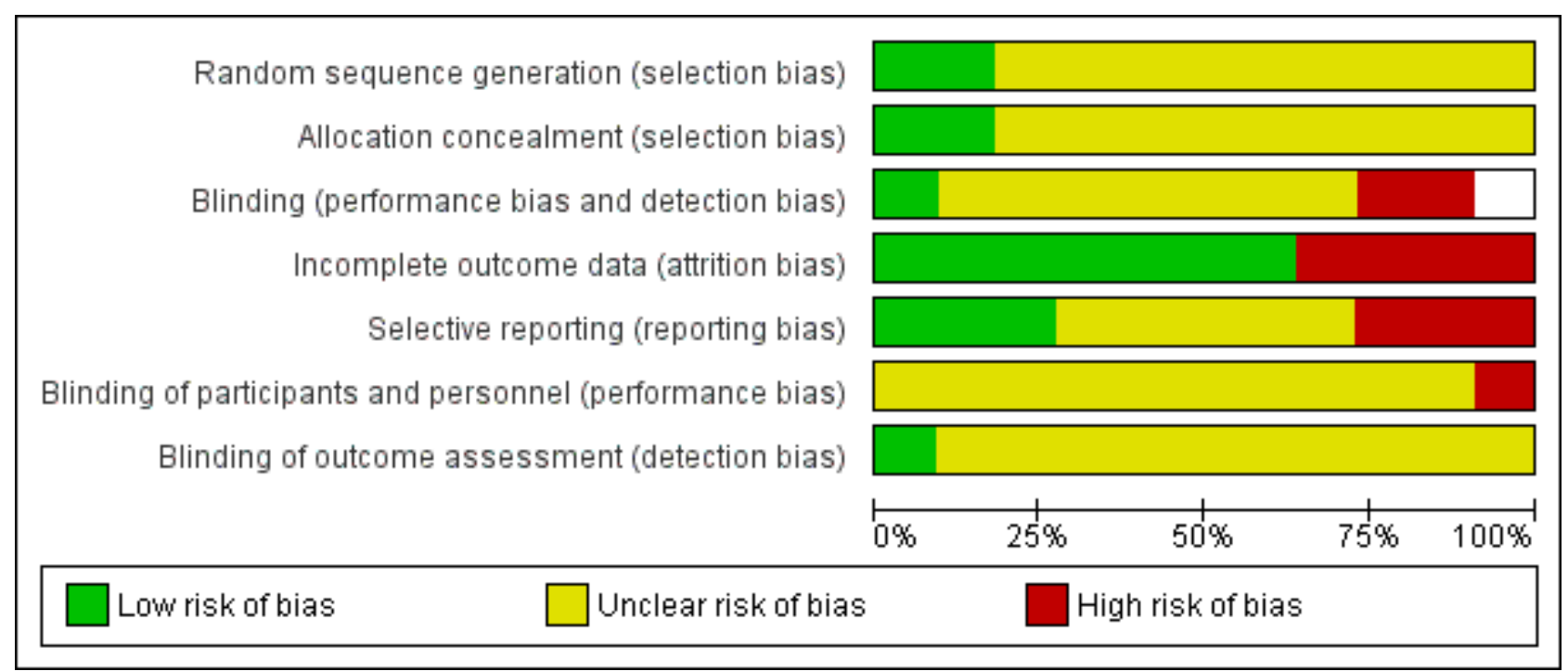

Two studies gave adequate descriptions of the randomisation method and allocation concealment and we judged them to be at low risk of bias in both of these domains (Lyketsos 2003; Banerjee 2011). The other studies stated that they were randomised but did not describe the methods used for sequence generation or allocation concealment so we judged the risk of bias to be unclear.

All 10 studies said they were double-blind but only two reported checking on this. The nature of the placebos was not stated in two studies (Fuchs 1993; An 2017). In seven studies (Reifler 1989; Petracca 1996; Petracca 2001; Lyketsos 2003; de Vasconcelos 2007; Rosenberg 2010; Banerjee 2011), drug and placebo were described as "identical" in appearance, and in one study it was described as "matched" (Roth 1996). With the exception of two studies that explicitly checked whether examiners were able to guess allocation status (Petracca 1996; Rosenberg 2010), there was insufficient information to permit judgement about the integrity of blinding, therefore the risk of bias due to performance or detection bias (or both) was rated as unclear in these studies. Study clinicians correctly guessed allocation status above chance levels in the active treatment group in one study (Rosenberg 2010), therefore we judged this risk of performance bias as high.

Four studies provided intention-to-treat data (Fuchs 1993; Lyketsos 2003; DIADS-2: Rosenberg 2010 and Weintraub 2010; Banerjee 2011), three studies only reported completers' data (Reifler 1989; Petracca 1996; An 2017), and two studies reported both types of data (Petracca 2001; de Vasconcelos 2007). We combined these data in the analyses and carried out sensitivity analyses where we considered this to be appropriate. The attrition rate was very high and unbalanced between groups in three studies (Banerjee 2011; de Vasconcelos 2007; An 2017), therefore we rated the attrition bias as high in these studies. In Weintraub 2010, only $57 \%$ of patients were receiving treatment by week 24 , therefore we rated the risk of attrition bias as high.

We considered three studies to be at high risk of selective reporting bias (Fuchs 1993; Roth 1996; An 2017). In An 2017, both ITT and per protocol analyses were performed but only the latter was reported.
The paper also mentioned response and remission analyses in the methods section, but did not report these. The other two studies reported incomplete data for the depression rating scale scores (Fuchs 1993; Roth 1996).

Most included studies did not publish enough information for us to assess risk of bias related to funding; we considered one study to have low risk of bias (Banerjee 2011), one study to have high risk of bias (Roth 1996), and the rest to have unclear risk of bias.

\section{Effects of interventions}

See: Summary of findings for the main comparison Antidepressant treatment compared with placebo for depression in dementia

See antidepressant versus placebo comparisons in Data and analyses, and Summary of findings for the main comparison.

We included 10 included studies with a total of 1592 participants. Two studies published results for trial completers but did not include the numbers in each treatment group who had completed (Fuchs 1993; Roth 1996). Therefore we were only able to use adverse events data from both of these studies. One study had a crossover design and we used data from the first treatment period only (Petracca 1996). Only one study used the Montgomery-Asberg Depression Rating Scale (MADRS) (de Vasconcelos 2007). One study reported outcomes using both the Cornell Scale for Depression in Dementia (CSDD) and the Hamilton Depression Rating Scale (HAMD) (Lyketsos 2003); when pooling data from all studies, we used the CSDD data from this study.

We pooled data separately for outcomes reported at 6 to 13 weeks and 24 to 39 weeks (6 to 9 months). Two studies contributed data to both time point analyses (DIADS-2: Rosenberg 2010; Weintraub 2010, 12 and 24 weeks; Banerjee 2011, 13 and 39 weeks).

\section{Treatment efficacy}

The analyses concerning efficacy included eight studies (An 2017; Banerjee 2011; de Vasconcelos 2007; Lyketsos 2003; Petracca 1996; 
Petracca 2001; Reifler 1989; Rosenberg 2010), with a total of 614 subjects.

\section{Depression (measured by rating scales)}

We found that there was little or no effect of antidepressant treatment on depression measured with symptom scales after 6 to 13 weeks of treatment, compared to placebo (standardised mean difference (SMD) $-0.10,95 \%$ confidence interval $(\mathrm{Cl})-0.26$ to 0.06 ; 614 participants; 8 studies; $1^{2}=7 \%$; Analysis 1.1 ; Figure 4). Although this analysis included treatment with different types of antidepressants, heterogeneity was low and we considered the evidence to be of high quality. Two of the studies included in this meta-analysis only reported completers' data (Reifler 1989; Petracca 1996), therefore we carried out a sensitivity analysis excluding these studies. The result, now based entirely on intention-to-treat data, was unchanged and indicated little or no difference between antidepressant and placebo treatment (SMD $-0.10,95 \% \mathrm{Cl}-0.27$ to $0.07, \mathrm{P}=0.24$ ). It is of note that the two studies excluded in the sensitivity analysis (Reifler 1989; Petracca 1996), investigated the effect of tricyclic antidepressants (TCAs) (drugs not commonly used in this population).

Figure 4. Forest plot of comparison: 1 Antidepressant versus placebo, outcome: 1.1 Depression endpoint mean scores at 6-13 weeks.

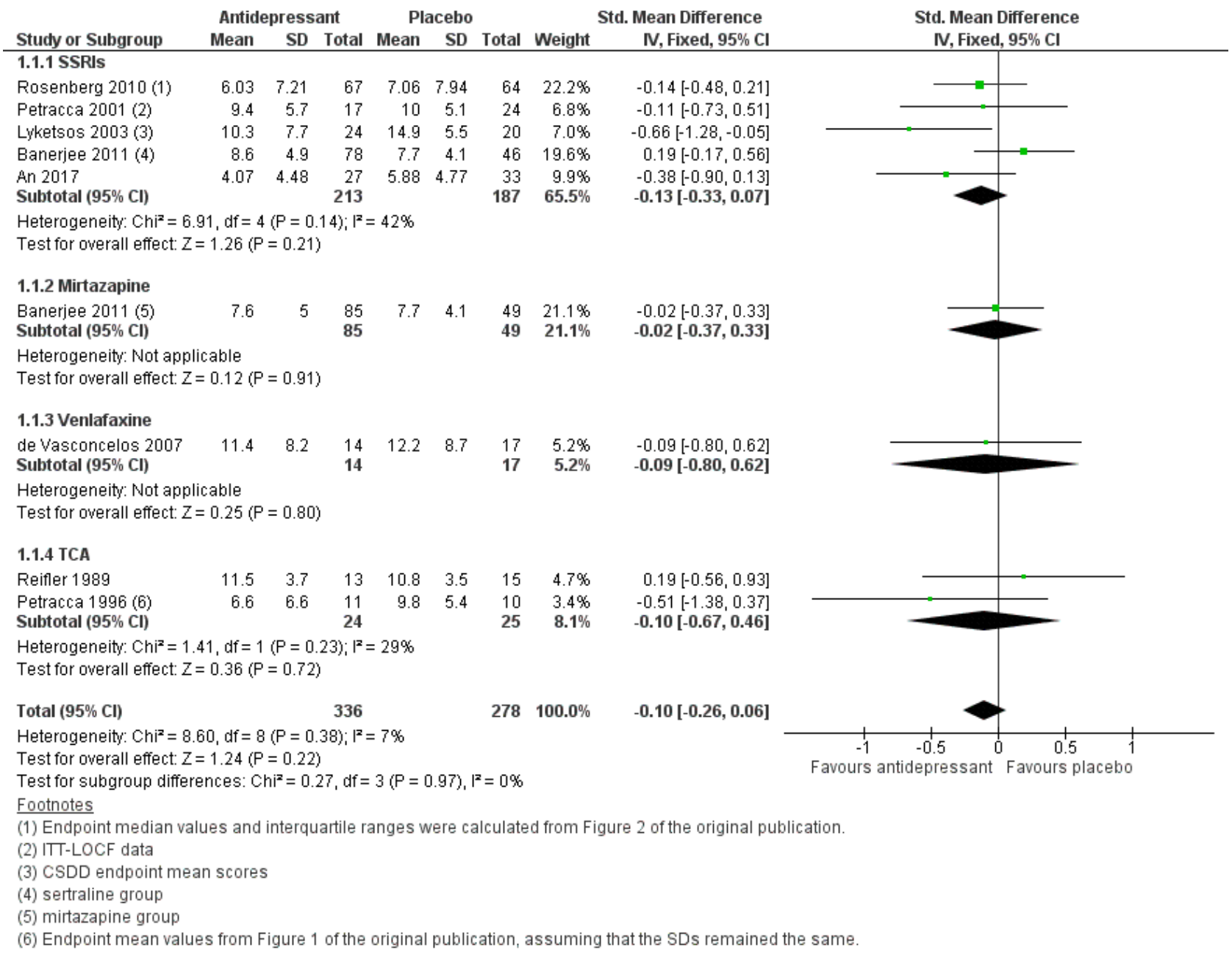

Two studies assessed outcomes after a longer treatment period: after 24 weeks, DIADS-2 (Weintraub 2010), and after 39 weeks (Banerjee 2011). Both measured depressive symptoms using the CSDD. We found that there was probably little or no effect of this more prolonged treatment on depressive symptoms (mean difference (MD) 0.59 point, $95 \% \mathrm{Cl}-1.12$ to $2.3,357$ participants; Analysis 1.2$)$. Heterogeneity was low $(12=0 \%)$, but we considered this moderate-quality evidence due to methodological limitations, as both studies had a high attrition rate and one study (DIADS-2) also had a high risk of bias related to blinding.
We looked separately at results from the studies which assessed depressive symptoms after 12 or 13 weeks using the CSDD (Lyketsos 2003; the DIADS-2 study in Rosenberg 2010; and Banerjee 2011). An analysis of the findings from these three studies indicated little or no benefit from treatment with an antidepressant (MD -0.10 point, $95 \% \mathrm{Cl}-0.99$ to $0.78 ; 433$ participants; 3 studies; Analysis 1.2).

In a pooled analysis of the four studies which used the Hamilton Depression Rating Scale (Reifler 1989; Petracca 1996; Petracca 2001; Lyketsos 2003), there was little or no difference between placebo 
and antidepressant after 6 to 12 weeks of treatment (MD -0.85, 95\% $\mathrm{Cl}-2.65$ to 0.95 ; participants $=134$; studies $=4 ; 1^{2}=24 \%$; Analysis 1.3 )

The only study using the Montgomery-Asberg Depression Rating Scale, de Vasconcelos 2007, reported no significant difference in mean score changes.

A subgroup analysis of the five studies using a selective serotonin reuptake inhibitor (SSRI) showed little or no difference between the antidepressant and placebo groups (SMD $-0.13,95 \% \mathrm{Cl}-0.33$ to 0.07 ; 400 participants; 5 studies; $\left.\right|^{2}=42 \%$; see 1.1 .1 in Analysis 1.1 ). There was moderate heterogeneity in the data, but nevertheless, we considered this overall to be high-quality evidence.

\section{Depression (measured by rates of response or remission)}

We also sought to examine rates of response and remission from depression. "Response" was defined as "partial response" by best clinical judgment rated by two psychiatrists (Lyketsos 2003), 50\% or more reduction in HAM-D scores (Petracca 2001), or a modified Alzheimer's Disease Cooperative Study Clinical Global Impression of Change (mADCS-CGI) rating of 2 or less (Weintraub 2010). Data on response to treatment after 6 to 12 weeks came from two studies using an SSRI (Petracca 2001; Lyketsos 2003). There may be a higher response rate among participants on antidepressants than on placebo (odds ratio (OR) $2.42,95 \% \mathrm{Cl} 0.97$ to $6.09 ; 85$ participants; 2 studies; $\left.\right|^{2}=0 \%$; Analysis 1.4.1; Figure 5), but there is a lot of uncertainty about this result, which is also consistent with little or no effect. We considered this evidence to be low-quality, due to indirectness (the definitions of "response" were different in the studies and some could be considered surrogate measures, e.g. "best clinical judgement") and imprecision (comparison was underpowered due to low numbers of participants). A third study, de Vasconcelos 2007, used $50 \%$ or more reduction in MADRS scores as a definition of remission as opposed to response, but to be consistent with other studies we also included their data in our meta-analysis of response rates. When we added this third study (Analysis 1.4), the result remained imprecise with uncertainty about the direction and size of the effect (OR $1.71,95 \% \mathrm{Cl} 0.80$ to 3.67 ; 116 participants; 3 studies; $1^{2}=13 \%$ ). Only one study (DIADS-2: Weintraub 2010) provided longer-term data on response. The result was imprecise so the effect of antidepressants after 24 weeks was uncertain (OR 1.45, 95\% Cl 0.72 to 2.92; 131 participants; 1 study; I $^{2}$ $=0 \%)$.

Figure 5. Forest plot of comparison: 1 Antidepressant versus placebo, outcome: 1.4 Number of responders (ITT) at 6-12 weeks.

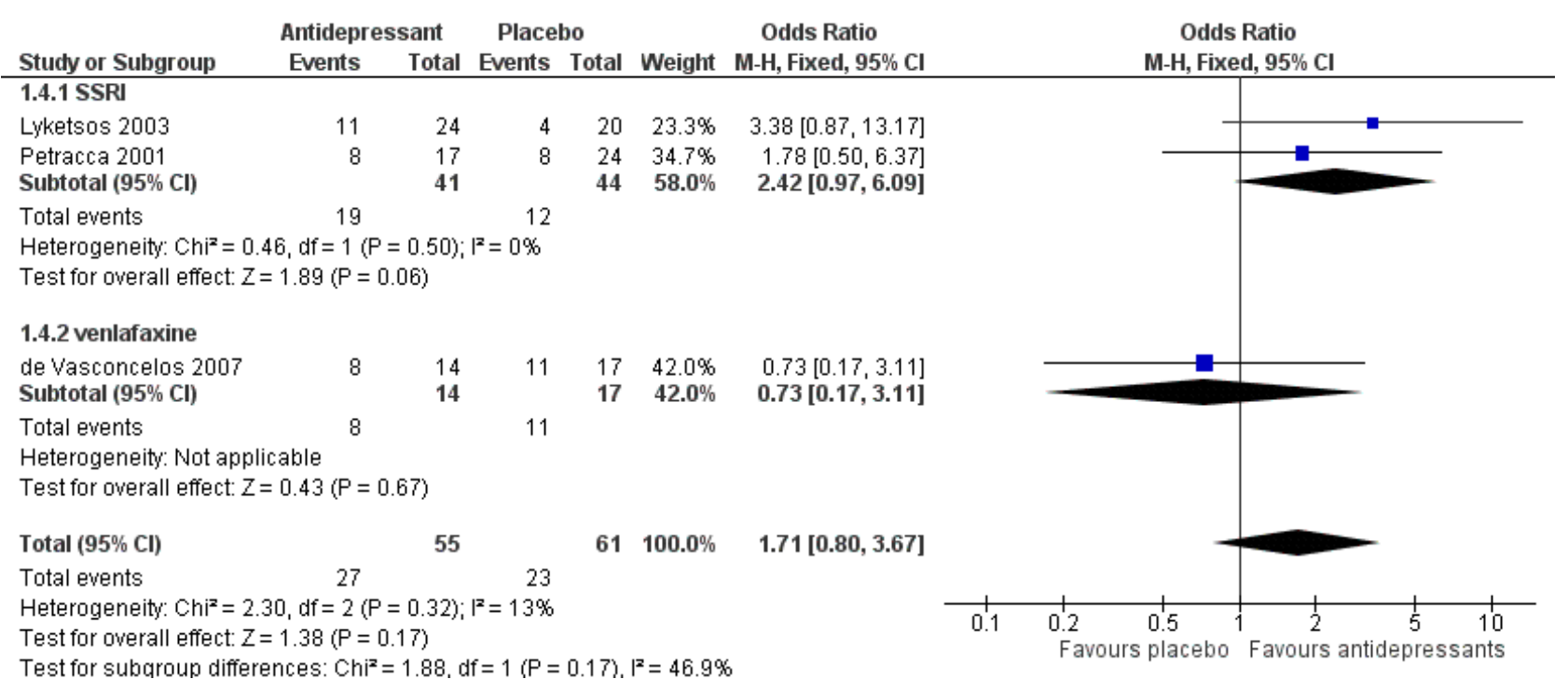

"Remission" was defined by the authors of the studies as a HAMD score of seven or lower (Petracca 1996), a HAM-D score of seven or lower and Clinical Global Impression rating of one or two (Petracca 2001), "full response" rated by two psychiatrists' best clinical judgment (Lyketsos 2003), or a mADCS-CGI rating of two or lower and a CSDD score of six or lower (DIADS-2: Rosenberg 2010, Weintraub 2010). Although with the exception of the smallest study (Petracca 1996), there was no significant difference in remission rates between the antidepressant and placebo treated groups reported in individual studies, a meta-analysis indicated that at 6 to 12 weeks remission rates favoured antidepressant over placebo (OR 2.57, $95 \% \mathrm{Cl} 1.44$ to $4.59 ; 240$ participants; 4 studies; $1^{2}=$ $0 \%$; Analysis 1.6; Figure 6). We regarded this as moderate-quality

evidence due to indirectness (i.e. definitions of "remission" were different in the studies and some could be considered surrogate measures, e.g. "best clinical judgement"). A subgroup analysis of the SSRI studies indicated that remission rates were higher in the antidepressant group than in the placebo group (OR 2.22, 95\% $\mathrm{Cl} 1.20$ to 4.12; 216 participants; 3 studies; $\left.\right|^{2}=0 \%$; Analysis 1.6 ), based on evidence graded as low-quality due to indirectness and imprecision (comparison was underpowered due to low number of participants). Again, only one study (DIADS-2: Weintraub 2010) provided longer term data and the result was imprecise so the effect of antidepressants on remission after 24 weeks is uncertain (OR $1.75,95 \% \mathrm{Cl} 0.80$ to 3.82 ; 131 participants; 1 study; Analysis 1.7). 
Figure 6. Forest plot of comparison: 1 Antidepressant versus placebo, outcome: 1.6 Number of patients with remission (ITT) at 6-12 weeks.

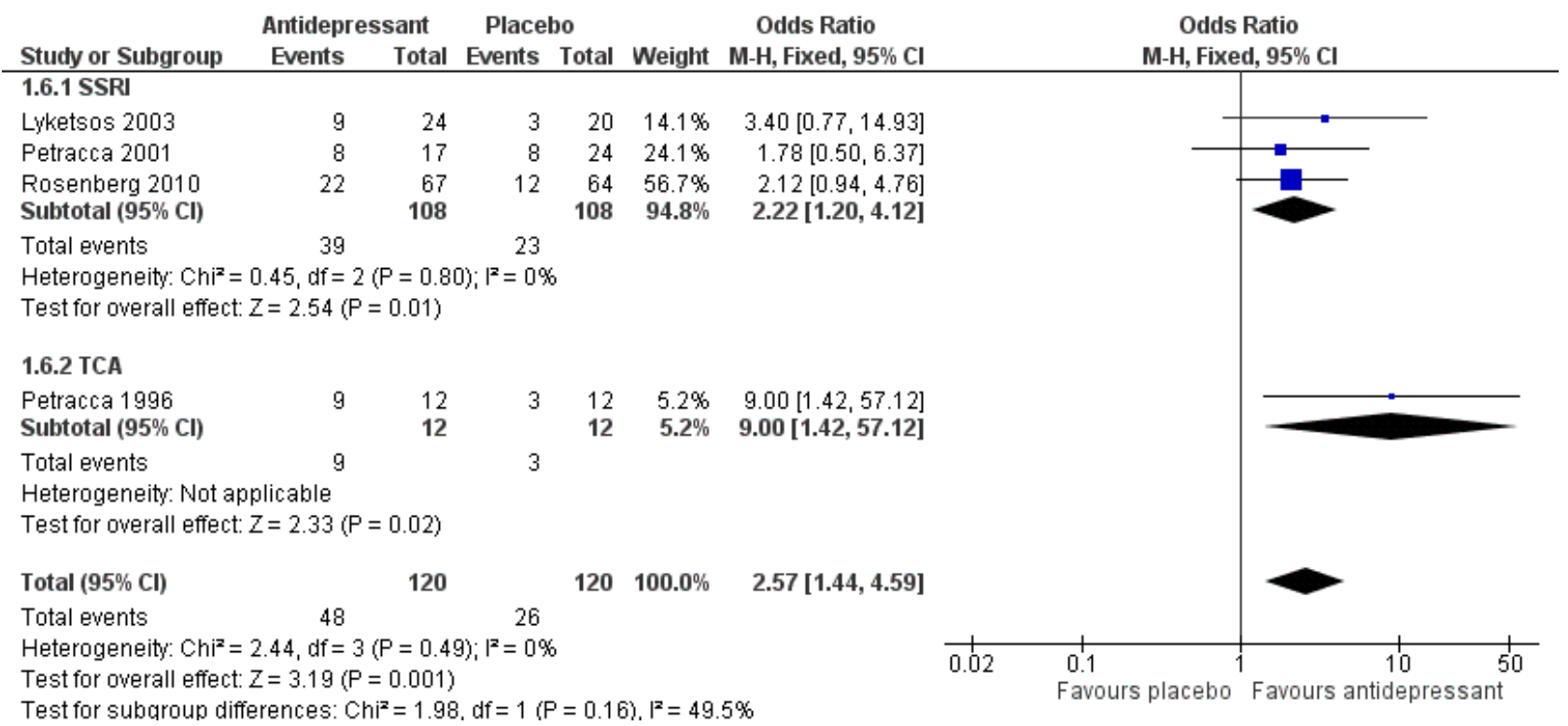

\section{Cognitive function}

Meta-analyses of cognitive function measured with the Mini Mental State Examination (MMSE) showed that there was probably little or no difference between antidepressant or placebo at weeks 6 to 12 , whether the outcome was endpoint mean scores (MD 0.33 point, $95 \% \mathrm{Cl}-1.31$ to 1.96 ; 194 participants; 5 studies; $12=0 \%$; Analysis 1.8) or change in mean scores (MD 0.19 point, $95 \% \mathrm{Cl}-0.81$ to $1.19 ; 5$ studies; Analysis 1.9). This was also true in sensitivity analyses looking at endpoint intention-to-treat (ITT) data (Petracca 2001; Lyketsos 2003: MD -0.76 point, $95 \% \mathrm{Cl}-3.78$ to $2.27, \mathrm{P}=$ 0.62) or completers-only data (Reifler 1989; Petracca 1996; Petracca 2001: MD -0.34 point, $95 \% \mathrm{Cl}-3.06$ to $2.39 ; \mathrm{P}=0.81$; analysis not presented). We regarded this as moderate-quality evidence due to imprecision (relatively few participants and wide confidence intervals). There was also no evidence of a difference between groups at six to nine months for endpoint mean scores (MD 1.00 point, $95 \% \mathrm{Cl}-1.14$ to 3.14 ; 131 participants; 1 study; see Analyis

1.7.2) or change in mean scores (MD - 0.38 point, $95 \% \mathrm{Cl}-1.90$ to 1.13 ; 2 studies; Analysis 1.9) on the MMSE.

\section{Activities of daily living}

Five studies measured performance of activities of daily living (ADLs) using different scales (Reifler 1989; Petracca 1996; Petracca 2001; Lyketsos 2003; An 2017). We were able to pool data from four studies to estimate a standardised mean difference between groups; we had to exclude the data from Petracca 1996, because they were available only as change-from-baseline while the other studies reported endpoint scores. There was little or no difference between antidepressants and placebo as regards ADLs at weeks 6 to 13 (SMD $-0.05,95 \% \mathrm{Cl}-0.36$ to $0.25 ; 173$ participants; 4 studies; $\left.\right|^{2}=$ $20 \%$; Analysis 1.10, Figure 7). We considered this to be high-quality evidence. The only study that reported data at six to nine months (Weintraub 2010) did not indicate any difference between groups either.

Figure 7. Forest plot of comparison: 1 Antidepressant versus placebo, outcome: 1.10 Activities of daily living, endpoint values at 6-13 weeks.

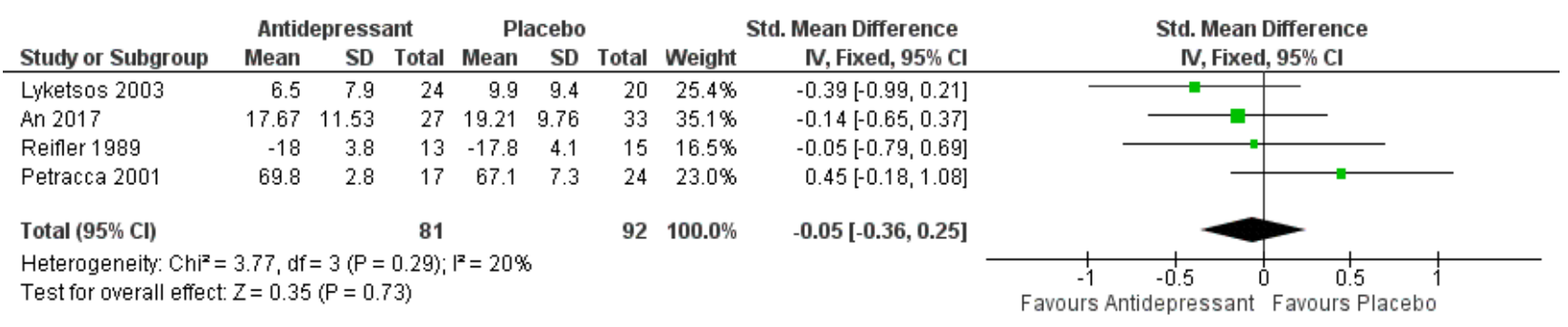

\section{Quality of life}

We could not pool the results on quality-of-life outcomes from two studies (Weintraub 2010; Banerjee 2011), as they reported data in very different formats. Neither study reported any significant difference by treatment group.

\section{Dropouts and adverse effects}

\section{Tolerability (measured as withdrawal from trial)}

Data from nine studies indicated that participants on antidepressant treatment were probably more likely to drop out 
of the study over 6 to 13 weeks (OR 1.51, 95\% Cl 1.07 to 2.14; 836 participants; 9 studies; $1^{2}=0 \%$; Analysis 1.12; Figure 8 ). We graded this evidence as moderate-quality due to imprecision. Subgroup analyses looking at SSRIs, venlafaxine, mirtazapine, and older antidepressants separately found that placebo was consistently favoured, but the results for the individual antidepressants were associated with more uncertainty and in each case were also consistent with little or no difference between groups. There was no clear evidence of a difference between groups after six to nine months (OR 1.25, 95\% Cl 0.83 to 1.88; 457 participants; 2 studies; Analysis 1.13), on the basis of evidence rated as moderate-quality due to imprecision.

\section{Figure 8. Forest plot of comparison: 1 Antidepressant versus placebo, outcome: 1.12 Tolerability: Number of} dropouts at 6-13 weeks.

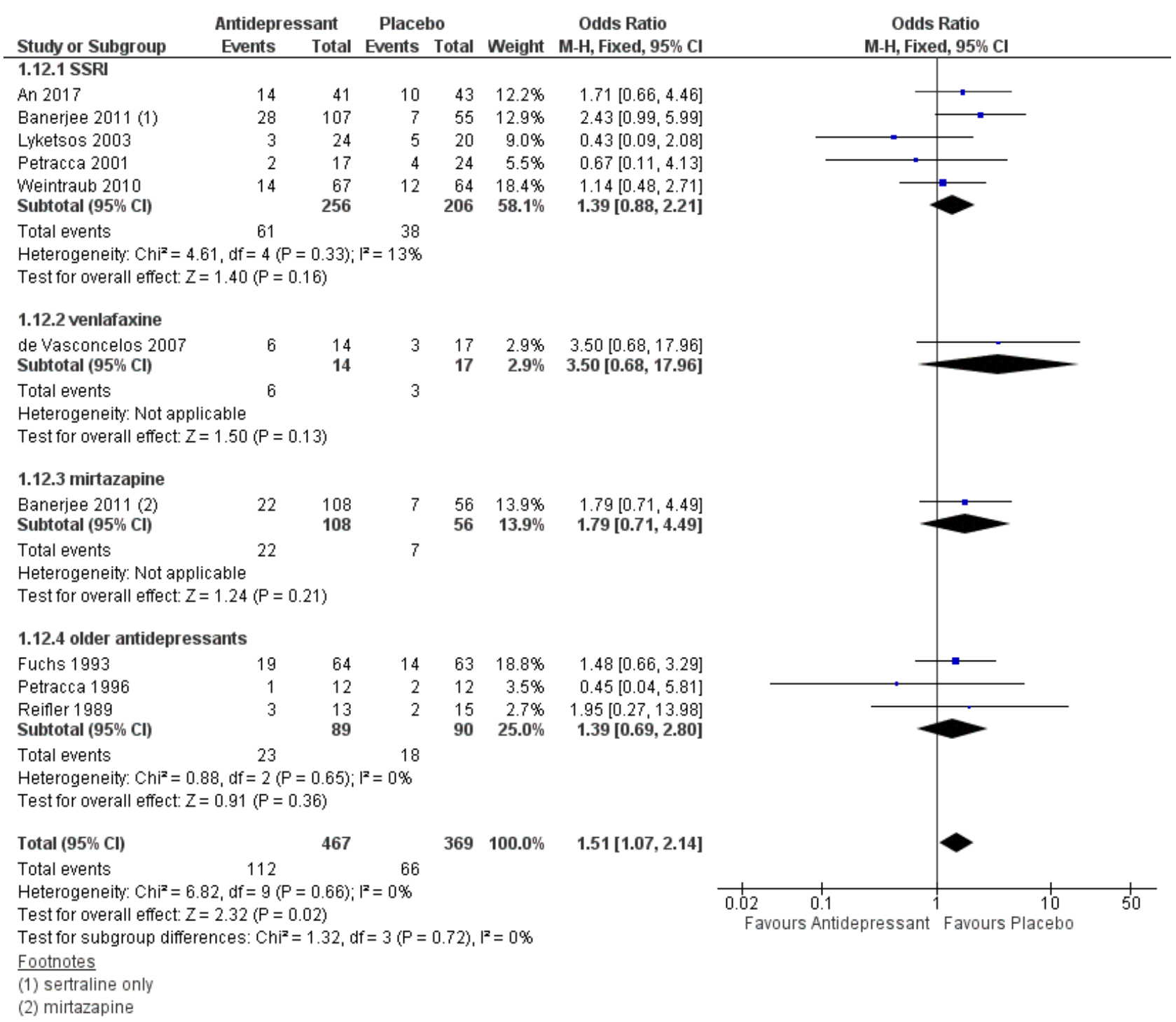

\section{Safety (measured by the incidence of adverse effects)}

Participants taking an antidepressant were probably more likely to experience at least one adverse event at 6 to 13 weeks (Peto OR $1.55,95 \% \mathrm{Cl} 1.21$ to $1.98 ; 1073$ participants; 3 studies; $\mathrm{I}^{2}=$ $26 \%$; Analysis 1.14), although we considered the evidence to be moderate-quality due to publication bias. This effect was more pronounced with SSRIs and older antidepressants, whilst the Peto OR in the mirtazapine data was not significant. There were statistically significant differences in favour of placebo for numbers of participants experiencing dry mouth (Peto OR 1.80, 95\% Cl 1.23 to 2.63 ; 1044 participants; 5 studies; $I^{2}=55 \%$; Analysis 1.15) and

dizziness (Peto OR 2.00, 95\% Cl 1.34 to 2.98 ; 1044 participants; 5 studies; $12=29 \%$; Analysis 1.18). We rated the evidence for both these outcomes as high-quality. Subgroup analyses revealed similar patterns with SSRIs and older antidepressants for both outcomes. There were no statistically significant differences found for fatigue (quality of the evidence rated as low due to selective reporting and imprecision; Analysis 1.16) or constipation (quality of evidence rated as moderate due to imprecision; Analysis 1.17).

Data on serious adverse events (SAEs) were reported in a number of the included studies but unfortunately in different formats, therefore they could not be pooled. Banerjee 2011, which looked 
at data at 13 weeks, reported 15 SAEs in the placebo group, 12 in the sertraline group, and 14 in the mirtazapine group; out of these, 3,8 , and 10 were severe, respectively, suggesting that although the overall number of SAEs did not differ between groups, more of these events were severe in those participants on antidepressants compared with placebo. Over 24 weeks in the DIADS-2 study (Weintraub 2010), SAEs occurred in $27.3 \%$ of participants on sertraline compared with $12.7 \%$ of those on placebo. Petracca and colleagues reported serious side effects in one participant who was in the group treated with an antidepressant (Petracca 2001); and in Roth 1996, 27.4\% of the adverse events were rated as severe in the placebo group compared with $29 \%$ in the moclobemide group (however it should be noted that their "safety" population included both participants with dementia with depressive symptoms and those with depression with cognitive decline). Overall, it seems that SAEs occurred more often in those participants given antidepressants compared to those on placebo.

\section{DISCUSSION}

\section{Summary of main results}

Meta-analyses of outcome measures relating to antidepressant treatment efficacy revealed little or no effect of antidepressants on depression rating scale mean scores at 6 to 12 weeks (high-quality evidence) or at 6 to 9 months (moderate-quality evidence). There was also no clear evidence of an effect of treatment on the number of responders (low-quality evidence). We found moderate-quality evidence favouring antidepressants in the comparison of remission rates at 6 to 12 weeks, but the result at 24 weeks was imprecise and we could not be sure that the difference was maintained.

Subgroup analyses looking at selective serotonin reuptake inhibitors (SSRIs), venlafaxine, mirtazapine, and tricyclic antidepressants (TCAs) separately did not indicate differences between these subgroups. A sensitivity analysis looking at studies which measured depression with the Cornell Scale for Depression in Dementia (CSDD), which is designed specifically to assess depression in dementia, found little or no effect of antidepressants when compared to placebo.

There was little or no difference in measures of cognitive function (Mini Mental State Examination (MMSE) scores) or activities of daily living between antidepressant and placebo groups (moderate- and high-quality evidence, respectively).

Participants taking antidepressants were probably more likely to drop out of treatment and more likely to experience at least one adverse event over 6 to 12 weeks. Patients on antidepressant were significantly more likely to experience dry mouth or dizziness, but not fatigue or constipation.

\section{Overall completeness and applicability of evidence}

The process of combining data from differing studies is problematic. The assumption is that the study samples are drawn from similar populations but the validity of this assumption is difficult to assess. The adherence to the inclusion criteria for studies ensures some homogeneity in that all participants included in the review meet recognised criteria for both depression and dementia.

As discussed earlier, the relationship between depression and dementia is complex, and depression is more difficult to diagnose in patients with dementia. DSM criteria for depression include anhedonia and poor concentration, which are both symptoms of dementia. Some studies attempted to take this potentially confounding factor into account when making the diagnosis of depression (Lyketsos 2003; Rosenberg 2010; Banerjee 2011). A further concern is that only one of the depression rating scales used in the included studies was developed for the specific purpose of measuring depression in dementia (CSDD). Other instruments used in the included studies were developed in younger subjects and may underestimate depression in older patients because of the atypical nature of depression in older people (e.g. the Hamilton Depression Scale, HAM-D). Even where scales are designed specifically for the older population, they may not be reliable in the specific scenario of depression in dementia (e.g. the Geriatric Depression Scale) (Burns 2002). Assessing response to treatment and remission is also fraught with difficulties in these patients.

Depression and dementia are both highly heterogeneous conditions. Patients with mild dementia who are unhappy at the threat to future independence which their diagnosis represents, may be different from those with a MMSE of 15, apathy, anhedonia, low mood and intermittent anxiety. Theoretically, this difference has the potential to obscure potentially useful benefits of antidepressants in patient subgroups. There was no important heterogeneity in our meta-analysis. However, this might be because all studies examined patients with a wide range of MMSE scores. It should therefore be regarded as absence of evidence rather than evidence of absence.

We only included studies using formal criteria for depression to improve the reliability and clinical applicability of our findings, thereby including the more severe end of the depressive spectrum which is more likely to respond to antidepressant treatment.

It cannot be excluded that adjuvants (e.g. lithium or antipsychotics) or combination treatments (not studied in this review) could show a significant effect in the treatment of patients with depression in dementia.

It is of note that activities of daily living and especially dementiaspecific quality-of-life measures have only been used in the more recent studies.

\section{Quality of the evidence}

As presented in the 'Risk of bias' and 'Summary of findings' tables, the quality of the evidence for most outcomes was of moderate- or low-quality principally due to risk of bias and imprecision.

The analysis of adverse event data in these studies was particularly difficult due to a number of factors. There was considerable heterogeneity in the reporting of adverse events across the studies in terms of comprehensiveness, mode of ascertainment, and format. Some studies reported all or nearly all side effects and adverse events, some grouped these into systems (e.g. respiratory system, gastrointestinal system, etc.), some only reported serious adverse events, and some a mixture of these. Ideally, figures for all categories should be reported in order that results from different studies (often using different medications) can be metaanalysed. The studies also differed in terms of whether they relied on spontaneous reporting or various types of questioning. Some reports included the total number of adverse events, others only published the number (or percentages) of participants reporting 
side effects, or those who withdrew from the study due to adverse events. Tolerability ratings (very good, good, etc.) presented by the investigator appear a subjective measure. Only one study made explicit reference to accepted guidelines in how the authors defined serious adverse events (SAEs) (Rosenberg 2010). They used the Food and Drug Administration definition, i.e. any adverse drug experience occurring at any dose that resulted in any of the following: death, a life-threatening adverse experience, inpatient hospitalisation or prolongation of existing hospitalisation, or persistent or significant disability/incapacity. Following a set of consistent guidelines on reporting would significantly enhance the reliability of the evidence base.

\section{Potential biases in the review process}

It is unfortunate that the results of two of the ten studies (Fuchs 1993, Roth 1996) included in this update could not be included in the efficacy meta-analysis, as they did not include the numbers in each treatment group who had completed the study. The authors of the studies were contacted and statistical elaboration requested, but for various reasons elaboration did not prove possible. This is of particular regret with regards to Roth 1996, as it was a large multicentre study with 476 participants meeting inclusion criteria for the review and the authors reported positive results. It is a limitation of our study that in order to be able to enter the sertraline and mirtazapine arms of Banerjee 2011, we had to split the control group into two groups which remained correlated.

We used endpoint data as opposed to change from baseline, as the latter are often not reported and calculating the standard deviation from the reported data is problematic.

It is also possible that our study has failed to find an effect that really exists (type 2 error). We argue that this possibility is less likely, as we have minimised the amount of data manipulation and simply combined symptom scores; therefore unwitting biases are less likely to have emerged.

\section{Agreements and disagreements with other studies or reviews}

Other reviews of this subject have been published. A review by Starkstein and colleagues, Starkstein 2006, drew attention to two individual studies that are also included in our analysis (Roth 1996; Lyketsos 2003), and reported efficacy in the treatment of depression in dementia with sertraline and moclobemide, respectively.

A systematic review by Thompson and colleagues concluded that antidepressants were efficacious (Thompson 2007). This review examined antidepressants in Alzheimer's disease rather than just in dementia as a whole but this difference is unlikely to have been important, as the authors included four of the same studies that we have used here (Reifler 1989; Petracca 1996; Petracca 2001; Lyketsos 2003). The fifth study used by Thompson and colleagues, Magai 2000, was excluded from our review because only $10 \%$ of the sample had diagnosed major depression and we felt the validity of the diagnosis of depression was questionable and not comparable with other studies, considering that they had to rely on proxy measures in a patient population much more severely demented than in the other studies included. Proxy measures included cutoff scores on the Cornell Scale and the Gestalt Depression Scale (Greenwald 1991), and also analysis of facial expression. Thompson and colleagues adopted a different approach, namely to define cases as responders on the basis of a $50 \%$ reduction in their depression scores (HAM-D or other) or as achieving remission (HAM-D score of less than eight, or equivalent) (Thompson 2007). However, the authors also went on to state that: "Other definitions of depression remission or response were considered if they were deemed clinically valid and (or) relevant". In contrast, we have looked at depression scores as continuous variables as well as examining response and remission. Introducing criteria for response and remission carries the possibility of introducing a bias in favour of treatment (type 1 error). In their narrative review, Farina and colleagues also concluded that antidepressants are not effective for depression (Farina 2017).

Another review, which included the de Vasconcelos and Rosenberg studies (both of which reported lack of efficacy) in addition to the same ones included in the Thompson review, was in accordance with our findings (Nelson 2011). A meta-analysis by Sephery and colleagues, Sepehry 2012, found a lack of efficacy for antidepressants based on data from five studies. Several other recent reviews also noted the limited evidence and concluded that more studies were needed (Modrego 2010; Saarinen 2010; Haight 2013; Leong 2014; Orgeta 2017).

Our findings are also somewhat different to some other reviews regarding drug safety. The Thompson review reported dropouts from treatment due to all causes and due to adverse events, but did not examine individual symptoms. From this relatively broad approach, they found no significant differences. However, we have analysed data regarding several side effects and found that participants treated with antidepressants experienced significantly more adverse events. It should be noted that three studies that contributed to this analysis were not available to Thompson and colleagues (the Banerjee, de Vasconcelos, and DIADS-2 studies).

\section{AUTHORS' CONCLUSIONS}

\section{Implications for practice}

Although depression is common in people with dementia and many patients are prescribed antidepressants, there is limited published evidence to support the efficacy of antidepressants for the treatment of depression in this patient group. They do not improve outcomes on depression rating scales, although there is moderate-quality evidence to show that they probably increase short-term remission rates. There is also moderate-quality evidence that they are associated with more adverse effects than placebo. Although we did not find differential effects of different antidepressants, these subgroup data were sparse. It is possible that patients with different clinical characteristics (subtypes or severities or dementia or depression) may respond differently.

\section{Implications for research}

With an expanding ageing population and a resultant increase in the prevalence of dementia, more research is needed in this important clinical area. There is a need for well-conducted randomised controlled trials, using scales validated in older people with depression and dementia (such as the Cornell Scale for Depression in Dementia), of modern, frequently used drugs and sufficient sample sizes that would allow a study of treatment response and detailed adverse event profile according to dementia aetiology and severity and depression severity. We would 
recommend that future research explores narrower spectra of cognitive impairment and more specific subsyndromes of affective disturbance in dementia.

\section{ACKN OWLEDGEMENTS}

We are grateful for the help of Dr Petracca (Raul Carrea Institute of Neurological Research, Buenos Aires) for providing us with the detailed results from his study which were not available in the published paper, and to Dr Gottfries (Göteborg University, Sweden) for clarification on the details of his study (Nyth 1992). We thank Dr Brian Draper (Prince of Wales Hospital, Sydney, Australia) for his comments on the paper, and Prof Sube Banerjee for replying to our inquiry about their study.

We would like to acknowledge the work of Dr Jatinder Bains and Jacqueline Birks who were co-authors of the original review. We are also indebted to Dr Helen Collins ( $\mathrm{HC}$ ) and Dr Rupert McShane who provided us support and useful technical advice throughout the recent review. We are grateful to Anna Noel-Storr for helping with the searches and entering the references into Archie, to Robin W.M. Vernooij for his help with the 'Summary of findings' table, and to Lee Yee Chong for her advice. 


\section{R E F E R E N C E S}

\section{References to studies included in this review}

\section{An 2017 \{published data only\}}

An H, Choi B, Park K-W, Kim D-H, Yang D-W, Hong CH, et al. The effect of escitalopram on mood and cognition in depressive Alzheimer's disease subjects. Journal of Alzheimer's disease 2017;2:727-35.

\section{Banerjee 2011 \{published data only\}}

* Banerjee S, Hellier J, Dewey M, Romeo R, Ballard C, Baldwin R, et al. Study of the use of antidepressants for depression in dementia: the HTA-SADD Trial - a multicentre randomised double-blind, placebo-controlled trial of the clinical effectiveness of sertraline and mirtazapine. Lancet 2011;378:403-11.

Banerjee S, Hellier J, Romeo R, Dewey M, Knapp M, Ballard C, et al. Study of the use of antidepressants for depression in dementia: the HTA-SADD trial - a multicentre, randomised, double-blind, placebo-controlled trial of the clinical effectiveness and cost-effectiveness of sertraline and mirtazapine. Health Technology Assessment March 2013; Vol. 17 , issue 7.

Romeo R, Knapp M, Hellier J, Dewey M, Ballard C, Baldwin R, et al. Cost-effectiveness analyses for mirtazapine and sertraline in dementia: randomised controlled trial. British Journal of Psychiatry 2013;202:121-8.

\section{de Vasconcelos 2007 \{published data only\}}

de Vasconcelos Cunha UG, Lopes Rocha F, Avila de Melo R, et al. A placebo-controlled double-blind randomized study of venlafaxine in the treatment of depression in dementia. Dementia \& Geriatric Cognitive Disorders 2007;24(1):36-41.

Fuchs 1993 \{published data only\}

Fuchs A, Hehnke CH, Erhart C, Schnell C, Pramshohler B, Danninger $\mathrm{B}$, et al. Video rating analysis of effect of maprotiline in patients with dementia and depression. Pharmacopsychiatry 1993;26:37-41.

Lyketsos 2003 \{published data only\}

* Lyketsos CG, DelCampo L, Steinberg M, Miles Q, Steele CD, Munro C, et al. Treating depression in alzheimer disease: efficacy and safety of sertraline therapy, and the benefits of depression reduction: the DIADS. Archives of General Psychiatry 2003;60(7):737-46

Lyketsos CG, Sheppard JME, Steele CD, Kopunke C, Baker AS, Brandt J, et al. A randomized, placebo-controlled, doubleblind, clinical trial of sertraline in the treatment of major depression complicating Alzheimer's disease: initial results from the depression in Alzheimer's disease study. Conference Proceedings World Alzheimer Congress; 9-13 July, 2000; Washington DC. 2000.

Mayer LS, Bay RC, Politis A, et al. Comparison of three rating scales as outcome measures for treatment trials of depression in Alzheimer disease: findings from DIADS. International Journal of Geriatric Psychiatry 2006;21(10):930-6.
Munro C, Lyketsos C. Cognitive response to sertraline treatment for depression in Alzheimer's disease: a possible sex effect. Research and Practice in Alzheimer's Disease 2006;11:361-5.

Munro CA, Brandt J, Sheppard J-ME, Steele CD, Samus QM, Steinberg $M$, et al. Cognitive response to pharmacological treatment for depression in Alzheimer disease: Secondary outcomes from the depression in Alzheimer's disease study (DIADS). American Journal of Geriatric Psychiatry 2004; Vol. 12, issue 5:491-8.

Munro CA, Brandt J, Sheppard JM, Samus QM, Steinberg M, Rabins PV, et al. Secondary outcomes from the depression in Alzheimer's disease Study (DIADS). American Journal of Geriatric Psychiatry 2004;12(5):491-8.

Steinberg M, Munro CA, Samus Q, et al. Patient predictors of response to treatment of depression in Alzheimer's disease: the DIADS study. International Journal of Geriatric Psychiatry 2004;19:144-50.

\section{Petracca 1996 \{published and unpublished data\}}

Petracca G, Teson A, Chemerinski E, Leguarda R, Starkstein SE. A double-blind placebo-controlled study of clomipramine in depressed patients with Alzheimer's disease. Journal of Neuropsychiatry and Clinical Neurosciences 1996;8(3):270-5.

\section{Petracca 2001 \{published data only\}}

Petracca GM, Chemerinski E, Starkstein SE. A double-blind, placebo-controlled study of fluoxetine in depressed patients with Alzheimer's disease. International Psychogeriatrics 2001;13(2):233-240.

\section{Reifler 1989 \{published data only\}}

Reifler BV, Teri L, Raskind M, Veith R, Barnes R, White E, et al. Double-blind trial of imipramine in Alzheimer's disease patients with and without depression. American Journal of Psychiatry 1989;146(1):45-9.

Teri L, Reifler BV, Veith RC, Barnes R, White E, McLean P, et al. Imipramine in the treatment of depressed Alzheimer's disease: impact on cognition. Journals of Gerontology: Psychological Sciences 1991;46(6):372-7.

\section{Rosenberg 2010 \{published data only\}}

Drye LT, Martin BK, Frangakis CE, Meinert CL, Mintzer JE, Munro CA, et al. Do treatment effects vary among differing baseline depression criteria in depression in Alzheimer's disease study \pm 2 (DIADS-2)?. International Journal of Geriatric Psychiatry 2011;26(6):573-83.

Flynn Longmire CV, Drye LT, Frangakis CE, Martin BK, Meinert CL, Mintzer JE, et al. Is sertraline treatment or depression remission in depressed alzheimer patients associated with improved caregiver well being? Depression In Alzheimer's Disease Study 2. American Journal of Geriatric Psychiatry 2014; Vol. 22, issue $1: 14-24$

* Rosenberg PB, Drye LT, Martin BK, Frangakis C, Mintzer JE, Weintraub $D$, et al. Sertraline for the treatment of depression 
in alzheimer disease. American Journal of Geriatric Psychiatry 2010;18(2):136-45.

\section{Roth 1996 \{published data only\}}

Roth M, Mountjoy CQ, Amrein R and the International Collaborative Study Group. Moclobemide in elderly patients with cognitive decline and depression: an international doubleblind, placebo-controlled trial. British Journal of Psychiatry 1996;168(2):149-57.

\section{Weintraub 2010 \{published data only\}}

Lyketsos CG. Depression in Alzheimer's disease (DIADS 2). ClinicalTrials.gov 2004. [Study ID Numbers: 1U0166136; ClinicalTrials.gov Identifier: NCT00086138]

Martin BK, Frangakis CE, Rosenberg PB, et al. Design of Depression in Alzheimer's Disease Study-2. American Journal of Geriatric Psychiatry 2006;14(11):920-30.

Munro CA, Longmire CF, Drye LT, Martin BK, Frangakis CE, Meinert $\mathrm{CL}$, et al. Cognitive outcomes after sertaline treatment in patients with depression of Alzheimer disease. American Journal of Geriatric Psychiatry 2012; Vol. 20, issue 12:1036-44.

Rosenberg PB, Drye LT, Martin BK, Frangakis C, Mintzer JE, Weintraub D, et al. Sertraline for the treatment of depression in alzheimer disease. American Journal of Geriatric Psychiatry 2010;18(2):136-45

* Weintraub D, Rosenberg PB, Drye LT, Martin BK, Frangakis C, Mintzer JE, et al. Sertraline for the treatment of depression in alzheimer disease: Week-24 outcomes. American Journal of Geriatric Psychiatry 2010;18(4):332-40.

\section{References to studies excluded from this review}

Barak 1996 \{published data only\}

Barak Y, Levine J, Glasman A, Elizur A, Belmaker RH. Inositol treatment of Alzheimer's disease: a double blind, cross-over placebo controlled trial. Progress in Neuro Psychopharmacology and Biological Psychiatry 1996;20(4):729-36.

\section{Brodaty 2003 \{published data only\}}

Brodaty H, Draper BM, Millar J, Low LF, Lie D, Sharah S, et al. Randomized controlled trial of different models of care for nursing home residents with dementia complicated by depression or psychosis. Journal of Clinical Psychiatry 2003;64(1):63-72.

\section{Bui 2012 \{published data only\}}

Bui Q. Antidepressants for agitation and psychosis in patients with dementia. American Family Physician 2012;85(1):20-2.

\section{Burke 1994 \{published data only\}}

Burke WJ, Folks DG, Roccaforte WH, Wengel SP. Serotonin reuptake inhibitors for the treatment of coexisting depression and psychosis in dementia of the Alzheimer type. American Journal of Geriatric Psychiatry 1994;2(4):352-4.

\section{Capote 1978 \{published data only\}}

Capote B, Parikh N. Cyclandelate in the treatment of senility: a controlled study. Journal of the American Geriatrics Society 1978;26(8):360-2.

\section{Choe 2014 \{published data only\}}

Choe YM, Kim KW, Jhoo JH, Ryu S-H, Choo IH, Seo EH, et al. Multi-center, randomized, placebo-controlled, double-blind clinical trial of escitalopram on the progression delaying effect in Alzheimer's disease: An MRI study for atrophy delaying effect. Alzheimer's \& Dementia 2014; Vol. 10, issue 4:111.

\section{Devanand 2003 \{published data only\}}

Devanand DP, Pelton GH, Marston K, et al. Sertraline treatment of elderly patients with depression and cognitive impairment. International Journal of Geriatric Psychiatry 2003;18(2):123-30.

Drye 2012 \{published data only\}

* Drye LT, Ismail Z, Porsteinsson AP, Rosenberg PB, Weintraub D, Marano $C$, et al. Citalopram for agitation in Alzheimer's disease: design and methods. Alzheimer's and Dementia 2012;8(2):121-30

Dunbar 2011 \{published data only\}

DunbarGC, Kuchibhatla RV, Lee G. A randomized double-blind study comparing 25 and $50 \mathrm{Mg}$ Tc-1734 (Azd3480) with placebo, in older subjects with age-associated memory impairment. Journal of Psychopharmacology 2011;25(8):1020-9.

Fairweather 1993 \{published data only\}

Fairweather DB, Kerr JS, Harrison DA, Moon CA, et al. A double blind comparison of the effects of fluoxetine and amitriptyline on cognitive function in elderly depressed patients. Human Psychopharmacology Clinical and Experimental 1993;8(1):41-7.

Finkel 2004 \{published data only\}

Finkel SI, Mintzer JE, Dysken M, Krishnan KR, Burt T, McRae T. A randomized, placebo-controlled study of the efficacy and safety of sertraline in the treatment of the behavioral manifestations of Alzheimer's disease in outpatients treated with donepezil. International Journal of Geriatric Psychiatry 2004;19(1):9-18.

Flicker 1998 \{published data only\}

Flicker C, Gottfries CG. Citalopram treatment of depression in elderly patients with or without dementia: results of a placebocontrolled study. Conference Proceedings 11th Annual Meeting of the American Association for Geriatric Psychiatry; 8th-11th March, 1998; San Diego, California, USA. 1998.

\section{Gottfries 1991 \{published data only\}}

Gottfries CG, Nyth AL. Effect of citalopram, a selective 5$\mathrm{HT}$ reuptake blocker, in emotionally disturbed patients with dementia. Annals of the New York Academy of Sciences 1991;640:276-9.

\section{Gottfries 1992 \{published data only\}}

* Gottfries CG, Karlsson I, Nyth AL. Treatment of depression in elderly patients with and without dementia disorders. International Clinical Psychopharmacology 1992;6(Suppl 5):55-64. 


\section{Hoyberg 1996 \{published data only\}}

Hoyberg OJ, Maragakis B, Mullin J, Norum D, Stordall E, Ekdahl $\mathrm{P}$, et al. A double-blind multicentre comparison of mirtazapine and amitriptyline in elderly depressed patients. Acta Psychiatrica Scandinavica 1996;93(3):184-90.

Jenike 1985 \{published data only\}

* Jenike MA. Monoamine oxidase inhibitors as treatment for depressed patients with primary degenerative dementia (Alzheimer's disease). American Journal of Psychiatry 1985;142:763-4.

\section{Karlsson 2000 \{published data only\}}

Karlsson I, Godderis J, Augusto De Mendoca Lima C, Nygaard H, Simanyi $\mathrm{M}$, et al. A randomised, double-blind comparison of the efficacy and safety of citalopram compared to mianserin in elderly, depressed patients with mild to moderate dementia. International Journal of Geriatric Psychiatry 2000;15:295-305.

\section{Katona 1998 \{published data only\}}

* Katona CLE, Hunter BN, Bray J. A double-blind comparison of the efficacy and safety of paroxetine and imipramine in the treatment of depression and dementia. International Journal of Geriatric Psychiatry 1998;13:103-8.

\section{Lebert 2006 \{published data only\}}

Lebert F, Stekke W, Hasenbroekx C, et al. Trazodone in frontotemporal dementia. Research and Practice in Alzheimer's Disease 2006;11:356-60.

\section{Magai 2000 \{published data only\}}

Magai C, Kennedy G, Cohen Cl, Gomberg D. A controlled clinical trial of sertraline in the treatment of depression in nursing home patients with late-stage Alzheimer's disease. American Journal of Geriatric Psychiatry 2000;8:66-74.

\section{Mizukami 2009 \{published data only\}}

Mizukami K, Hatanaka K, Tanaka Y, Sato S, Asada T. Therapeutic effects of the selective serotonin noradrenaline reuptake inhibitor milnacipran on depressive symptoms in patients with Alzheimer's disease. Progress in Neuro-Psychopharmacology \& Biological Psychiatry 2009;33(2):349-52.

\section{Mokhber 2014 \{published data only\}}

Mokhber N, Abdollahian E, Soltanifar A, Samadi R, Saghebi A, Haghighi M B, et al. Comparison of sertraline, venlafaxine and desipramine effects on depression, cognition and the daily living activities in alzheimer patients. Pharmacopsychiatry 2014; Vol. 47, issue 4-5:131-40.

\section{Moretti 2003 \{published data only\}}

Moretti R, Torre P, Antonello RM, Cazzato G, Bava A. Frontotemporal dementia: paroxetine as a possible treatment of behavior symptoms. A randomized, controlled, open 14month study. European Neurology 2003;49(1):13-9.

\section{Mossello 2008 \{published data only\}}

Mossello E, Boncinelli M, Caleri V, Cavallini MC, Palermo E, Di Bari M, et al. Is antidepressant treatment associated with reduced cognitive decline in Alzheimer's disease?. Dementia and Geriatric Cognitive Disorders 2008;25(4):372-9.

\section{Mowla 2007 \{published data only\}}

Mowla A, Mosavinasab M, Haghshenas H, Haghighi AB. Does serotonin augmentation have any effect on cognition and activities of daily living in Alzheimer's dementia? A doubleblind, placebo-controlled clinical trial. Journal of Clinical Psychopharmacology 2007;27(5):484-7.

Nebes 2003 \{published data only\}

Nebes RD, Pollock BG, Houck PR, Butters MA, Mulsant BH, Zmuda MD, et al. Persistence of cognitive impairment in geriatric patients following antidepressant treatment: a randomized, double-blind clinical trial with nortriptyline and paroxetine. Journal of Psychiatric Research 2003;37(2):99-108.

\section{Nelson 2006 \{published data only\}}

Nelson JC, Hollander SB, Betzel J, et al. Mirtazapine orally disintegrating tablets in depressed nursing home residents 85 years of age and older. International Journal of Geriatric Psychiatry 2006;21(9):898-901.

\section{Nyth 1990 \{published data only\}}

Nyth AL, Gottfries CG. The clinical efficacy of citalopram in the treatment of emotional disorders in dementia disorders. British Journal of Psychiatry 1990;157:894-901.

Nyth 1992 \{published data only\}

Nyth AL, Gottfries CG, Lyby K, Smedegaard-Andersen L, GyldingSabroe J, Kristensen M, et al. A controlled multicenter clinical study of citalopram and placebo in elderly patients with and without concomitant dementia. Acta Psychiatrica Scandinavica 1992;86:138-45.

\section{Oslin 2000 \{published data only\}}

Oslin DW, Streim JE, Katz IR, Smith BD, DiFilippo SD, Ten Have TR, et al. Heuristic comparison of sertraline with nortriptyline for the treatment of depression in frail elderly patients. American Journal of Geriatric Psychiatry 2000;8(2):141-9.

Oslin 2003 \{published data only\}

Oslin DW, Ten Have TR, Streim JE, Datto CJ, Weintraub D, DiFilippo $S$, et al. Probing the safety of medications in the frail elderly: evidence from a randomized clinical trial of sertraline and venlafaxine in depressed nursing home residents. Journal of Clinical Psychiatry 2003;64(8):875-82.

\section{Passeri 1987 \{published data only\}}

Passeri M, Cucinotta D, de Mello M, Biziere K. Comparison of minaprine and placebo in the treatment of Alzheimer's disease and multi-infarct dementia. International Journal of Geriatric Psychiatry 1987;2(2):97-103.

Pelton 2008 \{published data only\}

Pelton GH, Harper OL, Tabert MH, Sackeim HA, Scarmeas N, Roose SP, et al. Randomized double-blind placebo-controlled donepezil augmentation in antidepressant-treated elderly patients with depression and cognitive impairment: a pilot study. International Journal of Geriatric Psychiatry 2008;23(7):670-6. 
Pelton 2014 \{published data only\}

Pelton GH, Soleimani L, Roose SP, Tabert MH, Cunqueiro K, Devanand DP. Olfactory identification deficits predict cognitive improvement on donepezil in antidepressant-treated elderly patients with depression and cognitive impairment: A pilot study. Biological psychiatry 2014 Conference: 69th Annual Scientific Convention and Meeting of the Society of Biological Psychiatry. New York, NY United States: SOBP, Conference Start: 20140508 Conference End: 20140510:(var.pagings) 387S.

\section{Peters 2011 \{published data only\}}

Peters ME, Vaidya V, Drye LT, Rosenberg P, Martin BK, Porsteinsson AP, et al. Sertraline for the treatment of depression in Alzheimer's disease: Genetic influences [conference abstract]. American Journal of Geriatric Psychiatry [abstracts from the American Association for Geriatric Psychiatry, AAGP Annual Meeting 2011 San Antonio, TX United States. March 18-21, 2011]. 2011; Vol. http://www.mrw.interscience.wiley.com/cochrane/ clcentral/articles/795/CN-00795795/frame.html.

Pollock 2007 \{published data only\}

Pollock BG, Mulsant H, Rosen J, Mazumdar S, Blakesley RE, Houck PR, et al. A double-blind comparison of citalopram and risperidone for the treatment of behavioral and psychotic symptoms associated with dementia. American Journal of Geriatric Psychiatry 2007;15(11):942-52.

\section{Reynolds III 1987 \{published data only\}}

* Reynolds III CF, Perel JM, Kupfer DJ, Zimmer B, Stack JA, Hoch CC. Open-trial response of antidepressant treatment in elderly patients with mixed depression and cognitive impairment. Psychiatry Research 1997;21:111-22.

\section{Rozzini 2010 \{published data only\}}

Rozzini L, Chilovi BV, Conti M, Bertoletti E, Zanetti M, Trabucchi M, et al. Efficacy of SSRIs on cognition of Alzheimer's disease patients treated with cholinesterase inhibitors. International Psychogeriatrics 2010;22(1):114-9.

\section{Smith 1984 \{published data only\}}

* Smith DF, Stromgren E, Petersen HN, Williams DG, Sheldon W. Lack of effect of tryptophan treatment in demented gerontopsychiatric patients. Acta Psychiatrica Scandinavica 1984;70:470-7.

\section{Streim 2000 \{published data only\}}

Streim JE, Oslin DW, Katz IR, Smith BD, DiFilippo S, Cooper TB, et al. Drug treatment of depression in frail elderly nursing home residents. American Journal of Geriatric Psychiatry 2000;8(2):150-9.

\section{Swartz 1997 \{published data only\}}

* Swartz JR, Miller BL, Lesser IM, Darby AL. Frontotemporal dementia: treatment response to serotonin selective reuptake inhibitors. Journal of Clinical Psychiatry 1997;58:212-6.

\section{Taragano 1997 \{published data only\}}

Taragano FE, Lyketsos CG, Magone CA, Allegri RF, ComesanaDiaz E. A double-blind, randomized, fixed-dose trial of fluoxetine vs. amitriptyline in the treatment of major depression complicating Alzheimer's disease. Psychosomatics 1997;38(3):246-52.

Teranishi 2013 \{published data only\}

Teranishi M, Kurita M, Nishino S, Takeyoshi K, Numata Y, Sato T, et al. Efficacy and tolerability of risperidone, yokukansan, and fluvoxamine for the treatment of behavioral and psychological symptoms of dementia: a blinded, randomized trial. Journal of Clinical Psychopharmacology 2013; Vol. 33, issue 5:600-7.

van Asch 2013 \{published data only\}

van Asch IF, Nuyen J, Veerbeek MA, Frijters DH, Achterberg WP, Pot AM. The diagnosis of depression and use of antidepressants in nursing home residents with and without dementia. International Journal of Geriatric Psychiatry 2013; Vol. 28, issue 3:312-8.

\section{References to studies awaiting assessment}

Sverdlik 2005 \{published data only\}

Sverdlik A. Exploratory study to assess the efficacy of escitalopram versus placebo in the treatment of depressive syndrome in Alzheimers disease, vascular dementia and mixed vascular and Alzheimers dementia. ClinicalTrials.gov 2005.

\section{Additional references}

\section{Abas 1990}

Abas MA, Sahakian BJ, Levy R. Neuropsychological deficits and CT scan changes in elderly depressives. Psychological Medicine 1990;20:507-20.

\section{Alexopoulos 1988}

Alexopoulos GS, Abrams RC, Young RC, Shamoian CA. Cornell Scale for Depression in Dementia. Biological Psychiatry 1988;23(3):271-84

\section{Altman 1999}

Altman DG, Bland JM. Treatment allocation in controlled trials: why randomise?. BMJ 1999;318:1209.

\section{Anderson 2000}

Anderson IM. Selective serotonin reuptake inhibitors versus tricyclic antidepressants: a meta-analysis of efficacy and tolerability. Journal of Affective Disorders 2000;58:19-36.

\section{APA 1987}

American Psychiatric Association. Diagnostic and Statistical Manual of Mental Disorders. 4th Edition. Washington: APA, 1987.

\section{Barnes 2012}

Barnes DE, Yaffe K, Byers AL, McCormick M, Schaefer C, Whitmer RA. Midlife vs late-life depressive symptoms and risk of dementia: differential effects for Alzheimer Disease and vascular dementia. Archives of General Psychiatry 2012;69(5):493-8.

\section{Bennet 2014}

Bennett S, Thomas A. Depression and dementia: cause, consequence orcoincidence?. Maturitas 2014;79(2):184-90. 


\section{Black 2012}

Black BS, Johnston D, Morrison A, Rabins PV, Lyketsos CG, Samus QM. Quality of life of community-residing persons with dementia based on self-rated andcaregiver-rated measures. Quality of Life Research 2012;21(8):1379-89.

\section{Burns 2002}

Burns A, Lawlor B, Craig S. Rating Scales in Old Age Psychiatry. British Journal of Psychiatry 2002;180:161-7.

\section{Byers 2011}

Byers AL, Yaffe K. Depression and risk of developing dementia. Nature Reviews Neurology 2011;7(6):323-31.

\section{Diniz 2013}

Diniz BS, Butters MA, Albert SM, Dew MA, Reynolds CF 3rd. Late-life depressionand risk of vascular dementia and Alzheimer's disease: systematic review andmeta-analysis of community-based cohort studies. British Journal of Psychiatry 2013;202(5):329-35.

\section{Farina 2017}

Farina N, Morrell L, Banerjee S. What is the therapeutic value of antidepressants in dementia? A narrative review. International Journal of Geriatric Psychiatry 2017;32(1):32-49.

\section{Folstein 1975}

Folstein MF, Folstein SE, McHugh PR. "Mini-mental state". A practical method for grading the cognitive state of patients for the clinician. Journal of Psychiatric Research 1975;12(3):189-98.

\section{Galasko 1997}

Galasko D, Bennett D, Sano M, et al. An inventory to assess activities of daily living for clinical trials in Alzheimer's disease. Alzheimer Disease and Associated Disorders 1997;11(suppl 2):33S-39S

\section{Glassman 1981}

Glassman AH, Bigger JT Jr. Cardiovascular effects of therapeutic doses of tricyclic antidepressants: a review. Archives of General Psychiatry 1981;38:815-20.

\section{Granger 1986}

Granger CV, Hamilton BB, Kayton R. Functional Independence Measure. Guide for use of the uniform data set for medical rehabilitation. Buffalo, NY: Uniform Data System for Medical Rehabilitation, 1986.

\section{Greenwald 1991}

Greenwald B, Kramer-Ginsberg E, Kremen NJ, et al. Depression complicating dementia. Presented at American Psychiatric Association Annual Meeting, New Orleans May 1991.

\section{Haight 2013}

Haight T, Cheng $\mathrm{H}$. Antidepressant treatment for older adults with dementia and depression: re-visit the evidence from randomized controlled trials (RCT). Journal of the American Geriatrics Society. 2013; Vol. Conference: 2013 Annual Scientific Meeting of the American Geriatrics Society Grapevine, TX United States. Conference Start: 20130503 Conference End: 20130505.:var.pagings.

\section{Hamilton 1960}

Hamilton, M. A rating scale for depression. Journal of Neurology, Neurosurgery, and Psychiatry 1960;23:56-62.

\section{Heser 2013}

Heser K, Tebarth F, Wiese B, Eisele M, Bickel H, Köhler M, et al. Age of major depression onset, depressivesymptoms, and risk for subsequent dementia: results of the German study onAgeing, Cognition, and Dementia in Primary Care Patients (AgeCoDe). Psychological Medicine 2013;43(8):1597-610.

\section{Higgins 2011}

Higgins JPT, Green S (editors). Cochrane Handbook for Systematic Reviews of Interventions Version 5.1.0. The Cochrane Collaboration 2011 [updated March 2011]:www.cochrane-handbook.org.

\section{Ku 2004}

Ku HM, Kim JH, Kwon EJ, Kim SH, Lee HS, Ko HJ, et al. A Study on the Reliability and Validity of Seoul-Instrumental Activities of Daily Living(S-IADL). Journal of Korean Neuropsychiatric Association 2004;43(2):189-99.

\section{Leong 2014}

Leong C. Antidepressants for depression in patients with dementia: A review of the literature. Consultant Pharmacist 2014; Vol. 29, issue 4:254-63.

\section{Leyhe 2017}

Leyhe T, Reynolds CF 3rd, Melcher T, Linnemann C, Klöppel S, Blennow K, et al. A common challenge in older adults:classification, overlap, and therapy of depression and dementia. Alzheimer's \& Dementia 2017;13(1):59-71.

\section{Loreck 1993}

Loreck DJ, Folstein MF. Depression in Alzheimer Disease. In: Starkstein SE, Robinson RG editor(s). Depression in Neurologic Disease. The John Hopkins series in pyschiatry and neuroscience. Baltimore, MD, US: John Hopkins University Press, 1993:50-62.

\section{McKhann 1984}

McKhann G, Drachman D, Folstein M, Katzman R, Price D, Stadlan EM. Clinical diagnosis of Alzheimer's disease: report of the NINCDS-ADRDA work group under the auspices of the Department of Health and Human Services Task Force on Alzheimer's Disease. Neurology 1984;34(7):939-44.

\section{Modrego 2010}

Modrego PJ. Depression in Alzheimer's disease. Pathophysiology, diagnosis, and treatment. [Review]. Journal of Alzheimer's Disease 2010; Vol. 21, issue 4:1077-87.

\section{Montgomery 1979}

Montgomery SA, Åsberg M. A new depression scale designed to be sensitive to change. British Journal of Psychiatry 1979;134:382-89. 


\section{Naismith 2010}

Naismith SL, Norrie LM, Mowszowski L, Hickie IB. Recurrent depressive symptoms and the incidence of dementia and mild cognitive impairment. Neurology 2010;75:27-34.

\section{Nelson 2011}

Nelson JC, Devanand DP. A systematic review and meta-analysis of placebo-controlled antidepressant studies in people with depression and dementia. Journal of the American Geriatrics Society 2011;59(4):577-85.

\section{Olin 2002}

Olin JT, Schneider LT, Katz IR, et al. Provisional diagnostic criteria for depression of Alzheimer's disease. American Journal of Geriatric Psychiatry 2002;10:125-8.

\section{Orgeta 2014}

Orgeta V, Qazi A, Spector AE, Orrell M. Psychological treatments for depression and anxiety in dementia and mild cognitive impairment. Cochrane Database of Systematic Reviews 2014, Issue 1. [DOI: 10.1002/14651858.CD009125.pub2]

\section{Orgeta 2017}

Orgeta V, Tabet N, Nilforooshan R, Howard R. Efficacy of antidepressants for depression in Alzheimer's Disease: systematic review and meta-analysis. Journal of Alzheimer's Disease 2017;58(3):725-33.

\section{Parker 2000}

Parker G. Should paradigms lost be regained?. American Journal of Psychiatry 2000;157:1195-203.

\section{Pfeiffer 1975}

Pfeiffer E. Multidimensional functional assessment: The OARS methodology. Durham, North Carolina: Center for the Study of Aging and Human Development 1975.

\section{Raskind 1998}

Raskind MA. The clinical interface of depression and dementia. Journal of Clinical Psychiatry 1998;59(Suppl 10):9-12.

\section{Ryan 2016}

Ryan R, Hill S. How to GRADE the quality of the evidence. Cochrane Consumers and Communication Group. Version 1.0. Vol. http://cccrg.cochrane.org/author-resources, Cochrane Consumers and Communication Group, June 2016.

\section{Saarinen 2010}

Saarinen J, Kivela SL, Raiha I. [The effects of antidepressive drugs among the patients with memory disturbances-a systematic review]. Duodecim; laaketieteellinen aikakauskirja 2010; Vol. 126, issue 21:2503-9.

\section{Sepehry 2012}

Sepehry AA, Lee PE, Hsiung GYR, Beattie BL, Jacova C. Effect of selective serotonin reuptake inhibitors in Alzheimer's disease with Comorbid depression: a meta-analysis of depression and cognitive outcomes. Drugs and Aging 2012; Vol. 29, issue 10:793-806.

\section{Settle Jr 1998}

Settle EC Jr. Antidepressant drugs: disturbing and dangerous adverse events. Journal of Clinical Psychiatry 1998;59(Suppl 16):25-30

\section{Starkstein 2006}

Starkstein SE, Mizrahi R. Depression in Alzheimer's disease. Expert Review of Neurotherapeutics 2006;6(6):887-95.

\section{Teng 2008}

Teng E, Ringman JM, Ross LK, Mulnard RA, Dick MB, Bartzokis G, et al. Diagnosing depression in Alzheimer disease with the national institute of mental health provisional criteria. American Journal of Geriatric Psychiatry 2008;16(6):469-77.

\section{Thompson 2007}

Thompson S, Herrmann N, Rapoport MJ, et al. Efficacy and safety of antidepressants for treatment of depression in Alzheimer's disease: a metaanalysis. Canadian Journal of Psychiatry - Revue Canadienne de Psychiatrie 2007;52(4):248-55.

\section{Vaughan 2015}

Vaughan L, Corbin AL, Goveas JS. Depression and frailty in later life: a systematic review. Clinical Interventions in Aging 2015;10:1947-58

\section{Vida 1994}

Vida S, DesRosiers P, Carrier L, et al. Prevalence of depression in Alzheimer's disease and validity or research diagnostic criteria. Journal of Geriatric Psychiatry and Neurology 1994;7:238-44.

\section{WHO 1992}

World Health Organization. International Classification of Disease (ICD-10). Geneva: WHO, 1992.

\section{Wilkinson 1980}

Wilkinson IM, Graham-White, J. Psychogeriatric dependency rating scales (PGDRS): a method of assessment for use by nurses. British Journal of Psychiatry 1980;137:558-65.

\section{Williams 2000}

Williams JW Jr, Mulrow CD, Chiquette E, Noel PH, Aguilar C, Cornell J. A systematic review of newer pharmacotherapies for depression in adults: evidence report summary: Clinical Guidelines, Part 2. Annals of Internal Medicine 2000;132:743-56.

\section{Yesavage 1982}

Yesavage JA, Brink TL, Rose TL, et al. Development and validation of a geriatric depression screening scale: a preliminary report. Journal of Psychiatric Research 1982;17(1):37-49.

\section{References to other published versions of this review \\ Bains 2002}

Bains J, Birks JS, Dening TD. Antidepressants for treating depression in dementia. Cochrane Database of Systematic Reviews 2002, Issue 4. [DOI: 10.1002/14651858.CD003944] 
* Indicates the major publication for the study

\section{CHARACTERISTICS OF STUDIES}

Characteristics of included studies [ordered by study ID]

An 2017

\begin{tabular}{|c|c|}
\hline Methods & $\begin{array}{l}\text { 12-week randomised, double-blind, placebo-controlled multi-centre trial with open-label, 12-week ex- } \\
\text { tension }\end{array}$ \\
\hline Participants & $\begin{array}{l}\text { Country: South Korea } \\
\text { Setting: } 6 \text { dementia centres } \\
\text { Recruitment: prospective subjects } \\
\text { Numbers: } 84 \text { ( } 42 \text { in each group; } 91 \text { were screened) } \\
\text { Inclusion criteria: } \\
\text { 1. over the age of } 50 \text {; } \\
\text { 2. diagnosed with Alzheimer's disease in accordance with NINCDS-ADRDA criteria; } \\
\text { 3. three or more symptoms of the Olin depression (major depressive episode) diagnostic criteria; } \\
\text { 4. clinical dementia rating (CDR) of } 0.5 \text { to } 2 \text {; } \\
\text { 5. MMSE } 10 ~ 26 \text { (K-MMSE); } \\
\text { 6. GDS-15 } \geq 5 \text { points; } \\
\text { 7. care giver spending at least } 4 \text { hours a day, } 3 \text { days a week with the participant accompanying them to } \\
\text { each visit. } \\
\text { Exclusion criteria: } \\
\text { 1. antidepressant treatment within } 4 \text { weeks before the start of the trial; } \\
\text { 2. other mental illness; } \\
\text { 3. serious medical illness; } \\
\text { 4. organic brain disease or organic affective disorder; } \\
\text { 5. taking memantine; } \\
\text { 6. habitual drinking or a history of drug abuse. }\end{array}$ \\
\hline
\end{tabular}

Interventions

$5 \mathrm{mg}$ /day of escitalopram, increased $5 \mathrm{mg}$ /day every two weeks, up to a maximum dosage of $15 \mathrm{mg} /$ day, which was maintained over 8 weeks, unless the participant experienced medication side effects

Outcomes

Assessments from the first 12 weeks were used to measure efficacy, whereas data from all 24 weeks were included in safety analysis. Efficacy analysis was done using both intention-to-treat (ITT) and perprotocol (PP) populations, which were specified before subject enrolment. Only the PP analysis reported.

Efficacy measures:

1. Cornell Scale for Depression in Dementia (CSDD) and GDS-15 every 4 weeks during the double blind phase;

2. based on CSDD scores, response was categorized into 'No response', 'Partial response' (score reduction $\geq 25 \%$ ), and 'Full response' (score reduction $\geq 50 \%$ );

3. K-MMSE, CDR, ADAS-Cog, and Seoul Instrumental Activities of Daily Living (SIADL), Neuropsychiatric Inventory Questionnaire (NPIQ) and Pittsburgh Sleep Quality Index (PSQI) at 12 weeks.

Notes

Due to the way adverse event data were reported, we were only able to include these data in one of our outcomes. We have requested the completers' data from the authors, but have not received a reply to date. 
An 2017 (Continued)

This study was sponsored by Konkuk University Medical Center and supported by Dong-a ST, a pharmaceutical manufacturer specializing in CNS drugs. One of the authors (Do-Hoon Kim) made a disclosure of receiving grants from various pharmaceutical companies and lecture fees from Rundbeck (sic). (NB, Lundbeck is the manufacturer of escitalopram.)

\section{Risk of bias}

\begin{tabular}{|c|c|c|}
\hline Bias & Authors' judgement & Support for judgement \\
\hline $\begin{array}{l}\text { Random sequence genera- } \\
\text { tion (selection bias) }\end{array}$ & Unclear risk & No detail provided \\
\hline $\begin{array}{l}\text { Allocation concealment } \\
\text { (selection bias) }\end{array}$ & Unclear risk & No specific detail provided \\
\hline $\begin{array}{l}\text { Blinding (performance } \\
\text { bias and detection bias) } \\
\text { All outcomes }\end{array}$ & Unclear risk & $\begin{array}{l}\text { The trial registration mentions double masking under design, including partic- } \\
\text { ipant and investigator, however, no details are provided about the placebo. }\end{array}$ \\
\hline $\begin{array}{l}\text { Incomplete outcome data } \\
\text { (attrition bias) } \\
\text { All outcomes }\end{array}$ & High risk & $\begin{array}{l}\text { Twenty-four patients were unable to finish the study (the authors refer to this } \\
\text { as } 30 \% \text {, our calculation is a little lower: } 24 / 84=28.6 \% \text { ), } 40 \% \text { more in the esci- } \\
\text { talopram than in the placebo group ( } 14 \text { vs } 10 \text { ), the difference being largely due } \\
\text { to more people withdrawing consent in the escitalopram group. }\end{array}$ \\
\hline $\begin{array}{l}\text { Selective reporting (re- } \\
\text { porting bias) }\end{array}$ & High risk & $\begin{array}{l}\text { Efficacy analysis was done using both intention-to-treat (ITT) and per-proto- } \\
\text { col (PP) populations, which were specified before subject enrolment. The pub- } \\
\text { lished report only included the results of the PP analysis, arguing that "treat- } \\
\text { ment response could be more reliably assessed and the population would be } \\
\text { less heterogeneous than the ITT population". Partial and full response were } \\
\text { not prespecified outcomes in the protocol available on Clinicaltrials.gov but } \\
\text { described in the data analysis section of the report (NB, these outcomes were } \\
\text { eventually not reported in the results section of the An } 2017 \text { paper). }\end{array}$ \\
\hline
\end{tabular}

Blinding of participants Unclear risk The trial registration mentions double masking under design, including particand personnel (perfor- ipant and investigator, however, no details are provided about the placebo. mance bias)

All outcomes

Blinding of outcome as- Unclear risk
sessment (detection bias)

All outcomes

The trial registration mentions double masking under design, including participant and investigator, however, no details are provided about the placebo.

Banerjee 2011

Methods Placebo-controlled, parallel group, double-blind, randomised, pragmatic trial

Follow-up at 13 and 39 weeks

Participants Country: United Kingdom, multi-centre (9 centres in England)

Setting: outpatients

Number: 326

Inclusion criteria: NINCDS/ADRDA criteria for probable and possible Alzheimer's disease and co-existing depression with CSDD score $>8$ (nearly all met criteria for categorical diagnosis of depression in Alzheimer's disease as per Olin's criteria (Olin 2002) 
Banerjee 2011 (Continued)

Exclusion criteria: clinically too critical for randomisation (e.g. suicide risk), absolute contraindication to trial medication, currently taking antidepressant, being in another trial, and having no family or professional carer to give collateral information

\begin{tabular}{ll}
\hline Interventions & 1. sertraline (target dose: $150 \mathrm{mg} /$ day) \\
2. mirtazapine (target dose: $45 \mathrm{mg} /$ day) \\
3. placebo \\
$(1: 1: 1$ allocation)
\end{tabular}

Outcomes

Co-primary outcomes:

1. Cornell Scale for Depression in Dementia (CSDD);

2. costs measured by the Clients Service Receipt Inventory (CSR at 13 weeks analysed according to an intention to treat (ITT) approach.

Secondary outcomes and moderators:

1. disease-specific health-related quality of life (DEMQOL and DEMQOL-Proxy);

2. generic quality of life (EQ-5D interview administered to the carer);

3. withdrawal from treatment;

4. cognitive impairment (MMSE);

5. medication adherence;

6. adverse events;

7. carer mental health (General Health Questionnaire; GHQ-12);

8. carer quality of life (SF-12v2);

9. carer burden (Zarit Scale);

10. behavioural disorder (Neuropsychiatric Inventory; NPI);

11.dementia vascularity index (modified Hachinksi Scale) at baseline.

The study was funded by the UK National Institute of Health Research Health Technology Assessment programme. Most authors acknowledged receiving consultancy fees, speakers' fees, research funding, or educational support to attend conferences from companies involved in the manufacture of antidepressants and anti-dementia drugs. Two had been employed by the UK Department of Health and one by the Alzheimer's Society.

\section{Risk of bias}

\begin{tabular}{|c|c|c|}
\hline Bias & Authors' judgement & Support for judgement \\
\hline $\begin{array}{l}\text { Random sequence genera- } \\
\text { tion (selection bias) }\end{array}$ & Low risk & $\begin{array}{l}\text { Allocation to sertraline, mirtazapine, or placebo in a 1:1:1 ratio by clinical tri- } \\
\text { als unit at King's College London. Random allocation stratified by centre with } \\
\text { computer-generated sequence with randomly varying block sizes of } 3 \text { or } 6 \text {. }\end{array}$ \\
\hline $\begin{array}{l}\text { Allocation concealment } \\
\text { (selection bias) }\end{array}$ & Low risk & $\begin{array}{l}\text { The Mental Health \& Neuroscience Clinical Trials Unit (CTU) database pro- } \\
\text { grammer independently undertook treatment allocation. Further description } \\
\text { of the allocation is not available. }\end{array}$ \\
\hline $\begin{array}{l}\text { Blinding (performance } \\
\text { bias and detection bias) } \\
\text { All outcomes }\end{array}$ & Unclear risk & $\begin{array}{l}\text { Participants aiming to take } 6 \text { tablets orally once a day (up to three sertraline } \\
50 \text { mg or sertraline placebo and up to three mirtazapine } 15 \text { mg or mirtazapine } \\
\text { placebo, with the placebo looking identical in appearance for each antidepres- } \\
\text { sant). The authors state that "referring clinicians and research workers com- } \\
\text { pleting baseline and follow-up assessments were kept blind to group alloca- } \\
\text { tion as were patients and pharmacies", but no checks as to whether patients }\end{array}$ \\
\hline
\end{tabular}


or assessors could guess allocation status are mentioned. Statisticians were blind to group identity until after the analyses were completed. The statistician performing the final analyses was not involved in the re-assessment of the sample size.

\section{Incomplete outcome data High risk} (attrition bias)

All outcomes
"Analyses were pragmatic and based on the intention-to-treat sample." Although, overall, adequate sample sizes were achieved in each group, by week $39,24 \%$ of those on placebo, $35 \%$ of those on sertraline, and $29 \%$ of those on mirtazapine were withdrawn from the trial. Those on sertraline had a clearly higher attrition rate. For 2 patients in each group incomplete data were collected.

\begin{tabular}{|c|c|c|}
\hline $\begin{array}{l}\text { Selective reporting (re- } \\
\text { porting bias) }\end{array}$ & Unclear risk & $\begin{array}{l}\text { Drug adherence which was a prespecified secondary outcome measure was } \\
\text { not reported. }\end{array}$ \\
\hline $\begin{array}{l}\text { Blinding of participants } \\
\text { and personnel (perfor- } \\
\text { mance bias) } \\
\text { All outcomes }\end{array}$ & Unclear risk & $\begin{array}{l}\text { Participants aiming to take } 6 \text { tablets orally once a day (up to three sertraline } \\
50 \text { mg or sertraline placebo and up to three mirtazapine } 15 \mathrm{mg} \text { or mirtazapine } \\
\text { placebo, with the placebo looking identical in appearance for each antidepres- } \\
\text { sant). The authors state that "referring clinicians and research workers com- } \\
\text { pleting baseline and follow-up assessments were kept blind to group alloca- } \\
\text { tion as were patients and pharmacies", but no checks as to whether patients } \\
\text { or assessors could guess allocation status are mentioned. }\end{array}$ \\
\hline $\begin{array}{l}\text { Blinding of outcome as- } \\
\text { sessment (detection bias) } \\
\text { All outcomes }\end{array}$ & Unclear risk & $\begin{array}{l}\text { The authors state that "referring clinicians and research workers completing } \\
\text { baseline and follow-up assessments were kept blind to group allocation as } \\
\text { were patients and pharmacies", but no checks as to whether patients or as- } \\
\text { sessors could guess allocation status are mentioned. Statisticians were blind } \\
\text { to group identity until after the analyses were completed. The statistician per- } \\
\text { forming the final analyses was not involved in the re-assessment of the sample } \\
\text { size. }\end{array}$ \\
\hline
\end{tabular}

de Vasconcelos 2007

\begin{tabular}{ll}
\hline Methods & Placebo-controlled, double-blind, randomised, flexible dose \\
\hline Participants & Country: Brazil \\
Setting: outpatients & Recruitment: unclear \\
& Number: 31 patients with dementia and depression (41 approached, 10 excluded due to clinical co- \\
morbidities or insufficient caregiver support) & $\begin{array}{l}\text { Inclusion criteria: DSM-IV for dementia and depression, MMSE, Cornell Scale for Depression in Demen- } \\
\text { tia } \\
\text { Exclusion criteria: severe dementia (MMSE <= 10), suicidal, illusional, delirious, no caregiver to assure } \\
\text { compliance, unstable medical condition during screening, psychiatric condition other than dementia } \\
\text { and depression }\end{array}$ \\
$\begin{array}{l}\text { 1. venlafaxine (range: } 37.5-131.25 \text { mg/day; mean: } 75 \text { mg/day) } \\
\text { 2. placebo }\end{array}$ \\
$\begin{array}{l}\text { 1. Response rate (remission defined as at least 50\% reduction in MADRS score) } \\
\text { 2. Montgomery-Asberg Depression Rating Scale (MADRS) } \\
\text { 3. Clinical Global Impressions }\end{array}$ \\
\hline Outcomes
\end{tabular}


de Vasconcelos 2007 (Continued)

4. Analysed at week 1 and week 6 according to "last observation carried forward (LOCF)" and "per protocol" approach; ANCOVA with baseline score as a covariate

5. Safety and tolerability assessed as per adverse events and dropouts

Notes

AChEls (acetylcholinesterase inhibitors, the most commonly used group of dementia medications) were not permitted.

Funding was not specifically mentioned.

\section{Risk of bias}

\begin{tabular}{lll}
\hline Bias & Authors' judgement & Support for judgement \\
\hline $\begin{array}{l}\text { Random sequence genera- } \\
\text { tion (selection bias) }\end{array}$ & Unclear risk & No information is given on how randomisation was carried out. \\
\hline $\begin{array}{l}\text { Allocation concealment } \\
\text { (selection bias) }\end{array}$ & Unclear risk & Not enough detail is given on allocation concealment. \\
\hline $\begin{array}{l}\text { Blinding (performance } \\
\text { bias and detection bias) } \\
\text { All outcomes }\end{array}$ & Unclear risk & $\begin{array}{l}\text { The authors do not provide details on double blinding (e.g. assessor status } \\
\text { was not given), although they say that the venlafaxine and the placebo tablets } \\
\text { were identical in appearance and patients received a fixed number of tablets. }\end{array}$
\end{tabular}

\begin{tabular}{|c|c|c|}
\hline $\begin{array}{l}\text { Incomplete outcome data } \\
\text { (attrition bias) } \\
\text { All outcomes }\end{array}$ & High risk & $\begin{array}{l}41 \text { patients were approached; } 10 \text { were not included due to "clinical co-mor- } \\
\text { bidities and insufficient carer support". Out of the } 31 \text { patients enrolled, there } \\
\text { were } 9 \text { dropouts (lost to follow-up: } 1 \text { and } 1 \text {, withdrawals: } 2 \text { and } 0 \text {, and adverse } \\
\text { events: } 3 \text { and } 2 \text { in the venlafaxine and placebo groups, respectively. Both "in- } \\
\text { tention-to-treat last-observation-carried-forward" ( } \mathrm{N}=31 \text { ) and "per proto- } \\
\text { col" }(\mathrm{N}=23) \text { approaches are reported. }\end{array}$ \\
\hline
\end{tabular}

\begin{tabular}{|c|c|c|}
\hline $\begin{array}{l}\text { Selective reporting (re- } \\
\text { porting bias) }\end{array}$ & Unclear risk & $\begin{array}{l}\text { The figures in the table do not match the data in the text in the reporting on } \\
\text { causes of dropouts and adverse events. }\end{array}$ \\
\hline
\end{tabular}

\begin{tabular}{|c|c|c|}
\hline $\begin{array}{l}\text { Blinding of participants } \\
\text { and personnel (perfor- } \\
\text { mance bias) } \\
\text { All outcomes }\end{array}$ & Unclear risk & $\begin{array}{l}\text { The authors do not provide details on double blinding (e.g. assessor status } \\
\text { was not given), although they say that the venlafaxine and the placebo tablets } \\
\text { were identical in appearance and patients received a fixed number of tablets. }\end{array}$ \\
\hline
\end{tabular}

\begin{tabular}{|c|c|c|}
\hline $\begin{array}{l}\text { Blinding of outcome as- } \\
\text { sessment (detection bias) }\end{array}$ & Unclear risk & $\begin{array}{l}\text { The authors do not provide details on double blinding (e.g. assessor status } \\
\text { was not given). }\end{array}$ \\
\hline
\end{tabular}

\section{Fuchs 1993}

\begin{tabular}{|c|c|}
\hline Methods & $\begin{array}{l}\text { Randomised ("randomly assigned", no further details), double-blind, placebo controlled, parallel } \\
\text { group, } 8 \text { weeks duration }\end{array}$ \\
\hline \multirow[t]{5}{*}{ Participants } & Country: Austria \\
\hline & Setting: 5 centres, inpatients (geriatric wards) and nursing home \\
\hline & Number: 127 (72 female (57\%) and 55 male (43\%)) \\
\hline & $\begin{array}{l}\text { Inclusion criteria: DSM-III-R for primary degenerative dementia and depression, onset at age }>65 \text { years, } \\
\text { any severity }\end{array}$ \\
\hline & Exclusion criteria: need for antidepressant therapy \\
\hline
\end{tabular}


Fuchs 1993 (Continued)

\section{Placebo}

$\begin{array}{ll}\text { Outcomes } & \text { Geriatric Depression Scale (GDS) } \\ & \text { MMSE } \\ \text { global impression by video rating (primary parameter) }\end{array}$

Notes Problems

1. No information on the numbers of participants in the antidepressant and placebo groups included in the analyses of the MMSE and GDS scores (MMSE: 50 patients scored greater than 24 on baseline therefore not demented according to baseline or there were no MMSE data available, therefore these 50 were not analysed for the MMSE. GDS: 36 patients with either a baseline of less than 5 or without any GDS data were not included in the GDS analysis.)

2. 6 protocol violators under the age of 65 included in the analysis.

3. Patients "in need of antidepressant therapy" were excluded (therefore the group were mildly depressed).

A. Fuchs' affiliation was Ciba-Geigy AG, Basel, Switzerland. The authors acknowledge assistance from workers of Ciba-Geigy during all stages of the study.

\section{Risk of bias}

\begin{tabular}{lll}
\hline Bias & Authors' judgement & Support for judgement \\
\hline $\begin{array}{l}\text { Random sequence genera- } \\
\text { tion (selection bias) }\end{array}$ & Unclear risk & Not reported \\
\hline $\begin{array}{l}\text { Allocation concealment } \\
\text { (selection bias) }\end{array}$ & Unclear risk & Not reported \\
\hline $\begin{array}{l}\text { Blinding (performance } \\
\text { bias and detection bias) } \\
\text { All outcomes }\end{array}$ & Unclear risk & $\begin{array}{l}\text { Referring to the video ratings, the authors state "any content which could pos- } \\
\text { sibly destroy the blindness of the raters with regard to the date of recording } \\
\text { were cut out by an independent technician", however, no mention is made } \\
\text { about who assessed and recorded the adverse events (only this data was used } \\
\text { from this study in this review). }\end{array}$ \\
\hline
\end{tabular}

$\begin{array}{ll}\begin{array}{l}\text { Incomplete outcome data Low risk } \\ \text { (attrition bias) }\end{array} & \begin{array}{l}33 \text { patients discontinued the study before completing } 8 \text { weeks of treatment } \\ \text { (lack of tolerability: } 1 \text { and } 1 \text {, lack of compliance: } 2 \text { and } 1 \text {, other reasons [inter- } \\ \text { All outcomes } \\ \text { current disease, transfer to other hospital, return home, etc] } 16 \text { and } 12 \text { in the } \\ \text { maprotiline and placebo groups, respectively). Attrition in the maprotiline and } \\ \text { placebo groups was comparable and acceptable. }\end{array}\end{array}$

$\begin{array}{lll}\begin{array}{l}\text { Selective reporting (re- } \\ \text { porting bias) }\end{array} & \text { High risk } & \begin{array}{l}50 \text { patients had an MMSE score greater than } 24 \text { or missing data and therefore } \\ \text { were not analysed for their MMSE scores. } 36 \text { patients had a baseline of less } \\ \text { than } 5 \text { points on the GDS or missing GDS data and therefore were not analysed } \\ \text { for GDS scores. Although the authors present MMSE and GDS means for the } \\ \text { maprotiline and placebo groups, it was not possible to know how many pa- } \\ \text { tients there were in each group. Therefore, only adverse events data could be } \\ \text { included from this study into our review. This however included all partici- } \\ \text { pants, including those who had higher than the cut-off on the MMSE or lower } \\ \text { than the cut-off on the GDS. }\end{array} \\ & \begin{array}{l}\text { Referring to the video ratings, the authors state "any content which could pos- } \\ \text { sibly destroy the blindness of the raters with regard to the date of recording } \\ \text { were cut out by an independent technician", however, no mention is made } \\ \text { about who assessed and recorded the adverse events (only this data was used } \\ \text { and personnel (perfor- } \\ \text { mance bias) } \\ \text { All outcomes }\end{array} & \text { Unclear risk study in this review). } \\ \end{array}$


Fuchs 1993 (Continued)

Blinding of outcome as- Unclear risk Referring to the video ratings, the authors state "any content which could possessment (detection bias) sibly destroy the blindness of the raters with regard to the date of recording were cut out by an independent technician", however, no mention is made about who assessed and recorded the adverse events (only this data was used All outcomes from this study in this review).

\section{Lyketsos 2003}

Methods Randomised, placebo-controlled, parallel, 12-week, flexible clinical trial after a 1-week, single-blind
placebo phase.

Country: USA
Setting: 44 outpatients
Inclusion criteria: NINCDS-ADRDA for probable Alzheimer's disease, and DSM-IV for major depressive
episode, MMSE $=>10$
Exclusion criteria: unstable medical condition, lifetime diagnosis of schizophrenia, bipolar, pre-AD anx-
iety disorder, current substance misuse, acutely suicidal or requiring hospital admission

\begin{tabular}{ll}
\hline Interventions & 1. Sertraline $(25 \mathrm{mg}$ titrated to $150 \mathrm{mg} /$ day, mean peak doses $113 \mathrm{mg})$ \\
2. Placebo
\end{tabular}

The principal outcome measure was response to treatment.
Cornell Scale for Depression in Dementia (CSDD)
Hamilton Depression Rating Scale
Activities of daily living subscale of the Psychogeriatric Dependency Rating Scales
The Neuropsychiatric Inventory (NPI)
MMSE

Notes

Good, well-designed study. Attempted to address the diagnostic difficulties, e.g. possible overlap of symptoms of Alzheimer's disease and major depression, if DSM-IV criterion 2 were to count toward the diagnosis of depression of major depressive episode it had to be clearly because of loss of pleasure (anhedonia) and not entirely because of loss of interest. Similarly, DSM criterion 8 had to be attributed to indecisiveness and not entirely due to difficulty concentrating.

Supported by NIMH, Bethesda, Md. grant 1R01-MH56511. Dr Lyketsos has been or is a consultant and advisor for and has received or receives research support from several companies, as declared in the paper.

\begin{tabular}{lll}
\hline Risk of bias & & \\
\hline Bias & Authors' judgement & Support for judgement \\
\hline $\begin{array}{l}\text { Random sequence genera- } \\
\text { tion (selection bias) }\end{array}$ & Low risk & $\begin{array}{l}\text { "patients were assigned randomly using a random numbers generating com- } \\
\text { puter program, in blocks of 6, without stratification, to sertraline or to place- } \\
\text { bo" }\end{array}$ \\
\hline $\begin{array}{l}\text { Allocation concealment } \\
\text { (selection bias) }\end{array}$ & Low risk & $\begin{array}{l}\text { The research pharmacist implemented random allocation and masked treat- } \\
\text { ment assignment was communicated by telephone to study staff. }\end{array}$ \\
\hline $\begin{array}{l}\text { Blinding (performance } \\
\text { bias and detection bias) } \\
\text { All outcomes }\end{array}$ & Unclear risk & $\begin{array}{l}\text { "Identical appearing pills." Response to treatment was rated by } 2 \text { study psychi- } \\
\text { atrists (PVR or MS), who reviewed patients' scores on baseline and follow-up } \\
\text { depression rating scales after the study was completed. } \text { Rated each patient on } \\
\text { 3-point global scale as a non-responder, partial responder or full responder. } \\
\text { These psychiatrists were blind to medication or placebo and did not personal- }\end{array}$ \\
\hline
\end{tabular}


Lyketsos 2003 (Continued)

ly manage any patient in the study. No algorithm was used, instead they used their best clinical judgement. If there were any disagreements, the 2 raters met to provide a mutually agreeable rating.

$\begin{array}{ll}\begin{array}{l}\text { Incomplete outcome data } \\ \text { (attrition bias) }\end{array} & \begin{array}{l}50 \text { patients signed consent, } 3 \text { did not meet criteria, therefore } 47 \text { entered the } \\ \text { All outcomes }\end{array} \\ & \begin{array}{l}\text { wash-in phase. } 3 \text { patients withdrew prior to randomisation ( } 1 \text { hospitalised for } \\ \text { diac arrest). } 24 \text { patients were randomised to receive sertraline and } 20 \text { placebo. }\end{array} \\ & 3 \text { patients withdrew before completion in the sertraline arm (adverse events: } \\ 1, \text { lack of efficacy: } 2 \text { ) and } 5 \text { in the placebo arm (death: } 1, \text { lack of efficacy: } 3, \\ \text { withdrawal of consent: } 1 \text { ). These attrition figures are acceptable. }\end{array}$

\begin{tabular}{|c|c|c|}
\hline $\begin{array}{l}\text { Selective reporting (re- } \\
\text { porting bias) }\end{array}$ & Low risk & $\begin{array}{l}\text { The prespecified outcome measures were all reported. However, the adverse } \\
\text { event data could not be included in our review, because they were presented } \\
\text { for every 3-week period and the numbers could not be combined. }\end{array}$ \\
\hline $\begin{array}{l}\text { Blinding of participants } \\
\text { and personnel (perfor- } \\
\text { mance bias) } \\
\text { All outcomes }\end{array}$ & Unclear risk & "Identical appearing pills." \\
\hline $\begin{array}{l}\text { Blinding of outcome as- } \\
\text { sessment (detection bias) } \\
\text { All outcomes }\end{array}$ & Unclear risk & $\begin{array}{l}\text { Response to treatment was rated by } 2 \text { study psychiatrists (PVR or MS), who re- } \\
\text { viewed patients' scores on baseline and follow-up depression rating scales af- } \\
\text { ter the study was completed. Rated each patient on 3-point global scale as a } \\
\text { non-responder, partial responder or full responder. These psychiatrists were } \\
\text { blind to medication or placebo and did not personally manage any patient in } \\
\text { the study. No algorithm was used, instead they used their best clinical judge- } \\
\text { ment. If there were any disagreements, the } 2 \text { raters met to provide a mutually } \\
\text { agreeable rating. }\end{array}$ \\
\hline
\end{tabular}

\section{Petracca 1996}

$\begin{array}{ll}\text { Methods } & \text { Randomised ("patients were first randomized to receive } 6 \text { weeks of clomipramine or an identical } \\ \text { placebo. After a } 2 \text { week washout period, they received the complementary treatment (placebo or } \\ \text { clomipramine)"), double-blind, placebo controlled, cross-over design: } 6 \text { weeks + } 2 \text { weeks washout + } 6 \\ \text { weeks }\end{array}$

\begin{tabular}{ll}
\hline Participants & Country: Argentina \\
Setting: Neurology outpatient clinic \\
Recruitment: "consecutive series of patients attending the Neuro \\
sive cognitive decline" \\
Number: $24(91 \%$ female) \\
Mean age: $72(7.3)$ \\
Mean MMSE: 21.5 \\
Inclusion criteria: NINCDS-ADRDA for probable dementia, DSM-III-R \\
Hamilton Depression Rating Scale $>10$, Hachinski Ischaemic score \\
Exclusion criteria: MMSE < 10, psychotropic or cognition enhancing \\
herence \\
1. Clomipramine (titrated from 25 mg to 100 mg/day by 4 weeks) \\
2. Placebo \\
Interventions \\
Ham-D \\
MMSE \\
Functional Independence Measure (FIM) score
\end{tabular}


Petracca 1996 (Continued)

The following data were received following correspondence with authors.

Ham-D

1. Treatment $(n=11)$

2. Placebo $(n=10)$

3. Ham-D favours active drug

FIM

1. Treatment, mean change $+0.27, \mathrm{SD} 4.08$;

2. Placebo, mean change -0.81, SD 11.58

3. '3-way ANOVA for FIM scores (activities of daily living) revealed no significant main effects or interactions), $\mathrm{P}=.273$

MMSE

1. Treatment, mean change $+0.36, \mathrm{SD} 7.16$

2. Placebo, mean change $-0.30, S D 12.00$

Significant improvement on depression scores, no difference in MMSE scores

Notes Statistical elaboration was received from the authors.

Partially supported from the Raul Carrea Institute of Neurological research, a fellowship to G.P. from Qualitas Medicina, and a grant from Fundacion Perez Companc, as declared in the paper.

\section{Risk of bias}

\begin{tabular}{lll}
\hline Bias & Authors' judgement & Support for judgement \\
\hline $\begin{array}{l}\text { Random sequence genera- } \\
\text { tion (selection bias) }\end{array}$ & Unclear risk & $\begin{array}{l}\text { Consecutive series of patients presenting with cognitive decline meet- } \\
\text { ing inclusion and exclusion criteria were "randomized to either } 6 \text { weeks of } \\
\text { clomipramine, followed by a 2-week washout period and 6-weeks of placebo, } \\
\text { or } 6 \text { weeks of placebo, followed by a 2-week washout period and } 6 \text { weeks of } \\
\text { clomipramine". No information was given on how the randomisation was car- } \\
\text { ried out. }\end{array}$
\end{tabular}

\begin{tabular}{l}
\hline $\begin{array}{l}\text { Allocation concealment } \\
\text { (selection bias) }\end{array}$ \\
\hline
\end{tabular}

\begin{tabular}{|c|c|c|}
\hline $\begin{array}{l}\text { Blinding (performance } \\
\text { bias and detection bias) } \\
\text { All outcomes }\end{array}$ & Low risk & $\begin{array}{l}\text { Diagnostic assessments were made by a psychiatrist blind to the remaining } \\
\text { clinical data. "Clomipramine or placebo was given in a single daily bedtime } \\
\text { dose. The tablets containing } 25 \text { mg of clomipramine or placebo were iden- } \\
\text { tical in appearance, and patients received a fixed number of tablets (active } \\
\text { drug or placebo)." "The presence of adverse effects was determined by using } \\
\text { a structured questionnaire, and pills were counted to monitor compliance." } \\
\text { "To permit assessment of the integrity of the double blind, the (blind) examin- } \\
\text { er judged whether the patient was on active drug or placebo at the time of the } \\
\text { final evaluation of each treatment arm. Examiners did not appear to be able } \\
\text { correctly to guess allocation status. "Serum clomipramine was measured [...] } \\
\text { and results were not released to clinicians until the study was over." }\end{array}$ \\
\hline
\end{tabular}

\section{Incomplete outcome data Low risk} (attrition bias)

All outcomes

\begin{abstract}
"Patients in whom severe side effects (such as delirium) developed were dropped from the study and their treatment codes were broken. Data for these patients were not included in the statistical analysis. [...] Twenty-one out of 24 patients (88\%) who were randomised to enter the study completed the drug trial. One patient who was on placebo became suicidal and had to be put on active drug. Another patient, who was also on placebo, left the study after 4 weeks of treatment. The third patient who did not complete the study devel-
\end{abstract}


Petracca 1996 (Continued)

oped an acute confusional syndrome while he was on clomipramine (100 mg/ day) and had to be removed from the study."

\begin{tabular}{ll}
\hline $\begin{array}{l}\text { Selective reporting (re- } \\
\text { porting bias) }\end{array}$ & Low risk \\
& $\begin{array}{l}\text { Results for all outcome measures have been provided on contacting the au- } \\
\text { thors. }\end{array}$
\end{tabular}

Blinding of participants Unclear risk
and personnel (perforDiagnostic assessments were made by a psychiatrist blind to the remaining mance bias)

All outcomes clinical data. "Clomipramine or placebo was given in a single daily bedtime dose. The tablets containing $25 \mathrm{mg}$ of clomipramine or placebo were identical in appearance, and patients received a fixed number of tablets (active drug or placebo)." "The presence of adverse effects was determined by using a structured questionnaire, and pills were counted to monitor compliance." "Serum clomipramine was measured [...] and results were not released to clinicians until the study was over."

$\begin{array}{ll}\begin{array}{l}\text { Blinding of outcome as- } \\ \text { sessment (detection bias) }\end{array} & \text { Low risk } \\ \begin{array}{ll}\text { All outcomes } & \text { "The presence of adverse effects was determined by using a structured ques- } \\ \text { tionnaire, and pills were counted to monitor compliance." "To permit assess- } & \text { ment of the integrity of the double blind, the (blind) examiner judged whether } \\ \text { the patient was on active drug or placebo at the time of the final evaluation of } \\ \text { each treatment arm. Examiners did not appear to be able correctly to guess al- } \\ \text { location status. "Serum clomipramine was measured [...] and results were not } \\ \text { released to clinicians until the study was over." }\end{array}\end{array}$

\section{Petracca 2001}

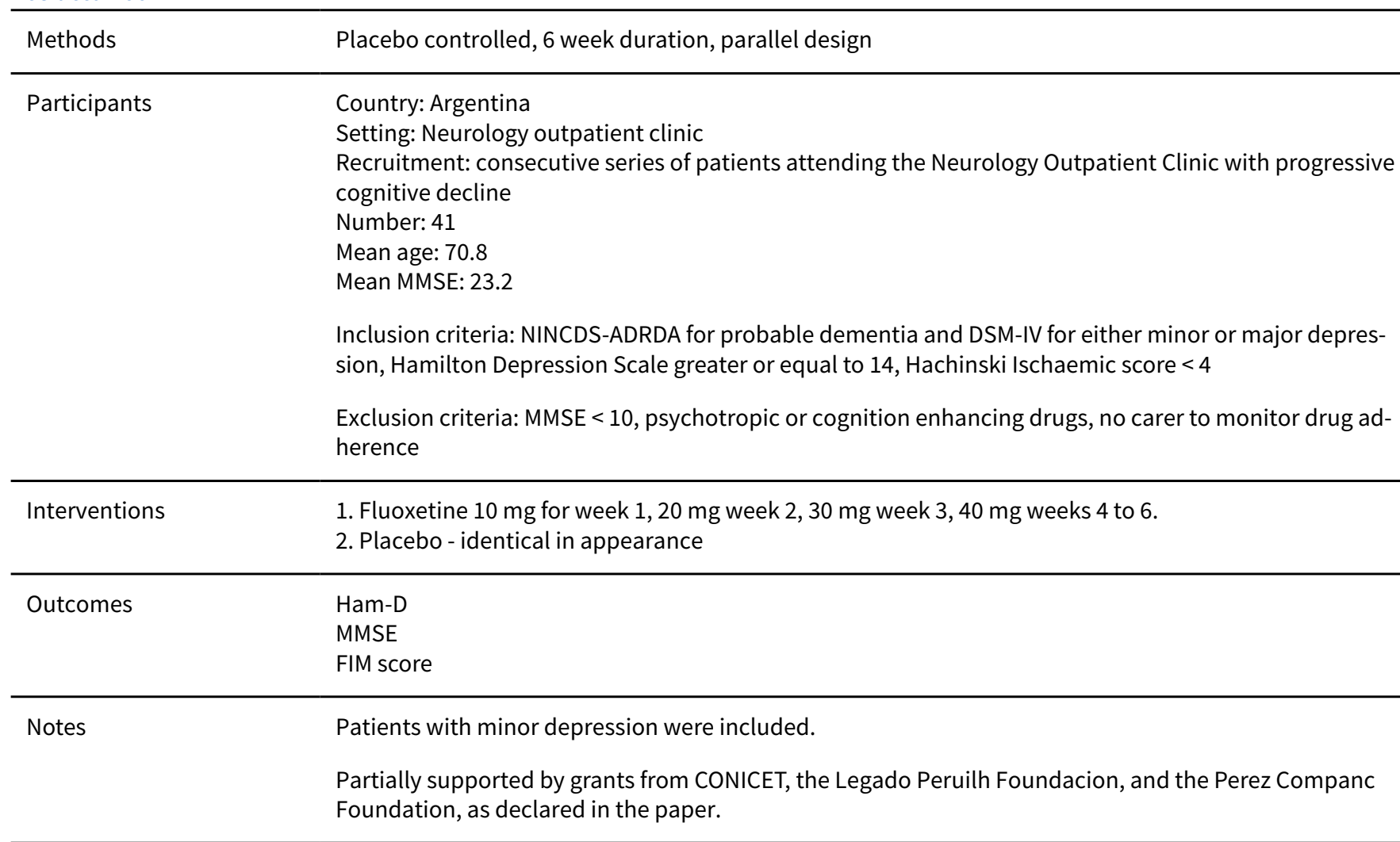

\section{Risk of bias}

Bias Authors' judgement Support for judgement


Petracca 2001 (Continued)

Random sequence genera- Unclear risk tion (selection bias)
Consecutive series of outpatients attending a dementia clinic meeting inclusion and exclusion criteria were randomised to receive either 6 weeks of fluoxetine or placebo. No information was given on how the randomisation was carried out.

Allocation concealment $\quad$ Unclear risk $\quad$ Description of this was not included.
(selection bias)

Incomplete outcome data Low risk

(attrition bias)

"Six subjects (four on placebo and two on fluoxetine) withdrew from the study All outcomes before completion, all of them within the first 2 weeks of the trial. One of the two subjects on fluoxetine developed a mild confusional state, whereas the remaining subject declined further participation due to lack of improvement or interest in the study. One subject on placebo withdrew from the study due to gastrointestinal side effects, whereas the remaining three subjects decline participation due to lack of improvement or difficulty getting to the center for repeated evaluations. There were no significant differences in background variables between subjects on fluoxetine $(n=15)$ or placebo $(n=20)$ who completed the drug trial." The attrition (6/41) was $14.6 \%$, which is relatively high, however, the number of completers $(n=35)$ was sufficient to provide the prespecified $80 \%$ power to detect between group differences in the HAM-D scores.

\begin{tabular}{ll}
\hline $\begin{array}{l}\text { Selective reporting (re- } \\
\text { porting bias) }\end{array}$ & Low risk
\end{tabular}

porting bias)

\begin{tabular}{|c|c|c|}
\hline $\begin{array}{l}\text { Blinding of participants } \\
\text { and personnel (perfor- } \\
\text { mance bias) } \\
\text { All outcomes }\end{array}$ & Unclear risk & $\begin{array}{l}\text { "The capsules containing } 20 \mathrm{mg} \text { of fluoxetine and those containing placebo } \\
\text { were identical in appearance, and patients received a fixed number of cap- } \\
\text { sules (active drug or placebo)." "The presence of adverse effects was deter- } \\
\text { mined by using a structured questionnaire. Pills were counted to monitor } \\
\text { compliance." No further description of how blinding was checked was provid } \\
\text { ed. }\end{array}$ \\
\hline
\end{tabular}

Blinding of outcome as- Unclear risk No description of how blinding was checked was provided.

sessment (detection bias)

All outcomes

\section{Reifler 1989}

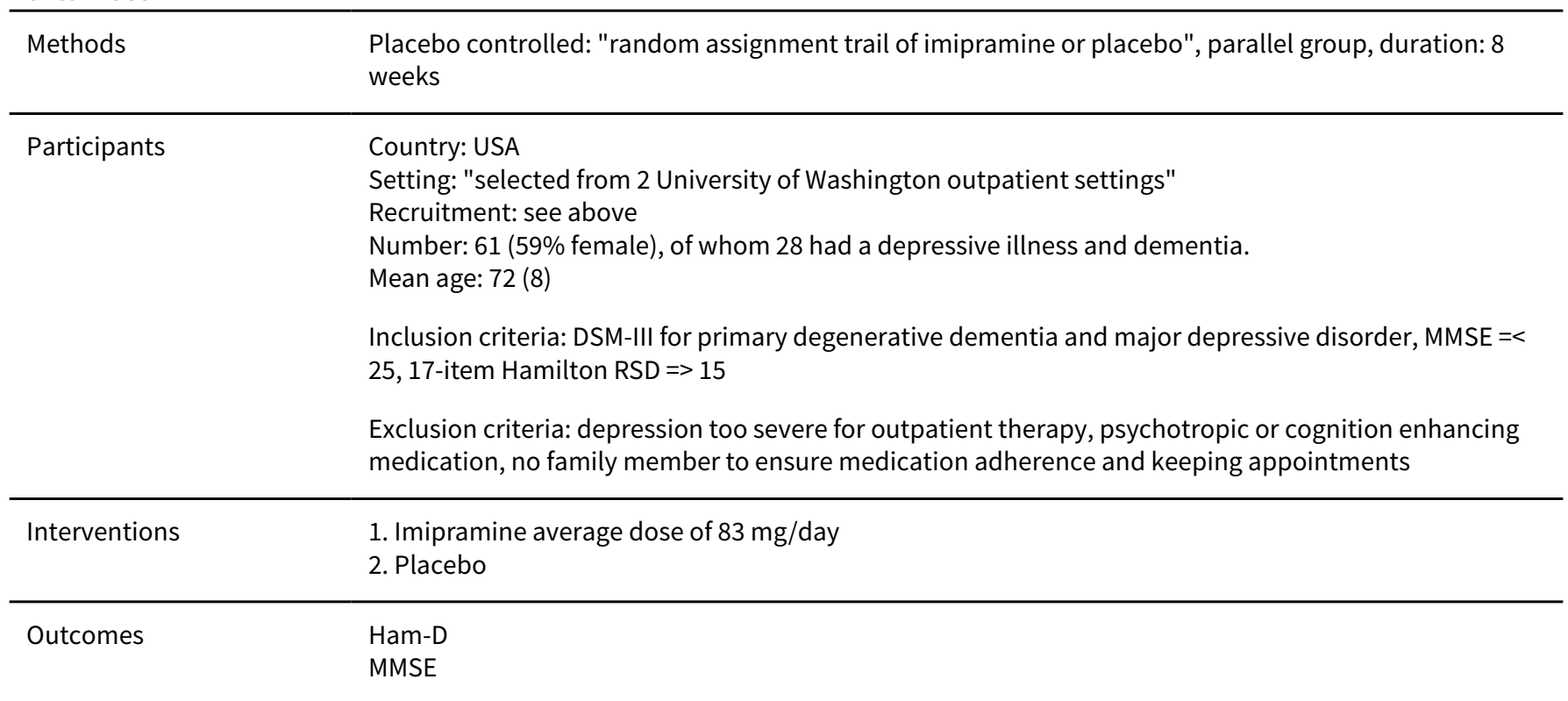


Reifler 1989 (Continued)

OARS ADL

Notes Supported by NIMH grant MH-36596. Ciba-Geigy provided the imipramine and placebo used in the study, as declared in the paper.

\section{Risk of bias}

\begin{tabular}{|c|c|c|}
\hline Bias & Authors' judgement & Support for judgement \\
\hline $\begin{array}{l}\text { Random sequence genera- } \\
\text { tion (selection bias) }\end{array}$ & Unclear risk & No information provided \\
\hline $\begin{array}{l}\text { Allocation concealment } \\
\text { (selection bias) }\end{array}$ & Unclear risk & No information provided \\
\hline $\begin{array}{l}\text { Blinding (performance } \\
\text { bias and detection bias) } \\
\text { All outcomes }\end{array}$ & Unclear risk & $\begin{array}{l}\text { The authors state that the imipramine and placebo tablets were "identical } \\
\text { in appearance" and "all parties were blind to the nature of the medication } \\
\text { throughout the study", but they do not report any methods to check on the lat- } \\
\text { ter. }\end{array}$ \\
\hline $\begin{array}{l}\text { Incomplete outcome data } \\
\text { (attrition bias) } \\
\text { All outcomes }\end{array}$ & Low risk & $\begin{array}{l}\text { "Of the } 61 \text { subjects with Alzheimer's disease who completed the study, } 57 \\
\text { completed the full } 8 \text { weeks and four completed the minimum of } 6 \text { weeks } \\
\text { required for inclusion in the data analysis (one each from the depressed } \\
\text { imipramine and depressed placebo groups and two from the nondepressed } \\
\text { imipramine group). Subjects who left the study before week } 6(\mathrm{~N}=8 \text { ) were } \\
\text { considered dropouts. Three dropouts were depressed subjects receiving } \\
\text { imipramine: two were hospitalized (one for congestive heart failure and one } \\
\text { for esophageal problems) and one dropped out because of transportation } \\
\text { problems. Two depressed subjects receiving placebo dropped out: one had in- } \\
\text { creasing anxiety and feelings of panic and the other had a change in his ECG. } \\
\text { Two dropouts were from the nondepressed imipramine group, one because of } \\
\text { dehydration and one because of flu; the sole nondepressed dropout receiving } \\
\text { placebo lost interest and decided not to return." The dropout rate is slightly } \\
\text { high at } 11.6 \%, \text { but appears symmetrical between the active drug and placebo } \\
\text { arms. }\end{array}$ \\
\hline
\end{tabular}

Selective reporting (re- Unclear risk porting bias)
Results with the prespecified outcome measures are only reported for completers. The authors say "There were no significant differences in side effects between completed subjects in the imipramine and placebo groups. Side effects when present were usually drowsiness or dizziness", but no detailed information is provided.

\begin{tabular}{|c|c|c|}
\hline $\begin{array}{l}\text { Blinding of participants } \\
\text { and personnel (perfor- } \\
\text { mance bias) } \\
\text { All outcomes }\end{array}$ & Unclear risk & $\begin{array}{l}\text { The authors state that the imipramine and placebo tablets were "identical } \\
\text { in appearance" and "all parties were blind to the nature of the medication } \\
\text { throughout the study", but they do not report any methods to check on this. }\end{array}$ \\
\hline $\begin{array}{l}\text { Blinding of outcome as- } \\
\text { sessment (detection bias) } \\
\text { All outcomes }\end{array}$ & Unclear risk & $\begin{array}{l}\text { No description of how blinding of outcome assessors was checked was provid- } \\
\text { ed. }\end{array}$ \\
\hline
\end{tabular}

Rosenberg 2010

\begin{tabular}{ll}
\hline Methods $\quad$ Randomised, double-blind, placebo-controlled, parallel assignment, efficacy and tolerability study \\
\hline
\end{tabular}

Participants

Country: USA 
Number: 131 (54.2\% female), median age of 79 years.

Inclusion criteria: ability of the participant, caregiver or surrogate to provide written informed consent, DSM-IV dementia due to Alzheimer's disease (MMSE = 10-26), stable treatment for Alzheimer's disease, meeting criteria for depression in Alzheimer's disease (dAD: compared with the DSM-IV major depressive disorder requires three [as opposed to five] or more symptoms within a 2-week period, one of which must be depressed mood or anhedonia, with irritability as a possible symptom), ability for the participant's caregiver to accompany the participant to study visits and participate in the study

Exclusion criteria: presence of a brain disease that might otherwise explain the presence of dementia, clinically significant hallucinations or delusions, current treatment of antipsychotics, anticonvulsants, and other antidepressants, benzodiazepines, or other psychotropic medications, need for hospitalisation or residence in a nursing facility

\begin{tabular}{ll}
\hline Interventions & 1. sertraline (range 25-125 mg per day) \\
2. placebo \\
12-week efficacy trial \\
\hline Primary: Modified Alzheimer's Disease Cooperative Study Clinical Global Impression of Change (mAD- \\
CS-CGIC; modified for clinician to rate mood change only). \\
Secondary: \\
$\begin{array}{l}\text { 1. Cornell Scale for Depression in Dementia (CSDD); } \\
\text { 2. remission defined as having a CSDD } \leq 6 \text { and mADCS-CGIC } \leq 2 .\end{array}$
\end{tabular}

Notes

Depression of Alzheimer's Disease - 2 (DIADS-2) Study

Intention to treat analysis with the imputation of data (missing data estimation) based on baseline characteristics and follow-up data.

Approximately $40 \%$ met criteria for major depressive episode.

Participants were ineligible if they were taking antipsychotics, benzodiazepines, or anticonvulsants (unless for the treatment of preexisting seizure disorder), which may have selected out some of the more severely ill patients.

Treatment adherence assessed by pill counts from returned medication bottles. Significantly more participants took their medications as prescribed in the placebo than in the sertraline-treated group (90.1\% vs $83.1 \% ; P=0.03)$.

The study was supported by NIHR grants. National Institute of Mental Health scientific collaborators participated on the trial's Steering Committee. Sertraline and matching placebo were provided by Pfizer, Inc., which did not otherwise participate in the design or conduct of the trial. Nine authors acknowledged receiving research, consultancy and other support from pharmaceutical companies.

\section{Risk of bias}

Bias Authors' judgement Support for judgement

Random sequence genera- Unclear risk tion (selection bias)

"Participants were recruited from memory clinics at five academic centers in the United States." "Participants were randomized by the study's Coordinating Center [...], in a 1:1 ratio to receive sertraline or placebo [...]." No further information is provided about the generation of the random sequence.

Allocation concealment Unclear risk
(selection bias)
lations that could affect the distribution of the outcomes, the randomization schedule was stratified by clinical site and it was designed with blocks of per- 

cealed.

Blinding (performance High risk
bias and detection bias)

"Participants began treatment with 50-mg sertraline or identically appearing All outcomes placebo tablets". However, study clinicians guessed treatment assignment correctly above chance rate in sertraline but not in placebo group at week 12 . "A symptom checklist was derived from the Food and Drug Administration approved prescribing information for sertraline (listed in Table 4). Starting at baseline and at all follow-up visits, participants and their caregivers were asked about whether any of these symptoms, or other self-reported AEs, occurred [...]."

Incomplete outcome data Low risk
(attrition bias)

"The planned sample size of 130 was based on $80 \%$ power, 0.05 significance (attrition bias) level, and $20 \%$ attrition, to detect a difference between the two treatment groups in the distribution of the seven categories of the mADCS-CGIC. [...] Seven participants (5\%) were lost to follow-up during the first 12 weeks of the study (three sertraline treated and four placebo treated). An additional two participants in the sertraline group and three participants in the placebo group missed their Week 12 study visit. The proportion of patients discontinuing study medications before Week 12 did not differ significantly between treatment groups (Fisher's exact test, P 0.64); 12 (18\%) participants in the sertraline-treated group and 9 (14\%) in the placebo-treated group discontinued study medications before Week 12." Although the attrition was relatively high, it was symmetrically so between the two groups.

$\begin{array}{ll}\begin{array}{l}\text { Selective reporting (re- } \\ \begin{array}{l}\text { porting bias) } \\ \text { Unclear risk }\end{array}\end{array} & \begin{array}{l}\text { The authors reported results with all pre-specified outcome measures. Never- } \\ \text { theless, they only presented an intention-to-treat analysis with imputation of } \\ \text { missing data. This would represent a degree of risk of bias. }\end{array}\end{array}$

Blinding of participants High risk and personnel (performance bias)

All outcomes

\begin{abstract}
"Participants began treatment with 50-mg sertraline or identically appearing placebo tablets". Clinicians had the option of increasing or decreasing the dose after randomisation depending on response and tolerability. The study physician guessed treatment assignment correctly above chance rate in the sertraline but not in placebo group at week 12. "A symptom checklist was derived from the Food and Drug Administration approved prescribing information for sertraline (listed in Table 4). Starting at baseline and at all follow-up visits, participants and their caregivers were asked about whether any of these symptoms, or other self-reported AEs, occurred [...]."
\end{abstract}

Clinicians assessed mood at each visit. The study physician guessed treatment assignment correctly above chance rate in the sertraline but not in placebo
Blinding of outcome as- Unclear risk sessment (detection bias) All outcomes group.

assignm
group.

\section{Roth 1996 \\ Methods \\ Randomised, placebo-controlled, parallel group study design of 6-week duration}


Roth 1996 (Continued)
3. 18-item SCAG >= 40;
4. Geriatric Depression Scale $>=5$;
5. 17-item Hamilton $>=14$.

Exclusion criteria: severe uncontrolled systemic disease, other neurological or major psychiatric disorder, psychotropic drugs

\begin{tabular}{ll}
\hline Interventions & $\begin{array}{l}\text { 1. Moclobe } \\
\text { 2. Placebo }\end{array}$ \\
\hline \multirow{2}{*}{ Outcomes } & 1. HAM-D \\
& 2. MMSE \\
& 3. SCAG \\
& 4. CGAE \\
& 5. BGP
\end{tabular}

\begin{tabular}{|c|c|}
\hline \multirow[t]{2}{*}{ Notes } & $\begin{array}{l}\text { No specific information on subgroup of patients with DSM depression and DSM dementia }(n=476) \\
\text { No usable statistics for efficacy analyses; after a discussion by the review team, only the adverse } \\
\text { events data were used. }\end{array}$ \\
\hline & $\begin{array}{l}\text { Source of funding not specifically mentioned but likely to have been Hoffmann-La Roche Ltd., Basel, } \\
\text { Switzerland, manufacturers of moclobemide, as one author was an employee of the company. }\end{array}$ \\
\hline
\end{tabular}

\section{Risk of bias}

\begin{tabular}{lll}
\hline Bias & Authors' judgement & Support for judgement \\
\hline $\begin{array}{l}\text { Random sequence genera- } \\
\text { tion (selection bias) }\end{array}$ & Unclear risk & $\begin{array}{l}\text { "random assignment within centre" - No further information on randomisa- } \\
\text { tion is provided. }\end{array}$ \\
\hline $\begin{array}{l}\text { Allocation concealment } \\
\text { (selection bias) }\end{array}$ & Unclear risk & No information provided \\
\hline $\begin{array}{l}\text { Blinding (performance } \\
\text { bias and detection bias) } \\
\text { All outcomes }\end{array}$ & Unclear risk & $\begin{array}{l}\text { "Treatment was with either a fixed dose of moclobemide } 400 \text { mg or a matched } \\
\text { placebo [...]. a placebo run-in period of } 14 \text { days was envisaged but not rigidly } \\
\text { enforced. Patients with signs of rapid deterioration during the run-in period } \\
\text { were entered into the double-blind treatment phase, after a minimum wash- } \\
\text { out of four days." }\end{array}$ \\
\hline
\end{tabular}

Incomplete outcome data Low risk (attrition bias)

All outcomes

Selective reporting (re- High risk
porting bias)
porting bias)
Out of 726 recruited patients, 14 had unclassifiable diagnoses and 18 missing efficacy data (but were still included in the "safety population").

\begin{abstract}
The depression rating scale scores were reported incompletely, therefore, only the adverse event and tolerability data from this study were used for the purposes of this review. "The safety data are based on the total group of randomised patients. All those who completed 10 days of treatment or gave as a reason for withdrawal, lack of efficacy, poor tolerability or adverse effects, were included in the analysis of efficacy as the 'intent to treat group' (ITT). The few patients who dropped out for any other reason were excluded from the efficacy analysis but were included in the safety analysis $(N=726)$.
\end{abstract}

\begin{tabular}{|c|c|c|}
\hline $\begin{array}{l}\text { Blinding of participants } \\
\text { and personnel (perfor- } \\
\text { mance bias) } \\
\text { All outcomes }\end{array}$ & Unclear risk & $\begin{array}{l}\text { "Treatment was with either a fixed dose of moclobemide } 400 \mathrm{mg} \text { or a matched } \\
\text { placebo [...]. a placebo run-in period of } 14 \text { days was envisaged but not rigidly } \\
\text { enforced. Patients with signs of rapid deterioration during the run-in period } \\
\text { were entered into the double-blind treatment phase, after a minimum wash- } \\
\text { out of four days." }\end{array}$ \\
\hline
\end{tabular}


Roth 1996 (Continued)

Blinding of outcome as- Unclear risk No description of how blinding of outcome assessors was checked was providsessment (detection bias) ed.

All outcomes

\section{Weintraub 2010}

Methods Randomised, double-blind, placebo-controlled, parallel assignment, safety and efficacy study, the double-blinded continuation of a 12-week efficacy study with participants who showed improvement on the modified Alzheimer's Disease Cooperative Study Clinical Global Impression of Change (mADCS-CGIC; modified for clinician to rate mood change only) after 12 weeks

\section{Participants}

Country: USA

Setting: outpatients, multi-centre (5 memory clinics)

Number: 131

Inclusion criteria: ability of the participant, caregiver, or surrogate to provide written informed consent, DSM-IV dementia due to Alzheimer's disease (MMSE =10-26), stable treatment for Alzheimer's disease, meeting criteria for depression in Alzheimer's disease (dAD: different from DSM-IV major depressive disorder in requiring three [as opposed to five] or more total symptoms and not requiring the gateway symptoms [most of the day, nearly every day], distinguishing social isolation or withdrawal from anhedonia, and adding irritability as a symptom), ability for the participant's caregiver to accompany the participant to study visits and participate in the study

Exclusion criteria: presence of a brain disease that might otherwise explain the presence of dementia, clinically significant hallucinations or delusions, current treatment with antipsychotics, anticonvulsants, and other antidepressants, benzodiazepines, or other psychotropic medications, need for hospitalisation or residence in a nursing facility

Interventions $\quad$ Sertraline (range 25-125 mg per day)

For 24 weeks (12-week efficacy trial + 12-week extension phase with randomised treatment for at least partial responders and the option for open label treatment for non-responders)

$\begin{array}{ll}\text { Outcomes } & \text { Primary: } \\ & \text { 1. response to treatment; } \\ \text { 2. remission from depression. }\end{array}$

Measured at 24 weeks measured by the Cornell Scale for Depression in Dementia and a global response measure (mADCS-CGIC measuring mood, activity enjoyment, neurovegetative [autonomic, i.e. not under conscious control] function and depressive cognitions)

Secondary:

1. non-mood neuropsychiatric symptoms;

2. global cognitive functioning;

3. quality of life.

Measured at Week 24 (in the trial description at clinicaltrials.gov telephone follow-up at weeks 36 and 48 is also mentioned). 
Weintraub 2010 (Continued)

Intention to treat analysis with the imputation of data (missing data estimation) based on baseline characteristics and follow-up data

Approximately $40 \%$ met criteria for major depressive episode.

The study was supported by NIHR grants. National Institute of Mental Health scientific collaborators participated on the trial's Steering Committee. Sertraline and matching placebo were provided by Pfizer, Inc., which did not otherwise participate in the design or conduct of the trial. Nine authors acknowledged receiving research, consultancy and other support from pharmaceutical companies.

\section{Risk of bias}

\begin{tabular}{lll} 
Bias & Authors' judgement & Support for judgement \\
\hline $\begin{array}{l}\text { Random sequence genera- } \\
\text { tion (selection bias) }\end{array}$ & Unclear risk & $\begin{array}{l}\text { As per Rosenberg 2010, "Participants were recruited from memory clinics at } \\
\text { five academic centers in the United States." "Participants were randomized by } \\
\text { the study's Coordinating Center }[. . .], \text { in a } 1: 1 \text { ratio to receive sertraline or place- } \\
\text { bo }[. . .] . " \text { No further information is provided about the generation of the ran- } \\
\text { dom sequence. }\end{array}$
\end{tabular}

$\begin{array}{ll}\begin{array}{l}\text { Allocation concealment } \\ \text { (selection bias) }\end{array} & \begin{array}{l}\text { "Because the five clinical sites have demographically different patient popu- } \\ \text { lations that could affect the distribution of the outcomes, the randomization } \\ \text { schedule was stratified by clinical site and it was designed with blocks of per- } \\ \text { muted length." No information is provided on how allocation status was con- } \\ \text { cealed. }\end{array}\end{array}$

Blinding (performance

bias and detection bias)

All outcomes

\section{High risk}

\begin{abstract}
"Because the five clinical sites have demographically different patient popumuted length." No information is provided on how allocation status was con-
\end{abstract} "Participants began treatment with $50 \mathrm{mg}$ sertraline or identically appearing placebo tablets" However, study clinicians guessed treatment assignment correctly above chance rate in sertraline but not in placebo group at week 12. "A symptom checklist was derived from the Food and Drug Administration approved prescribing information for sertraline. Starting at baseline and at all follow-up visits, participants and their caregivers were asked about whether any of these symptoms, or other self-reported AEs, occurred [...]."
The data presented in the consort chart does not completely tally with that in the abstract regarding numbers of participants completing treatment. As per the abstract, 74 participants (56.5\%) completed all 24 weeks on randomized treatment; this indicates very significant attrition, which is made better only partially by the fact that 117 participants $(89.3 \%)$ completed all study assessments. All analyses presented were intention to treat. The authors state that "Missing outcomes were imputed using the method of multiple imputation. Prediction models of the missing data were estimated based on the patients' other baseline and follow-up data...", but no clear description is given of how this was done.

\begin{tabular}{|c|c|c|}
\hline $\begin{array}{l}\text { Selective reporting (re- } \\
\text { porting bias) }\end{array}$ & Unclear risk & $\begin{array}{l}\text { The authors reported results with all pre-specified outcome measures. Howev- } \\
\text { er, they only presented an intention-to-treat analysis with imputation of miss- } \\
\text { ing data. }\end{array}$ \\
\hline
\end{tabular}

Blinding of participants Unclear risk
and personnel (performance bias)

All outcomes 
Weintraub 2010 (Continued)

Blinding of outcome as- Unclear risk Clinicians assessed mood at each visit. The study physician guessed treatment sessment (detection bias) assignment correctly above chance rate in the sertraline but not in placebo All outcomes group.

ADCS-CGIC: Alzheimer's Disease Cooperative Study Clinical Global Impression of Change

BGP: Rating Scale for Geriatric Patients

CGAE: Clinical Global Assessment of Efficacy

CGI: Clinical Global Impression Scale

CSDD: Cornell Scale for Depression in Dementia

FIM score: Functional independence score

GBS: Geriatric-Brane-Steen geriatric rating scale, to assess level of dementia

GDS: Geriatric Depression Scale

Ham-D: Hamilton depression scale

MADRS: Montgomery-Asberg Depression Rating Scale

MMSE: Mini-mental state examination

OARS ADL: Activities of daily living scales

SCAG: Sandoz clinical assessment geriatric scale

UKUSRS UKU: Side Effect Rating Scale

mADCS-CGIC: modified Alzheimer's Disease Cooperative Study - Clinical Global Impression of Change

Characteristics of excluded studies [ordered by study ID]

Study Reason for exclusion

Barak 1996

Excluded as study investigates the properties of inositol which is not generally regarded as an antidepressant (it is an isomer of glucose and precursor for the second messenger system involving phospatidylinositol, and it has been reported as having antidepressant properties). This study investigated its utility in improving cognitive functioning in a group of subjects with Alzheimer's disease. Subjects whose estimate of depressive symptoms was higher than minimal were excluded.

Brodaty 2003

Patients were diagnosed with dementia, but only some suffered from depression which was not diagnosed using DSM criteria.

\begin{tabular}{ll}
\hline Bui 2012 & Case report, not a treatment trial \\
\hline Burke 1994 & $\begin{array}{l}\text { Case reports of four patients with Alzheimer's disease and accompanying depression and psy- } \\
\text { chosis treated with SSRIs }\end{array}$
\end{tabular}

Capote 1978

RCT of patients with senile dementia, but treatment given was not an antidepressant (Cyclandelate is a vasodilator)

\begin{tabular}{ll}
\hline Choe 2014 & Patients were not depressed \\
\hline Devanand 2003 & No well-defined dementia diagnosis \\
\hline Drye 2012 & Only patients without major depression were included. \\
\hline
\end{tabular}

Dunbar $2011 \quad$ Patients were not diagnosed with dementia and depression.

$\begin{array}{ll}\text { Fairweather } 1993 & \begin{array}{l}\text { Study (RCT) designed to compare the effects on cognition of fluoxetine and amitriptyline in de- } \\ \text { pressed elderly patients; patients not demented and study not placebo-controlled }\end{array}\end{array}$

Finkel 2004

Placebo controlled RCT of sertraline, patients diagnosed with probable AD, all on donepezil, and with behavioural manifestations but not necessarily depressed 


\begin{tabular}{|c|c|}
\hline Study & Reason for exclusion \\
\hline Gottfries 1991 & $\begin{array}{l}\text { Subjects do not meet criteria for depression, it is a study of citalopram for 'emotional disturbance' } \\
\text { associated with dementia. }\end{array}$ \\
\hline Gottfries 1992 & Review article reviewing the 2 Nyth studies \\
\hline Hoyberg 1996 & RCT of mirtazapine in the depressed elderly, but they were not demented \\
\hline Jenike 1985 & $\begin{array}{l}\text { Case reports of two patients with Alzheimer's disease and depression who failed to respond to } \\
\text { standard antidepressants but did respond to MAOIs }\end{array}$ \\
\hline Karlsson 2000 & $\begin{array}{l}\text { RCT of citalopram vs mianserin in depressed elderly patients who may also have had dementia, but } \\
\text { not placebo controlled, therefore excluded }\end{array}$ \\
\hline Katona 1998 & $\begin{array}{l}\text { Not placebo controlled, imipramine compared with paroxetine in cognitively impaired, depressed } \\
\text { patients }\end{array}$ \\
\hline Lebert 2006 & No standardised criteria for the diagnoses of dementia and depression \\
\hline Magai 2000 & $\begin{array}{l}\text { Although the participants were demented, only } 10 \% \text { were also diagnosed cases of major depres- } \\
\text { sion. }\end{array}$ \\
\hline Mizukami 2009 & No placebo group \\
\hline Mokhber 2014 & No placebo group \\
\hline Moretti 2003 & $\begin{array}{l}\text { Study of paroxetine vs piracetam for patients with frontotemporal dementia, and behavioural } \\
\text { manifestations, but not depression }\end{array}$ \\
\hline
\end{tabular}

\begin{tabular}{|c|c|}
\hline Mossello 2008 & Retrospective study, no blinding to treatment status, no formal criteria used to define depression \\
\hline Mowla 2007 & The patients were not diagnosed with depression. \\
\hline Nebes 2003 & $\begin{array}{l}\text { Study of citalopram vs placebo for patients with probable AD, all on donepezil, all with behavioural } \\
\text { symptoms which may include depression; not clear whether it is randomised }\end{array}$ \\
\hline Nelson 2006 & No clear dementia diagnosis, no placebo control \\
\hline Nyth 1990 & $\begin{array}{l}\text { Combined double-blind and open technique; looks at the effect of citalopram on emotional distur- } \\
\text { bance in patients with various subtypes of dementia; patients are not diagnosed with depression } \\
\text { according to any recognised criteria }\end{array}$ \\
\hline Nyth 1992 & $\begin{array}{l}\text { Amalgamated depressed patients also suffering from somatic disorders or dementia (or both); out } \\
\text { of the } 149 \text { patients, } 98 \text { had DSM-III major depression and } 29 \text { dementia; those with concurrent de- } \\
\text { mentia and depression not separated }\end{array}$ \\
\hline Oslin 2000 & $\begin{array}{l}\text { Two trials, one open-label of sertraline, another an RCT of low versus high dose nortriptyline, but } \\
\text { no placebo group; patients were depressed and some may have been demented }\end{array}$ \\
\hline Oslin 2003 & $\begin{array}{l}\text { RCT of venlataxine versus sertraline in patients with DSM-IV diagnosed depressive disorder and de- } \\
\text { mentia; no placebo group }\end{array}$ \\
\hline Passeri 1987 & $\begin{array}{l}\text { Participants did not meet recognised criteria for depressive illness; minaprine not generally avail- } \\
\text { able or used as an antidepressant }\end{array}$ \\
\hline Pelton 2008 & $\begin{array}{l}\text { Study on donepezil augmentation to antidepressant treatment, no blinding to antidepressant } \\
\text { treatment status }\end{array}$ \\
\hline
\end{tabular}




\begin{tabular}{|c|c|}
\hline Study & Reason for exclusion \\
\hline Pelton 2014 & Not an antidepressant RCT \\
\hline Peters 2011 & Not a treatment trial \\
\hline Pollock 2007 & $\begin{array}{l}\text { Study on treatment of behavioural and psychotic symptoms with risperidone or citalopram in de- } \\
\text { mentia; non-depressed patients }\end{array}$ \\
\hline Reynolds III 1987 & Open trial, not randomised, placebo-controlled or double-blind \\
\hline Rozzini 2010 & Not an RCT, not blind \\
\hline Smith 1984 & $\begin{array}{l}\mathrm{N}=28 \text {, severely demented, six with endogenous or reactive depression; no information on whether } \\
\text { formal diagnostic criteria met. In addition to the above problems, they used a cross-over design, all } \\
\text { patients prescribed tryptophan for one month, and then switched to placebo. }\end{array}$ \\
\hline Streim 2000 & $\begin{array}{l}\text { There was no placebo group. The study examined response to high and low dose nortriptyline } \\
\text { among } 69 \text { patients living in nursing homes. Patients were depressed according to psychiatric inter- } \\
\text { view and depression scales. Moderate cognitive impairment was not a reason for exclusion. }\end{array}$ \\
\hline Swartz 1997 & Not randomised, double-blind or placebo-controlled; not specifically looking at dementia \\
\hline Taragano 1997 & $\begin{array}{l}\text { Randomised trial of amitriptyline vs fluoxetine, for patients with probable AD and major depressive } \\
\text { disorder, but not placebo-controlled }\end{array}$ \\
\hline Teranishi 2013 & BPSD, not depression per se; no placebo group \\
\hline van Asch 2013 & Not an RCT \\
\hline
\end{tabular}

AD: Alzheimer's disease

BPSD: behavioural and psychological symptoms of dementia

MAOIs: monoamine oxidase inhibitors

$\mathrm{RCT}$ : randomised controlled trial

SSRIs: selective serotonin reuptake inhibitors

VD: vascular dementia

Characteristics of studies awaiting assessment [ordered by study ID]

\section{Sverdlik 2005}

\begin{tabular}{ll}
\hline Methods & Randomised, double-blind, placebo-controlled, parallel assignment, interventional efficacy study \\
\hline Participants & $\begin{array}{l}\text { Age } 60 \text { years and above, diagnosed with AD, VD, or mixed AD and VD and major depressive episode } \\
\text { according to DSM-IV }\end{array}$ \\
\hline Interventions & Escitalopram or placebo treatment for 8 weeks \\
\hline Outcomes & Primary: Cornell Scale foe Depression in Dementia (CSDD) total score \\
& Secondary: Cohen-Mansfield Agitation Inventory (CMAI) \\
\hline Notes & Anticipated end date: not known \\
(As per ClinicalTrials.gov on 11 March 2015, "status unknown".) \\
We emailed Dr Anna Sverdlik on 14 Jan 2014, but have not received any response as of 15 July \\
2015.
\end{tabular}


AD: Alzheimer's disease

SSRIs: selective serotonin reuptake inhibitors

VD: vascular dementia

\section{DATA AND ANALYSES}

\section{Comparison 1. Antidepressant versus placebo}

\begin{tabular}{|c|c|c|c|c|}
\hline Outcome or subgroup title & No. of studies & $\begin{array}{l}\text { No. of partici- } \\
\text { pants }\end{array}$ & Statistical method & Effect size \\
\hline $\begin{array}{l}1 \text { Depression endpoint mean } \\
\text { scores at 6-13 weeks }\end{array}$ & 8 & 614 & $\begin{array}{l}\text { Std. Mean Difference (IV, Fixed, 95\% } \\
\mathrm{Cl} \text { ) }\end{array}$ & $-0.10[-0.26,0.06]$ \\
\hline 1.1 SSRIS & 5 & 400 & $\begin{array}{l}\text { Std. Mean Difference (IV, Fixed, 95\% } \\
\mathrm{CI} \text { ) }\end{array}$ & $-0.13[-0.33,0.07]$ \\
\hline 1.2 Mirtazapine & 1 & 134 & $\begin{array}{l}\text { Std. Mean Difference (IV, Fixed, 95\% } \\
\mathrm{Cl} \text { ) }\end{array}$ & $-0.02[-0.37,0.33]$ \\
\hline 1.3 Venlafaxine & 1 & 31 & $\begin{array}{l}\text { Std. Mean Difference (IV, Fixed, 95\% } \\
\mathrm{CI} \text { ) }\end{array}$ & $-0.09[-0.80,0.62]$ \\
\hline 1.4 TCA & 2 & 49 & $\begin{array}{l}\text { Std. Mean Difference (IV, Fixed, 95\% } \\
\mathrm{CI} \text { ) }\end{array}$ & $-0.10[-0.67,0.46]$ \\
\hline $\begin{array}{l}2 \text { Cornell Scale for Depres- } \\
\text { sion in Dementia (CSDD) }\end{array}$ & 4 & & Mean Difference (Random, 95\% Cl) & Subtotals only \\
\hline 2.1 At week 6-13 & 3 & 433 & Mean Difference (Random, 95\% Cl) & $-0.10[-0.99,0.78]$ \\
\hline 2.2 At 6-9 months & 2 & 357 & Mean Difference (Random, 95\% Cl) & $0.59[-1.12,2.30]$ \\
\hline $\begin{array}{l}3 \text { Hamilton Depression rating } \\
\text { Scale (HDRS) }\end{array}$ & 4 & 134 & Mean Difference (IV, Fixed, 95\% CI) & $-0.85[-2.65,0.95]$ \\
\hline $\begin{array}{l}4 \text { Number of responders (ITT) } \\
\text { at } 6-12 \text { weeks }\end{array}$ & 3 & 116 & Odds Ratio (M-H, Fixed, 95\% Cl) & $1.71[0.80,3.67]$ \\
\hline 4.1 SSRI & 2 & 85 & Odds Ratio (M-H, Fixed, 95\% Cl) & $2.42[0.97,6.09]$ \\
\hline 4.2 venlafaxine & 1 & 31 & Odds Ratio (M-H, Fixed, 95\% Cl) & $0.73[0.17,3.11]$ \\
\hline $\begin{array}{l}5 \text { Number of responders (ITT) } \\
\text { at } 24 \text { weeks }\end{array}$ & 1 & 131 & Odds Ratio (M-H, Fixed, 95\% Cl) & $1.45[0.72,2.92]$ \\
\hline $\begin{array}{l}6 \text { Number of patients with re- } \\
\text { mission (ITT) at 6-12 weeks }\end{array}$ & 4 & 240 & Odds Ratio (M-H, Fixed, 95\% Cl) & $2.57[1.44,4.59]$ \\
\hline 6.1 SSRI & 3 & 216 & Odds Ratio (M-H, Fixed, 95\% Cl) & $2.22[1.20,4.12]$ \\
\hline $6.2 \mathrm{TCA}$ & 1 & 24 & Odds Ratio (M-H, Fixed, 95\% Cl) & $9.0[1.42,57.12]$ \\
\hline $\begin{array}{l}7 \text { Number of patients with re- } \\
\text { mission (ITT) at } 24 \text { weeks }\end{array}$ & 1 & 131 & Odds Ratio (M-H, Fixed, 95\% Cl) & $1.75[0.80,3.82]$ \\
\hline
\end{tabular}




\begin{tabular}{|c|c|c|c|c|}
\hline Outcome or subgroup title & No. of studies & $\begin{array}{l}\text { No. of partici- } \\
\text { pants }\end{array}$ & Statistical method & Effect size \\
\hline $\begin{array}{l}8 \text { Cognitive function end- } \\
\text { point mean scores }\end{array}$ & 6 & & Mean Difference (IV, Fixed, 95\% CI) & Subtotals only \\
\hline $\begin{array}{l}8.1 \text { Mini-mental state scores } \\
\text { at } 6-12 \text { weeks }\end{array}$ & 5 & 194 & Mean Difference (IV, Fixed, 95\% CI) & $0.33[-1.31,1.96]$ \\
\hline $\begin{array}{l}8.2 \text { Mini-mental state scores } \\
\text { at } 6-9 \text { months }\end{array}$ & 1 & 131 & Mean Difference (IV, Fixed, 95\% CI) & $1.0[-1.14,3.14]$ \\
\hline $\begin{array}{l}9 \text { Change in MMSE mean } \\
\text { scores }\end{array}$ & 6 & & Mean Difference (Fixed, 95\% Cl) & Subtotals only \\
\hline 9.1 at 6 to 13 weeks & 5 & & Mean Difference (Fixed, 95\% Cl) & $0.19[-0.81,1.19]$ \\
\hline 9.2 at $6-9$ months & 2 & & Mean Difference (Fixed, 95\% Cl) & $-0.38[-1.90,1.13]$ \\
\hline $\begin{array}{l}10 \text { Activities of daily living, } \\
\text { endpoint values at 6-13 } \\
\text { weeks }\end{array}$ & 4 & 173 & $\begin{array}{l}\text { Std. Mean Difference (IV, Fixed, 95\% } \\
\mathrm{CI})\end{array}$ & $-0.05[-0.36,0.25]$ \\
\hline $\begin{array}{l}11 \text { Activities of daily living at } \\
6-9 \text { months }\end{array}$ & 1 & & Mean Difference (IV, Fixed, 95\% CI) & Totals not selected \\
\hline $\begin{array}{l}12 \text { Tolerability: Number of } \\
\text { dropouts at 6-13 weeks }\end{array}$ & 9 & 836 & Odds Ratio (M-H, Fixed, 95\% Cl) & $1.51[1.07,2.14]$ \\
\hline 12.1 SSRI & 5 & 462 & Odds Ratio (M-H, Fixed, 95\% Cl) & $1.39[0.88,2.21]$ \\
\hline 12.2 venlafaxine & 1 & 31 & Odds Ratio (M-H, Fixed, 95\% Cl) & $3.5[0.68,17.96]$ \\
\hline 12.3 mirtazapine & 1 & 164 & Odds Ratio (M-H, Fixed, 95\% Cl) & $1.79[0.71,4.49]$ \\
\hline 12.4 older antidepressants & 3 & 179 & Odds Ratio (M-H, Fixed, 95\% Cl) & $1.39[0.69,2.80]$ \\
\hline $\begin{array}{l}13 \text { Tolerability: Number of } \\
\text { dropouts at 6-9 months }\end{array}$ & 2 & 457 & Odds Ratio (M-H, Fixed, 95\% Cl) & $1.25[0.83,1.88]$ \\
\hline $\begin{array}{l}14 \text { Safety: number experienc- } \\
\text { ing at least one adverse event }\end{array}$ & 3 & 1073 & $\begin{array}{l}\text { Peto Odds Ratio (Peto, Fixed, 95\% } \\
\mathrm{Cl} \text { ) }\end{array}$ & $1.55[1.21,1.98]$ \\
\hline 14.1 Older antidepressants & 2 & 747 & $\begin{array}{l}\text { Peto Odds Ratio (Peto, Fixed, 95\% } \\
\mathrm{Cl} \text { ) }\end{array}$ & $1.41[1.06,1.89]$ \\
\hline 14.2 Mirtazapine & 1 & 164 & $\begin{array}{l}\text { Peto Odds Ratio (Peto, Fixed, 95\% } \\
\mathrm{Cl} \text { ) }\end{array}$ & $1.83[0.93,3.57]$ \\
\hline 14.3 SSRI & 1 & 162 & $\begin{array}{l}\text { Peto Odds Ratio (Peto, Fixed, 95\% } \\
\mathrm{Cl} \text { ) }\end{array}$ & $2.11[1.08,4.13]$ \\
\hline $\begin{array}{l}15 \text { Safety: } N \text { experiencing at } \\
\text { least one event of dry mouth }\end{array}$ & 5 & 1044 & $\begin{array}{l}\text { Peto Odds Ratio (Peto, Fixed, 95\% } \\
\mathrm{Cl} \text { ) }\end{array}$ & $1.80[1.23,2.63]$ \\
\hline 15.1 Older antidepressants & 3 & 874 & $\begin{array}{l}\text { Peto Odds Ratio (Peto, Fixed, 95\% } \\
\mathrm{Cl} \text { ) }\end{array}$ & $1.71[1.09,2.68]$ \\
\hline
\end{tabular}




\begin{tabular}{|c|c|c|c|c|}
\hline Outcome or subgroup title & No. of studies & $\begin{array}{l}\text { No. of partici- } \\
\text { pants }\end{array}$ & Statistical method & Effect size \\
\hline 15.2 SSRI & 2 & 170 & $\begin{array}{l}\text { Peto Odds Ratio (Peto, Fixed, 95\% } \\
\mathrm{Cl} \text { ) }\end{array}$ & $2.04[1.01,4.12]$ \\
\hline $\begin{array}{l}16 \text { Safety: } N \text { experiencing at } \\
\text { least one event of fatigue }\end{array}$ & 3 & 982 & $\begin{array}{l}\text { Peto Odds Ratio (Peto, Fixed, 95\% } \\
\mathrm{Cl} \text { ) }\end{array}$ & $1.22[0.79,1.87]$ \\
\hline 16.1 Older antidepressants & 2 & 853 & $\begin{array}{l}\text { Peto Odds Ratio (Peto, Fixed, 95\% } \\
\mathrm{Cl} \text { ) }\end{array}$ & $1.28[0.78,2.10]$ \\
\hline $16.2 \mathrm{SSRI}$ & 1 & 129 & $\begin{array}{l}\text { Peto Odds Ratio (Peto, Fixed, 95\% } \\
\mathrm{Cl} \text { ) }\end{array}$ & $1.06[0.45,2.50]$ \\
\hline $\begin{array}{l}17 \text { Safety: N experiencing at } \\
\text { least one event of constipa- } \\
\text { tion }\end{array}$ & 5 & 1044 & $\begin{array}{l}\text { Peto Odds Ratio (Peto, Fixed, 95\% } \\
\mathrm{Cl} \text { ) }\end{array}$ & $1.18[0.76,1.83]$ \\
\hline 17.1 Older antidepressants & 3 & 874 & $\begin{array}{l}\text { Peto Odds Ratio (Peto, Fixed, 95\% } \\
\mathrm{Cl} \text { ) }\end{array}$ & $1.18[0.68,2.06]$ \\
\hline 17.2 SSRI & 2 & 170 & $\begin{array}{l}\text { Peto Odds Ratio (Peto, Fixed, 95\% } \\
\mathrm{Cl} \text { ) }\end{array}$ & $1.17[0.56,2.43]$ \\
\hline $\begin{array}{l}18 \text { Safety: } N \text { experiencing at } \\
\text { least one event of dizziness }\end{array}$ & 5 & 1044 & $\begin{array}{l}\text { Peto Odds Ratio (Peto, Fixed, 95\% } \\
\mathrm{Cl} \text { ) }\end{array}$ & $2.00[1.34,2.98]$ \\
\hline 18.1 Older antidepressants & 3 & 874 & $\begin{array}{l}\text { Peto Odds Ratio (Peto, Fixed, 95\% } \\
\mathrm{Cl} \text { ) }\end{array}$ & $1.64[1.00,2.68]$ \\
\hline 18.2 SSRI & 2 & 170 & $\begin{array}{l}\text { Peto Odds Ratio (Peto, Fixed, 95\% } \\
\mathrm{Cl} \text { ) }\end{array}$ & $2.93[1.48,5.80]$ \\
\hline
\end{tabular}

Analysis 1.1. Comparison 1 Antidepressant versus placebo, Outcome 1 Depression endpoint mean scores at 6-13 weeks.

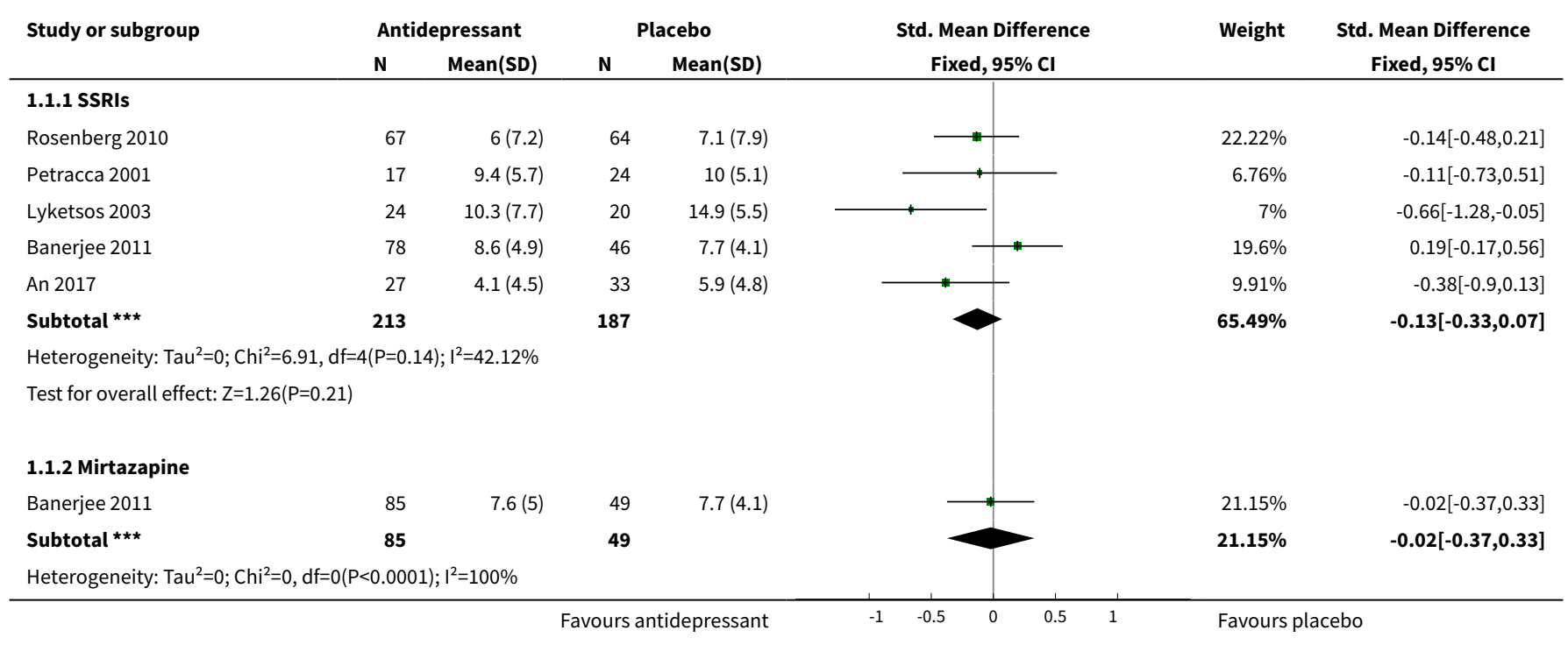




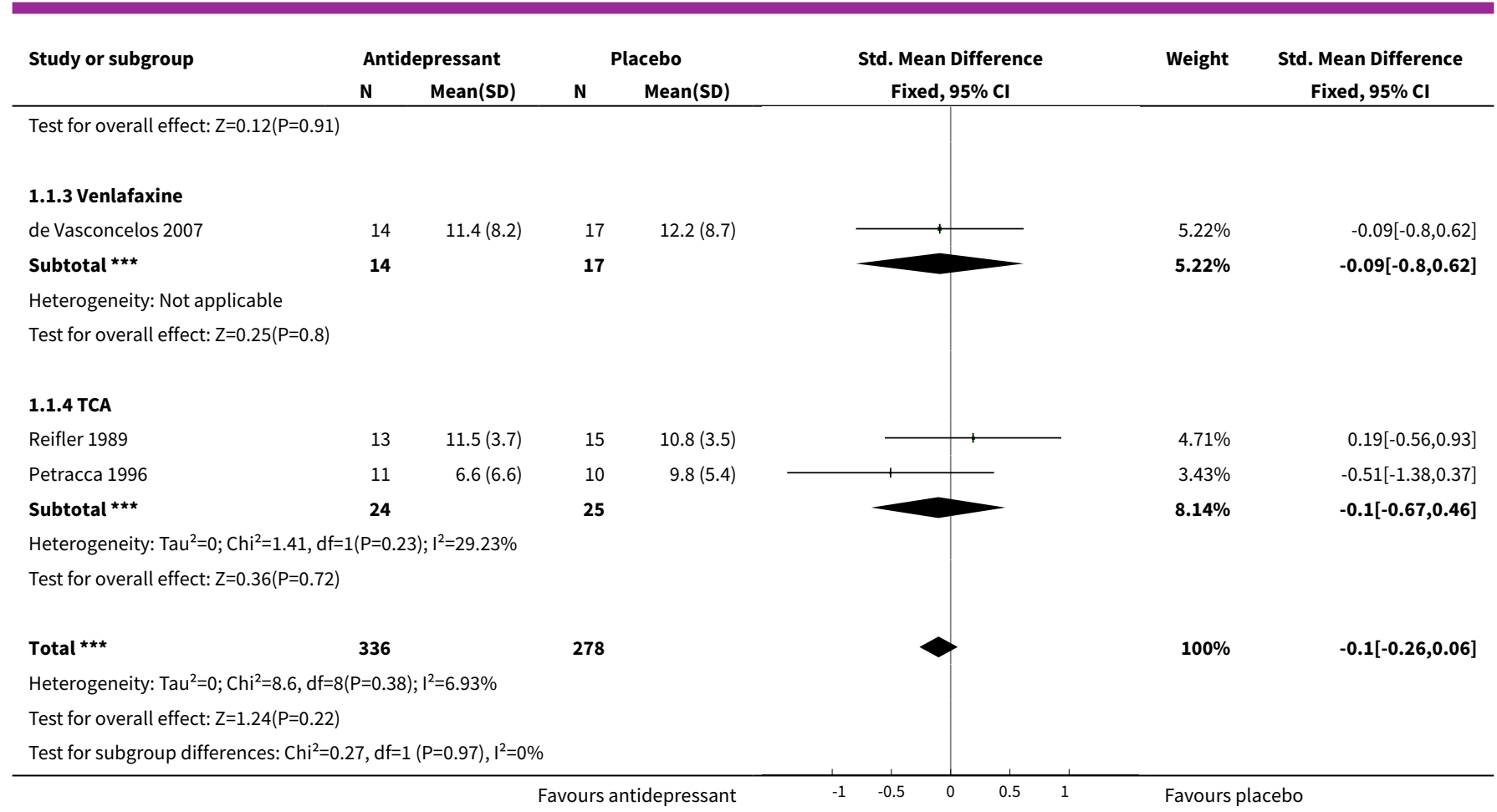

Analysis 1.2. Comparison 1 Antidepressant versus placebo, Outcome 2 Cornell Scale for Depression in Dementia (CSDD).

\begin{tabular}{|c|c|c|c|}
\hline Study or subgroup & $\begin{array}{c}\text { Antide- } \\
\text { pressant } \\
\text { N }\end{array}$ & $\begin{array}{c}\text { placebo } \\
\text { N }\end{array}$ & $\begin{array}{c}\text { Mean Dif- } \\
\text { ference } \\
\text { (SE) }\end{array}$ \\
\hline \multicolumn{4}{|l|}{ 1.2.1 At week 6-13 } \\
\hline Lyketsos 2003 & 24 & 20 & $-0.8(0.38)$ \\
\hline Banerjee 2011 & 163 & 95 & $0.2(0.16)$ \\
\hline Rosenberg 2010 & 67 & 64 & $1.2(1.454)$ \\
\hline
\end{tabular}

Subtotal $(95 \% \mathrm{Cl})$

Heterogeneity: $\mathrm{Tau}^{2}=0.37 ; \mathrm{Chi}^{2}=6.6, \mathrm{df}=2(\mathrm{P}=0.04) ; \mathrm{I}^{2}=69.7 \%$

Test for overall effect: $Z=0.23(P=0.82)$

1.2.2 At 6-9 months

Banerjee 2011

Weintraub 2010

Mean Difference

IV, Random, $95 \% \mathrm{CI}$

Weight

Mean Difference

IV, Random, 95\% CI

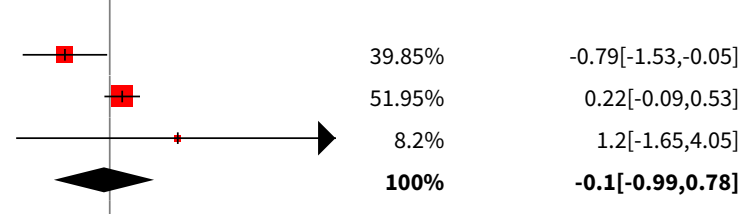


Analysis 1.3. Comparison 1 Antidepressant versus placebo, Outcome 3 Hamilton Depression rating Scale (HDRS).

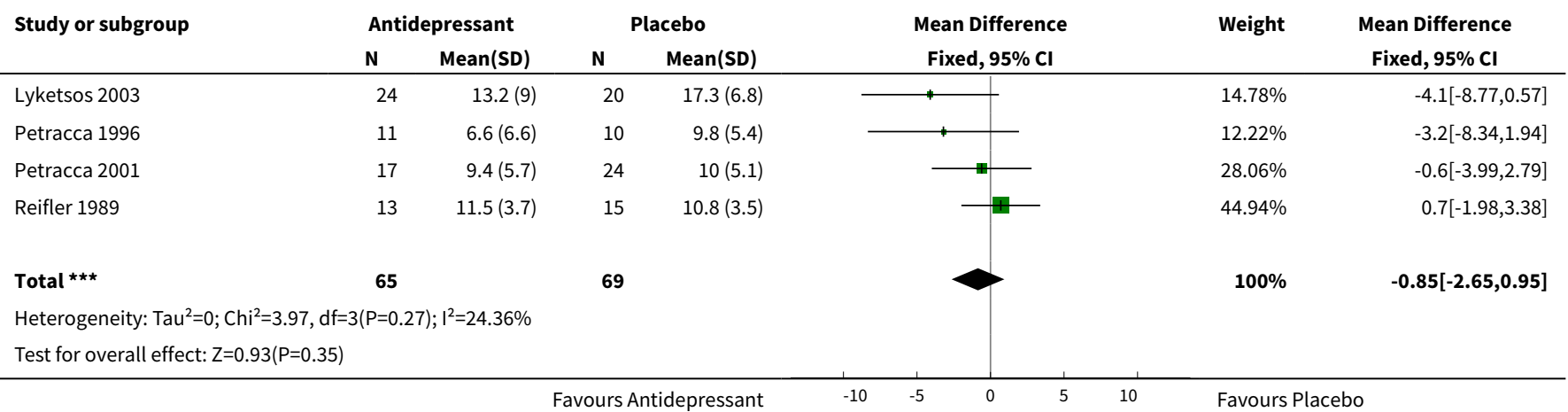

Analysis 1.4. Comparison 1 Antidepressant versus placebo, Outcome 4 Number of responders (ITT) at 6-12 weeks.

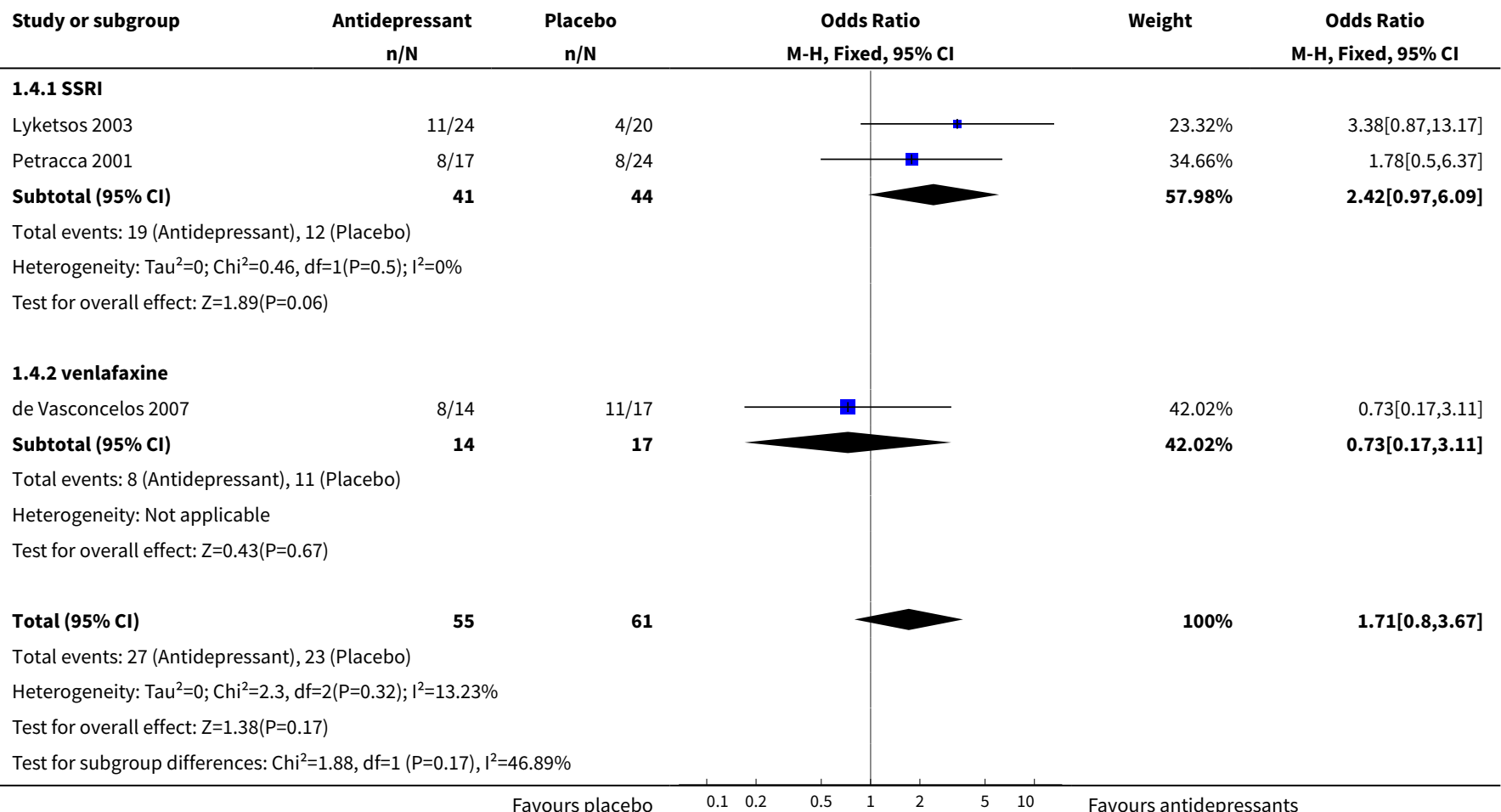

Analysis 1.5. Comparison 1 Antidepressant versus placebo, Outcome 5 Number of responders (ITT) at 24 weeks.

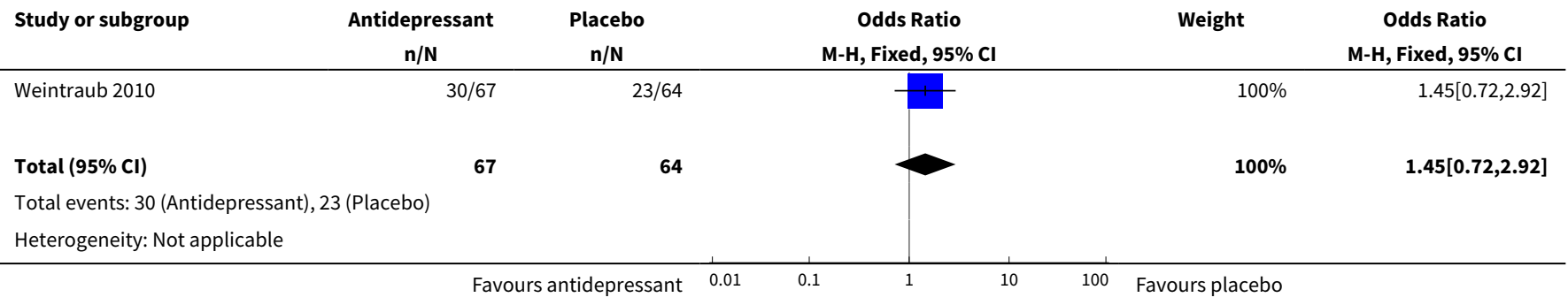




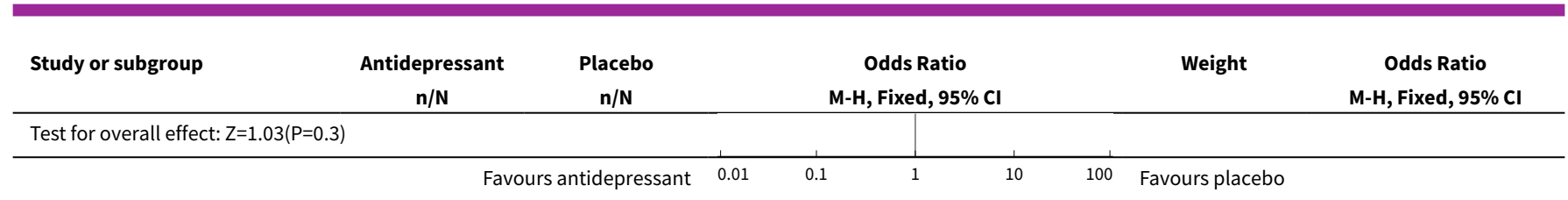

Analysis 1.6. Comparison 1 Antidepressant versus placebo, Outcome 6 Number of patients with remission (ITT) at 6-12 weeks.

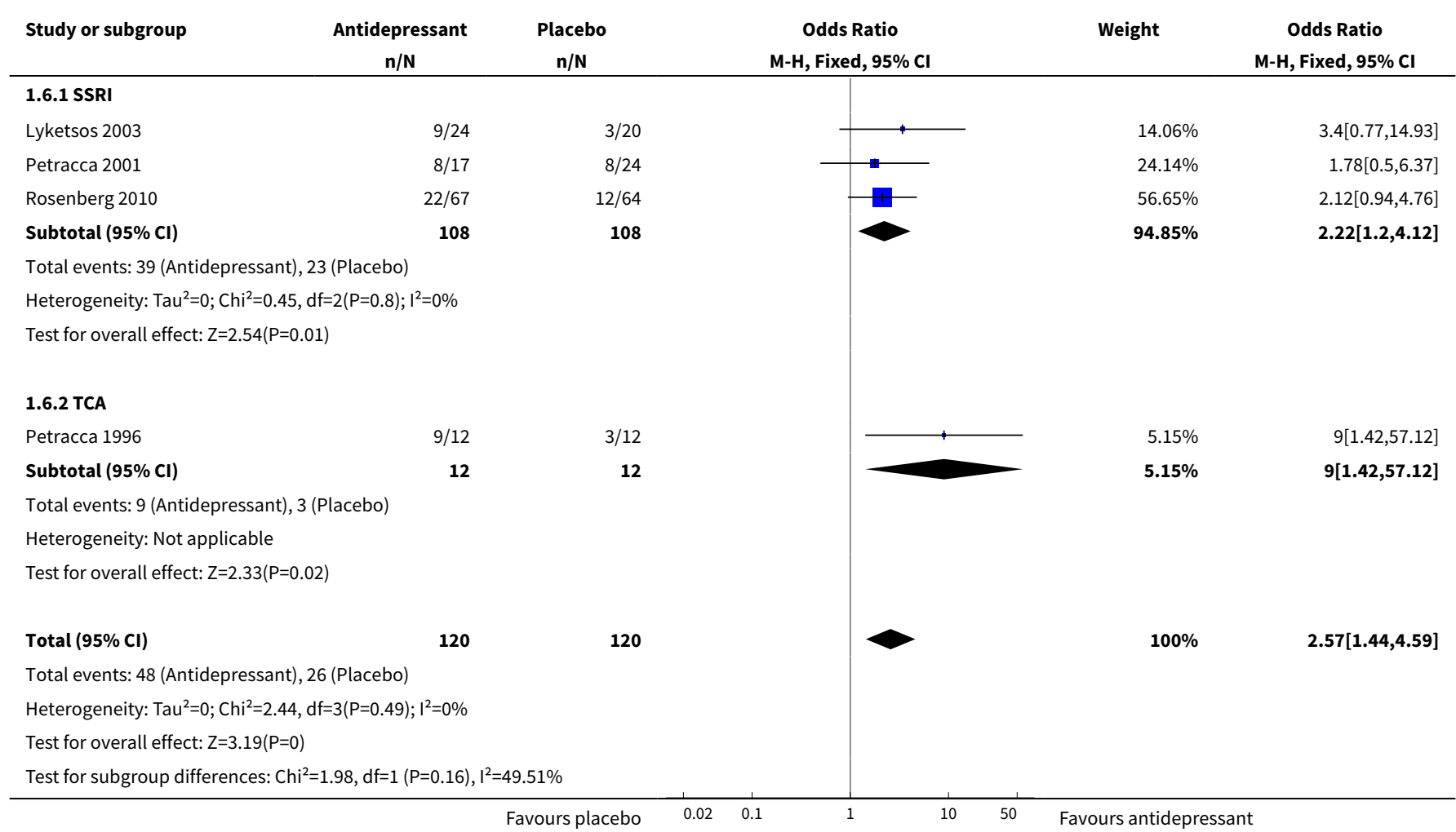

Analysis 1.7. Comparison 1 Antidepressant versus placebo, Outcome 7 Number of patients with remission (ITT) at 24 weeks.

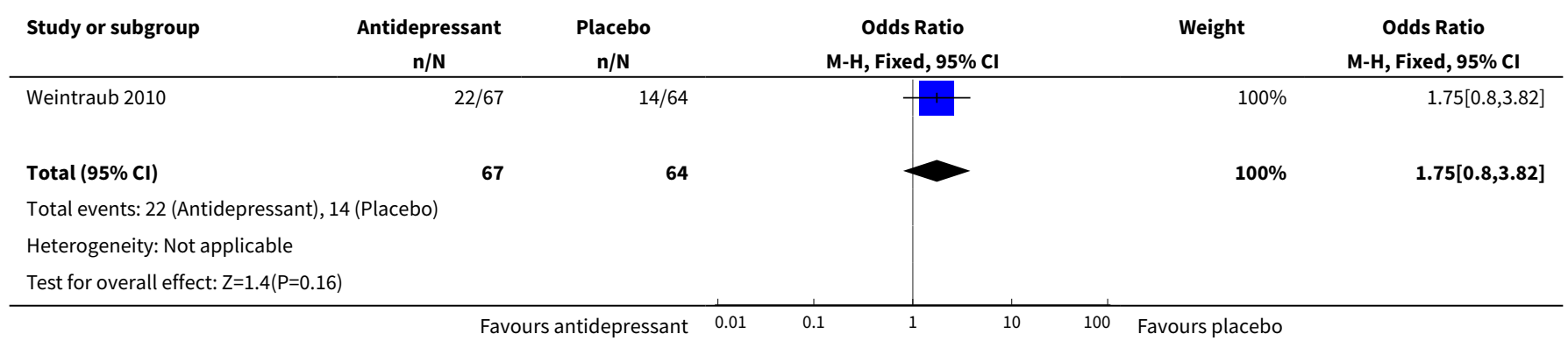


Analysis 1.8. Comparison 1 Antidepressant versus placebo, Outcome 8 Cognitive function endpoint mean scores.

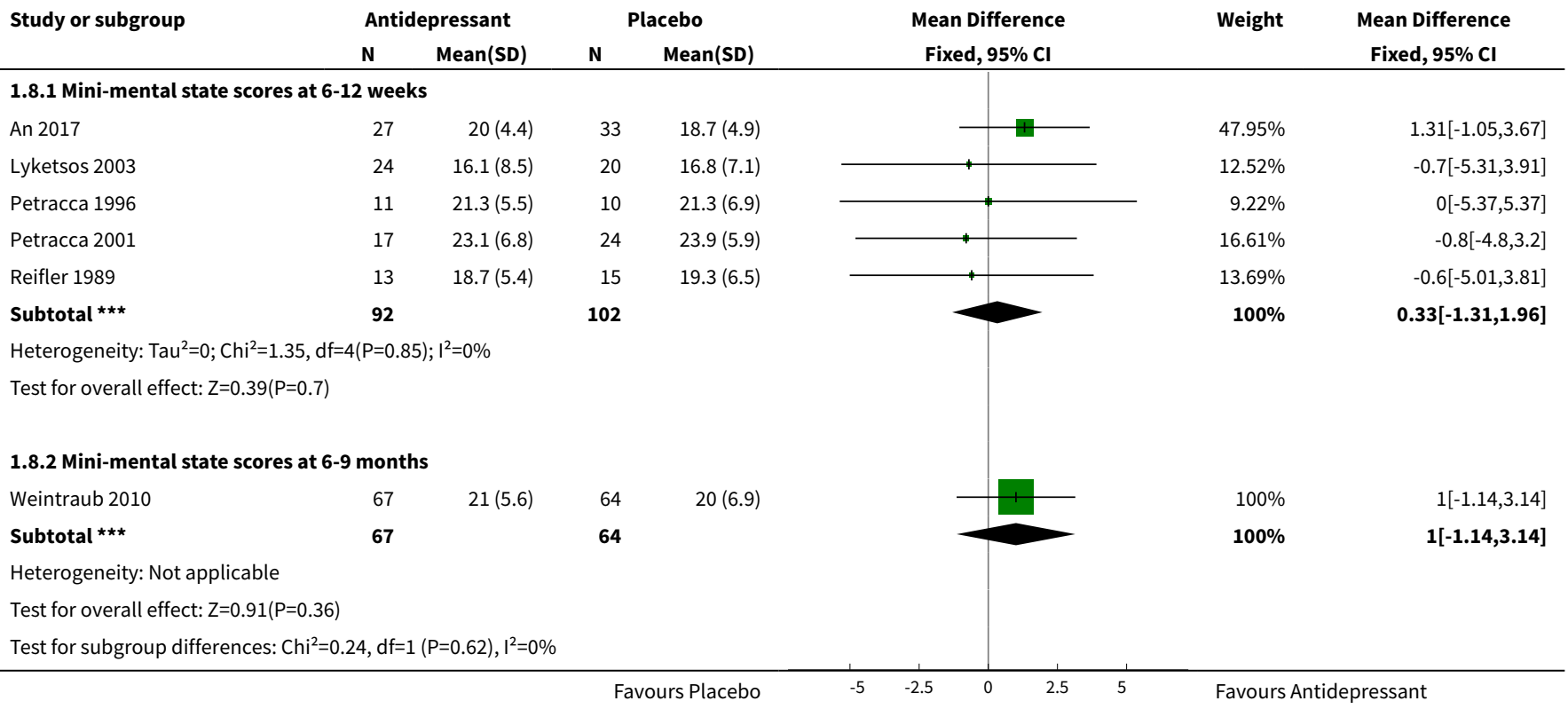

Analysis 1.9. Comparison 1 Antidepressant versus placebo, Outcome 9 Change in MMSE mean scores.

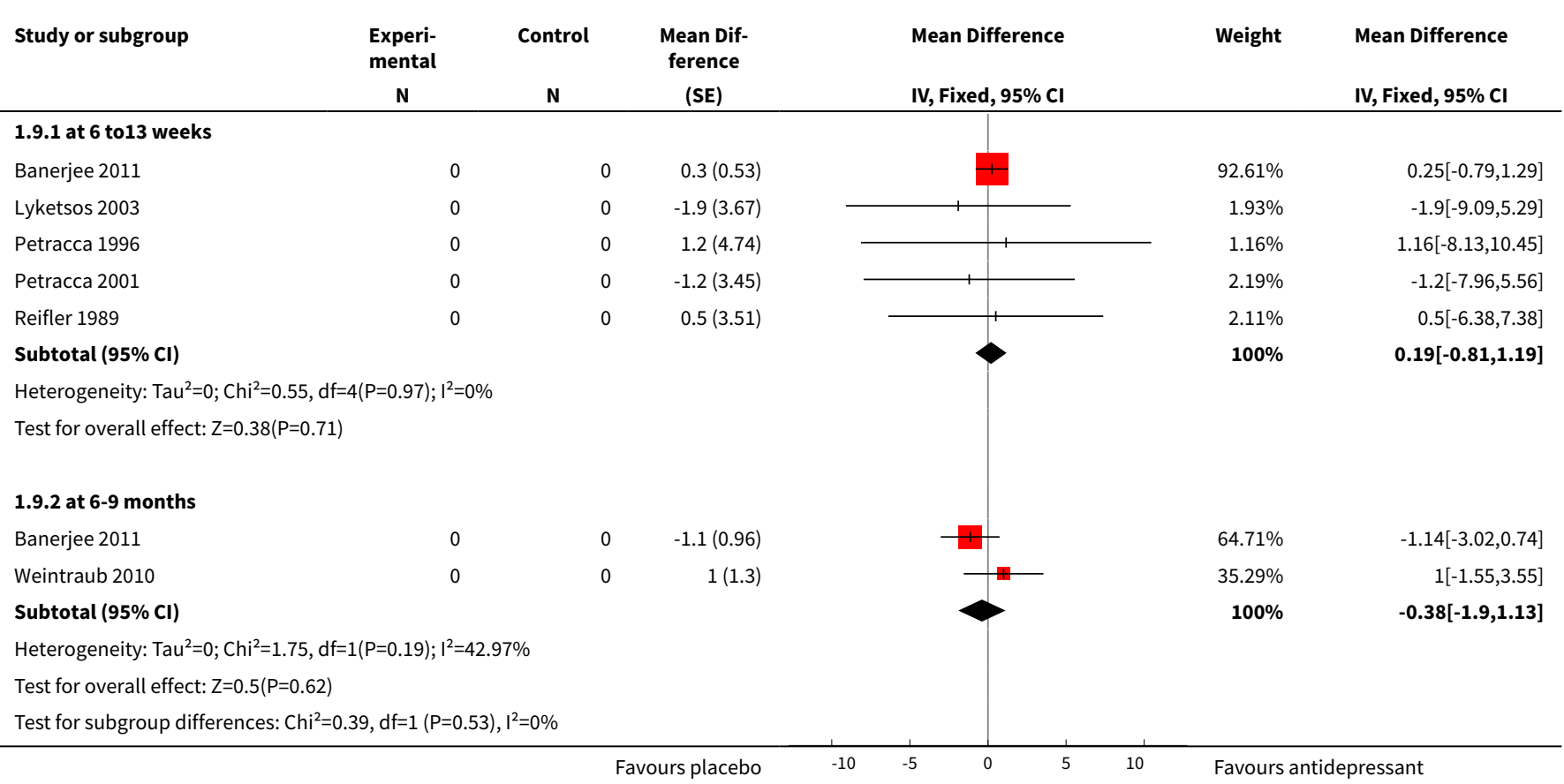


Analysis 1.10. Comparison 1 Antidepressant versus placebo,

Outcome 10 Activities of daily living, endpoint values at 6-13 weeks.

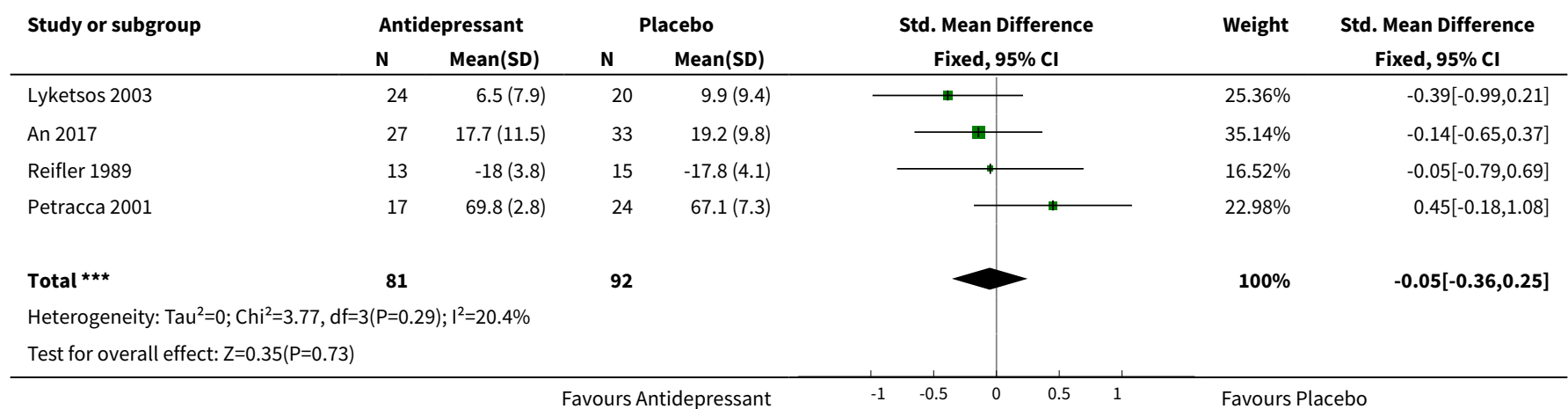

Analysis 1.11. Comparison 1 Antidepressant versus placebo, Outcome 11 Activities of daily living at 6-9 months.

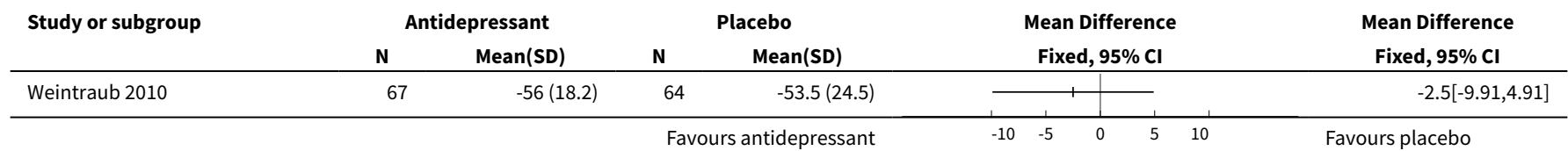

Analysis 1.12. Comparison 1 Antidepressant versus placebo, Outcome 12 Tolerability: Number of dropouts at 6-13 weeks.

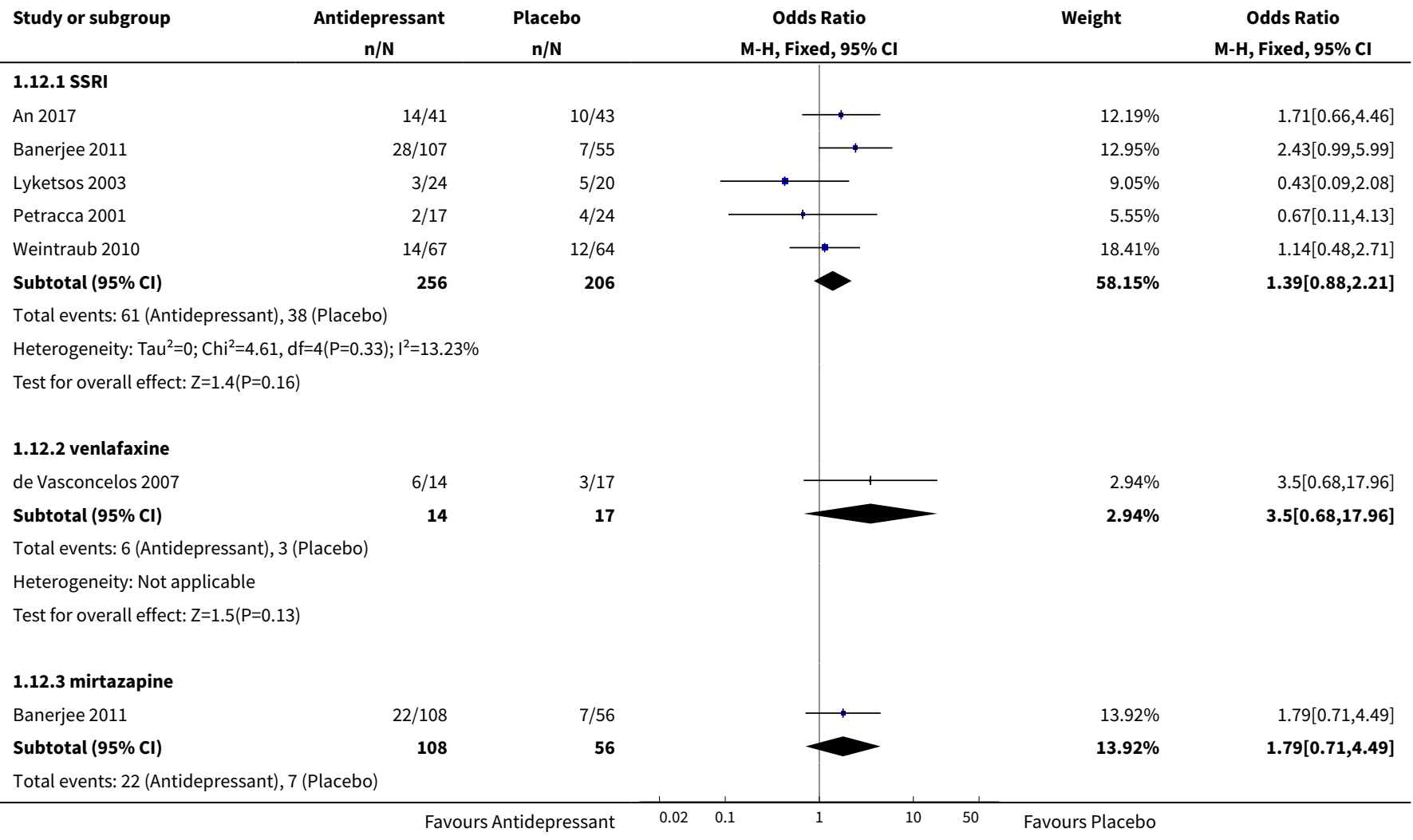




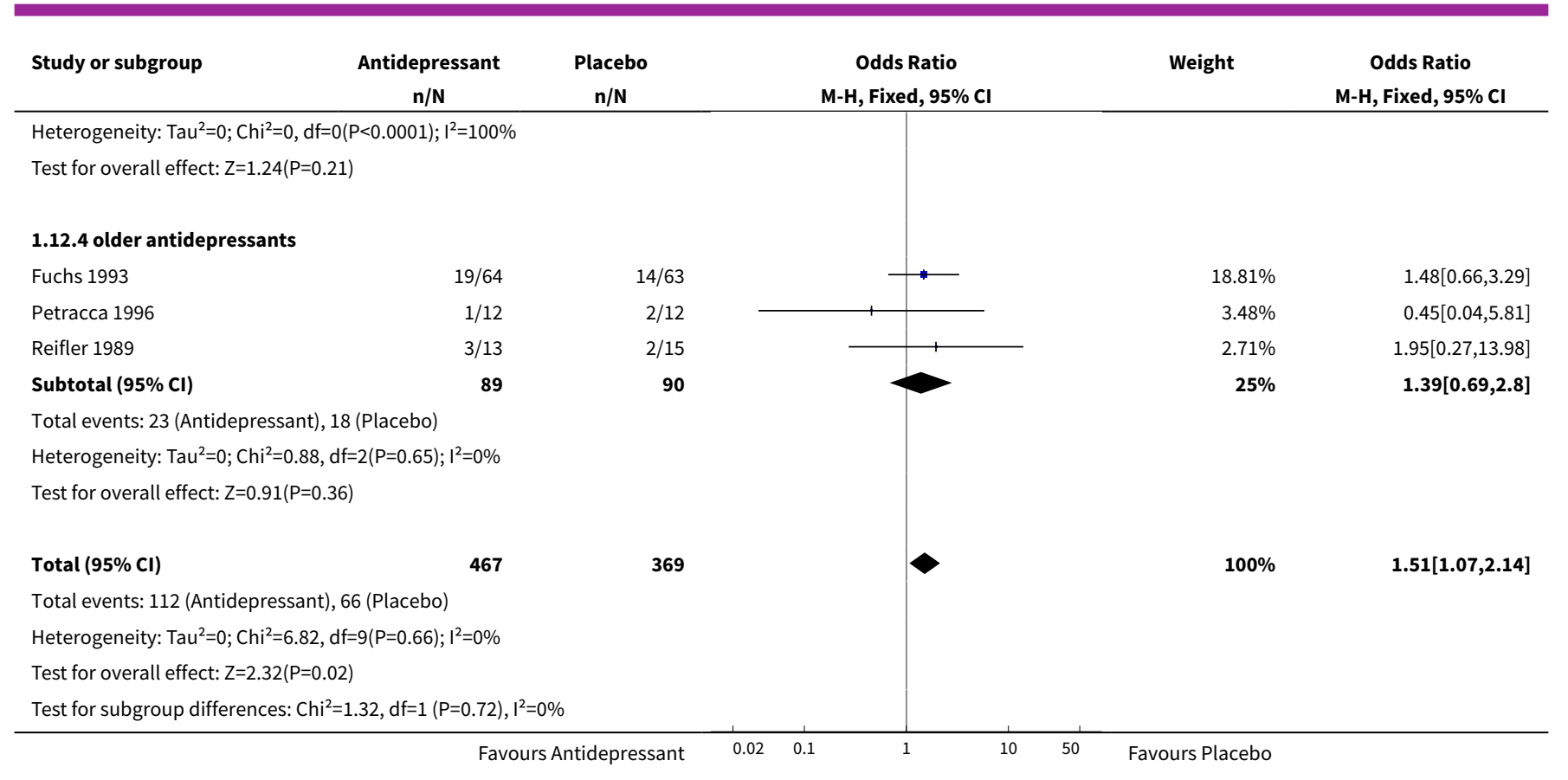

Analysis 1.13. Comparison 1 Antidepressant versus placebo, Outcome 13 Tolerability: Number of dropouts at 6-9 months.

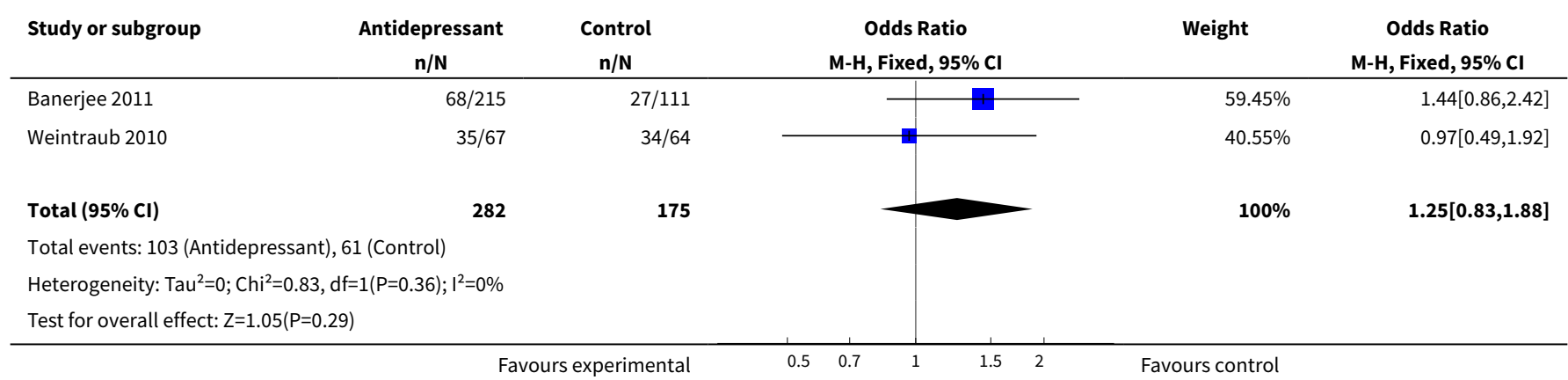

Analysis 1.14. Comparison 1 Antidepressant versus placebo, Outcome 14 Safety: number experiencing at least one adverse event.

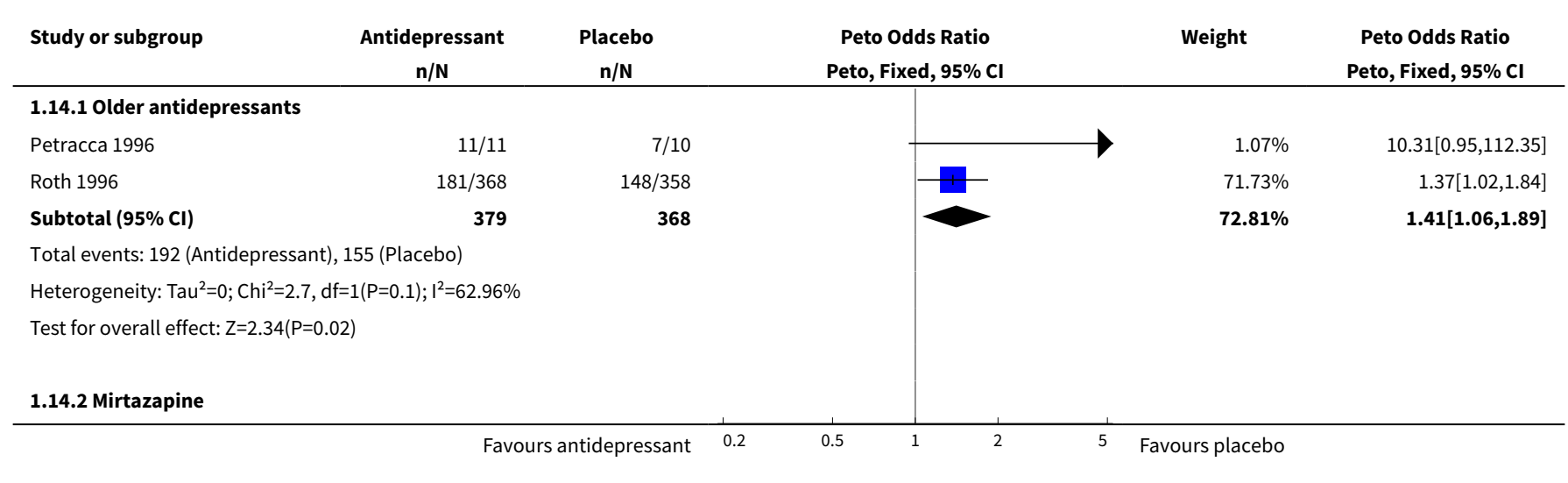




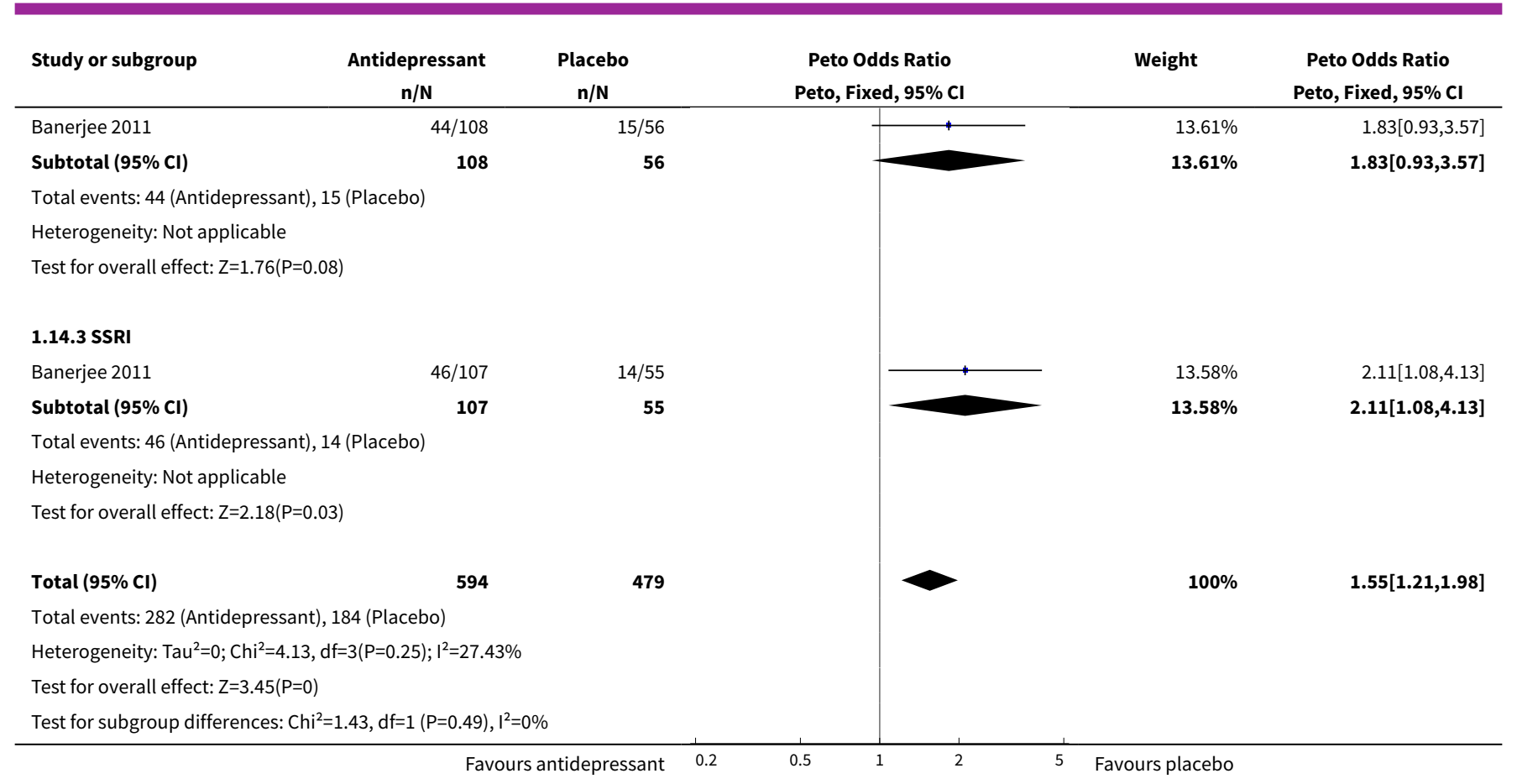

Analysis 1.15. Comparison 1 Antidepressant versus placebo, Outcome 15 Safety: $N$ experiencing at least one event of dry mouth.

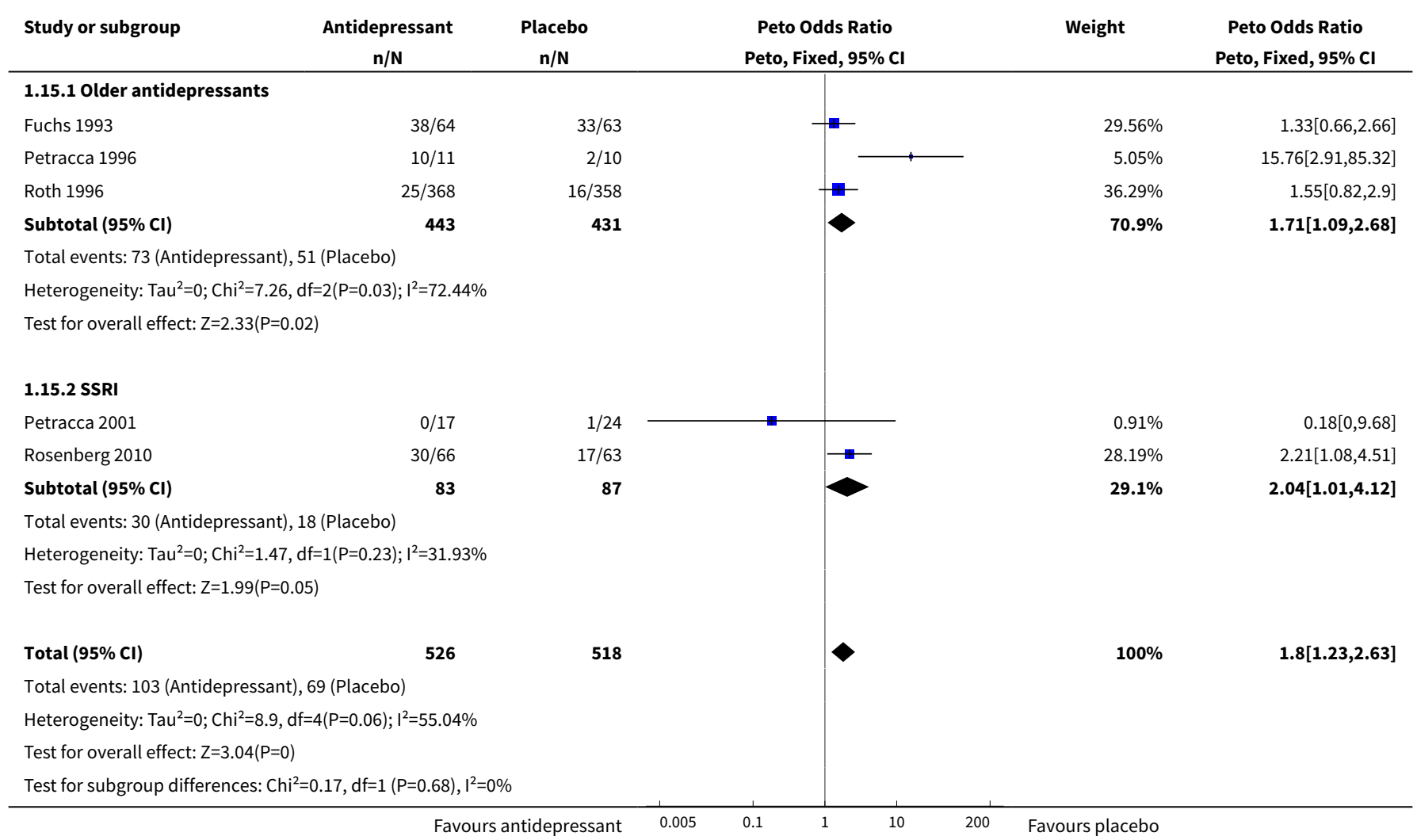


Analysis 1.16. Comparison 1 Antidepressant versus placebo, Outcome 16 Safety: $N$ experiencing at least one event of fatigue.

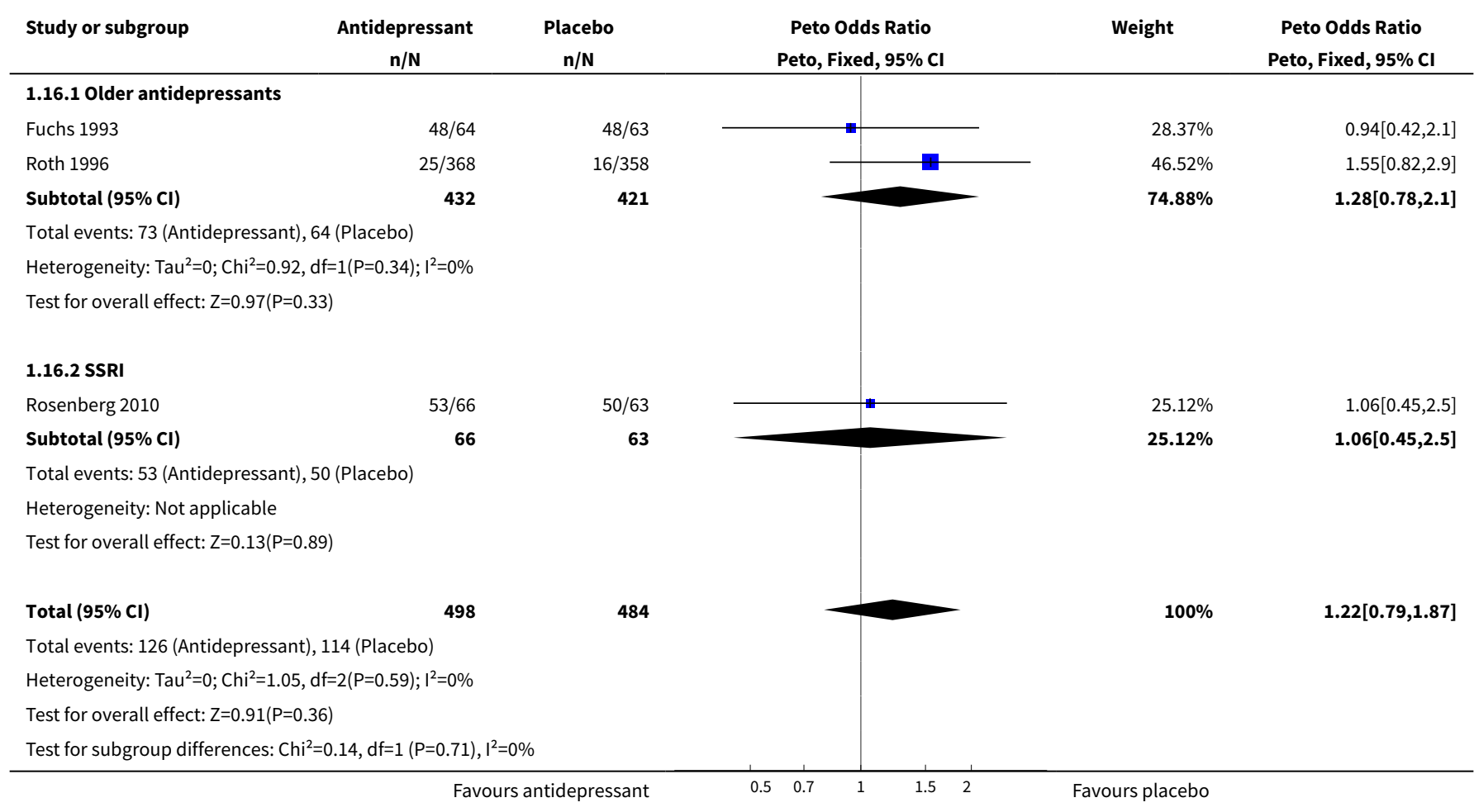

Analysis 1.17. Comparison 1 Antidepressant versus placebo, Outcome 17 Safety: $N$ experiencing at least one event of constipation.

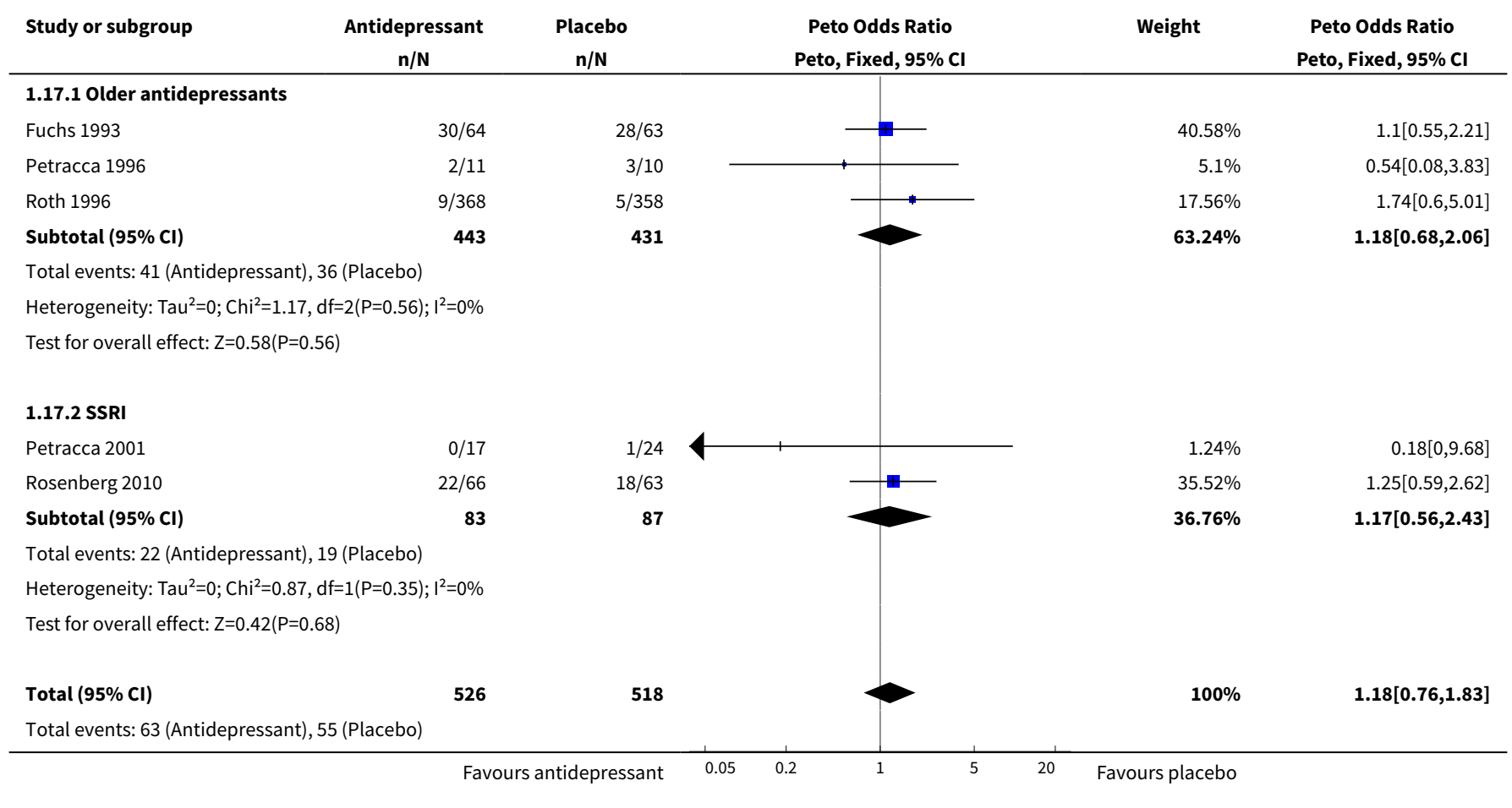




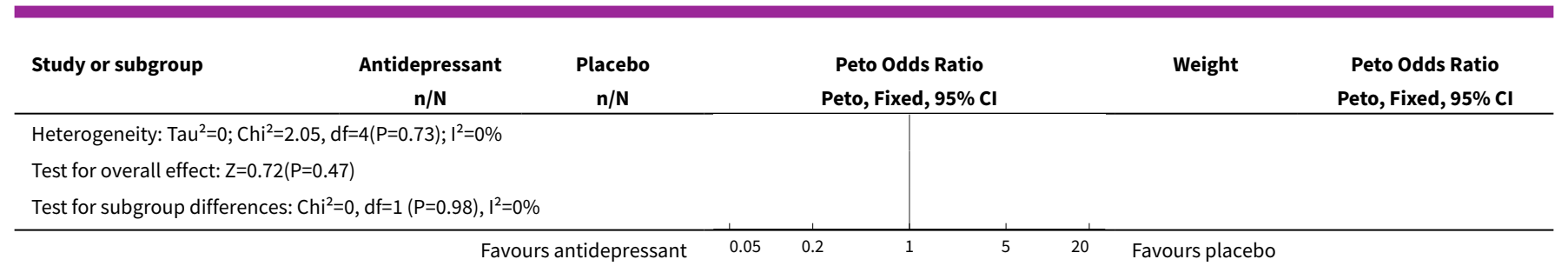

Analysis 1.18. Comparison 1 Antidepressant versus placebo, Outcome 18 Safety: $N$ experiencing at least one event of dizziness.

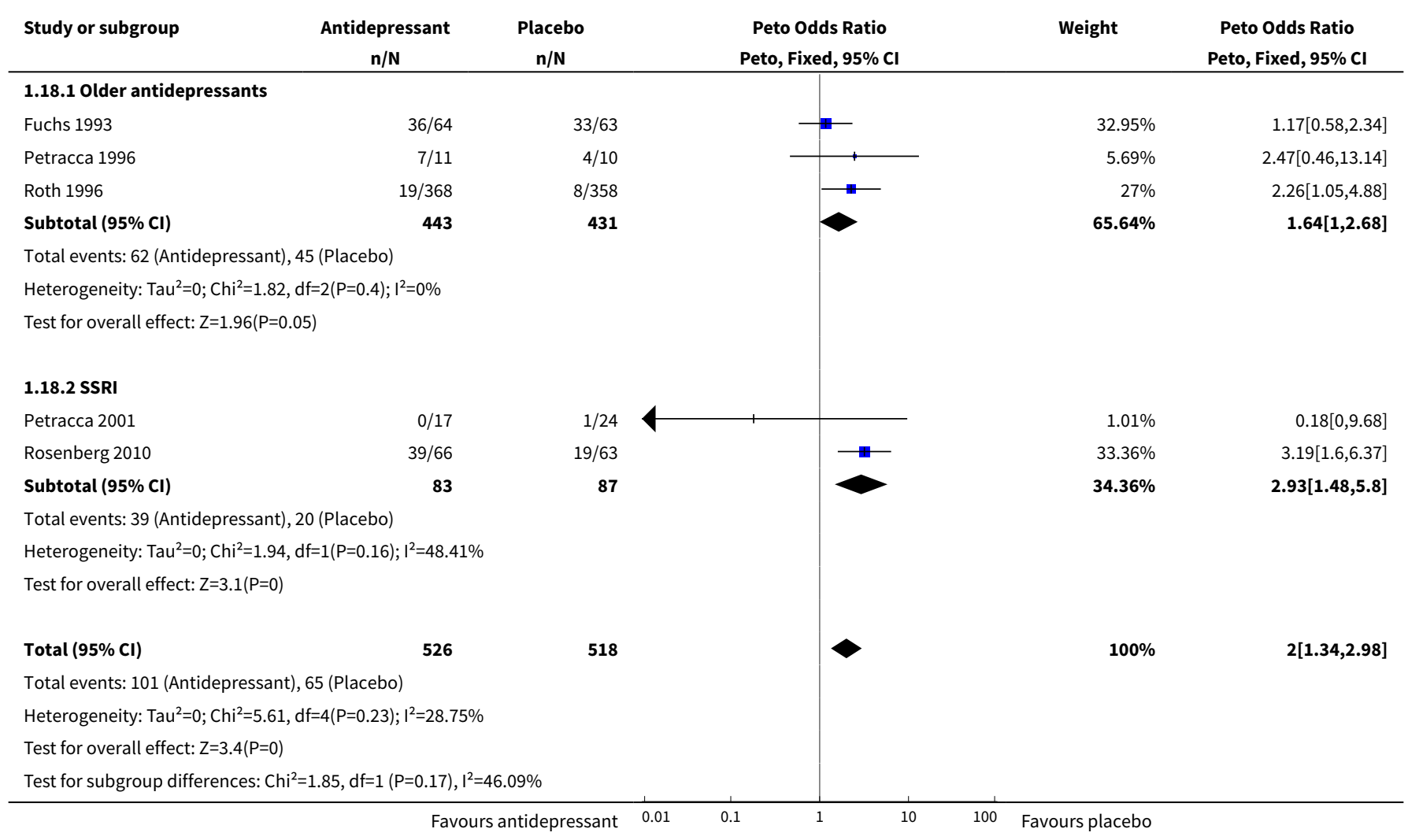

\section{ADDITIONAL TABLES}

Table 1. Outcome measures

\begin{tabular}{|c|c|c|c|c|c|}
\hline $\begin{array}{l}\text { Outcome } \\
\text { measure }\end{array}$ & Abbreviation & Reference & $\begin{array}{l}\text { Type of mea- } \\
\text { sure }\end{array}$ & Brief description & Used in \\
\hline \multicolumn{6}{|c|}{ Depression rating scales } \\
\hline $\begin{array}{l}\text { Hamilton De- } \\
\text { pression Rat- } \\
\text { ing Scale }\end{array}$ & HAMD & Hamilton 1960 & $\begin{array}{l}\text { depressive } \\
\text { symptom lev- } \\
\text { els }\end{array}$ & $\begin{array}{l}\text { Clinician-rated, multiple choice rating scale } \\
\text { of depressive symptom severity designed to } \\
\text { be sensitive to change with treatment in the } \\
\text { general adult population. }\end{array}$ & $\begin{array}{l}\text { Reifler 1989, } \\
\text { Petracca 1996, } \\
\text { Petracca 2001, } \\
\text { Lyketsos 2003 }\end{array}$ \\
\hline
\end{tabular}


Table 1. Outcome measures (Continued)

\begin{tabular}{|c|c|c|c|c|c|}
\hline $\begin{array}{l}\text { Cornell Scale } \\
\text { for Depression } \\
\text { in Dementia }\end{array}$ & CSDD & $\begin{array}{l}\text { Alexopoulos } \\
1988\end{array}$ & $\begin{array}{l}\text { depressive } \\
\text { symptom lev- } \\
\text { els }\end{array}$ & $\begin{array}{l}\text { For the diagnosis of depression in patients } \\
\text { with a dementia syndrome administered by } \\
\text { a clinician. It takes } 20 \text { minutes with the carer } \\
\text { and } 10 \text { minutes with the patient. The scale } \\
\text { has } 19 \text { items, rated on a } 3 \text { point scale: ab- } \\
\text { sent, mild or intermittent and severe, based } \\
\text { on the week prior to the interview. }\end{array}$ & $\begin{array}{l}\text { Lyketsos 2003, } \\
\text { Weintraub } \\
2010 \text { Banerjee } \\
2011 \text {, }\end{array}$ \\
\hline
\end{tabular}

\begin{tabular}{|c|c|c|c|c|c|}
\hline $\begin{array}{l}\text { Montgomery } \\
\text { Asberg De- } \\
\text { pression Rat- } \\
\text { ing Scale }\end{array}$ & MADRS & $\begin{array}{l}\text { Montgomery } \\
1979\end{array}$ & $\begin{array}{l}\text { depressive } \\
\text { symptom lev- } \\
\text { els }\end{array}$ & $\begin{array}{l}\text { A } 10 \text {-item clinician-rated diagnostic ques- } \\
\text { tionnaire to measure the severity of depres- } \\
\text { sive symptomatology in mood disorders. }\end{array}$ & $\begin{array}{l}\text { de Vasconce- } \\
\text { los } 2007\end{array}$ \\
\hline $\begin{array}{l}\text { Geriatric De- } \\
\text { pression Scale }\end{array}$ & GDS & Yesavage 1982 & $\begin{array}{l}\text { depressive } \\
\text { symptom lev- } \\
\text { els }\end{array}$ & $\begin{array}{l}\text { A } 30 \text {-item, self-report assessment used to } \\
\text { identify depression in the elderly. The sim- } \\
\text { ple response format (yes/no questions) } \\
\text { makes it more suitable for use in those with } \\
\text { cognitive impairment. }\end{array}$ & Fuchs 1993 \\
\hline
\end{tabular}

Cognitive measure

\begin{tabular}{lllll}
\hline $\begin{array}{l}\text { Mini-mental } \\
\begin{array}{l}\text { State Exami- } \\
\text { nation }\end{array}\end{array}$ & FMSE & Folstein 1975 & $\begin{array}{l}\text { level of cogni- } \\
\text { tive function- } \\
\text { ing }\end{array}$ & $\begin{array}{l}\text { A 30-point clinician-administered cognitive } \\
\text { test for cognitive impairment, assessing ori- } \\
\text { entation, concentration, memory, language, } \\
\text { and visuo-spatial function. Higher scores in- } \\
\text { dicate better functioning. }\end{array}$ \\
\hline
\end{tabular}

Activities of daily living

\begin{tabular}{|c|c|c|c|c|c|}
\hline $\begin{array}{l}\text { Psychogeri- } \\
\text { atric depen- } \\
\text { dency rating } \\
\text { scales - ADL } \\
\text { subscale }\end{array}$ & PGDRS-ADL & $\begin{array}{l}\text { Wilkinson } \\
1980\end{array}$ & $\begin{array}{l}\text { need for as- } \\
\text { sistance with } \\
\text { functional } \\
\text { abilities }\end{array}$ & $\begin{array}{l}\text { Physical capacity consists of } 7 \text { sub-cate- } \\
\text { gories. Higher scores indicate more disabili- } \\
\text { ty. }\end{array}$ & Lyketsos 2003 \\
\hline $\begin{array}{l}\text { Alzheimer's } \\
\text { Disease Coop- } \\
\text { erative Study } \\
\text { - Activities of } \\
\text { Daily Living } \\
\text { Scale }\end{array}$ & ADCS-ADL & Galasko 1997 & $\begin{array}{l}\text { functional } \\
\text { ability }\end{array}$ & $\begin{array}{l}\text { Informant-based, last } 4 \text { weeks. Higher score } \\
\text { indicates better performance. }\end{array}$ & $\begin{array}{l}\text { Weintraub } \\
2010\end{array}$ \\
\hline $\begin{array}{l}\text { Functional In- } \\
\text { dependence } \\
\text { Measure }\end{array}$ & FIM & Granger 1986 & $\begin{array}{l}\text { need for as- } \\
\text { sistance with } \\
\text { functional } \\
\text { abilities }\end{array}$ & $\begin{array}{l}18 \text { items on self-care, sphincter control, mo- } \\
\text { bility, locomotion, communication, social } \\
\text { cognition. Higher scores indicate more dis- } \\
\text { ability. }\end{array}$ & $\begin{array}{l}\text { Petracca 1996, } \\
\text { Petracca } 2001\end{array}$ \\
\hline $\begin{array}{l}\text { Older Ameri- } \\
\text { can Resources } \\
\text { and Services }\end{array}$ & OARS-ADL & Pfeiffer 1975 & $\begin{array}{l}\text { functional } \\
\text { ability }\end{array}$ & $\begin{array}{l}\text { An 14-item assessment for physical function, } \\
\text { including bathing, dressing, grooming, and } \\
\text { continence, relying on self report. Higher } \\
\text { scores indicate better functioning. }\end{array}$ & Reifler 1989 \\
\hline $\begin{array}{l}\text { Seoul-Instru- } \\
\text { mental Activ- } \\
\text { ities of Daily } \\
\text { Living }\end{array}$ & SIADL & Ku 2004 & $\begin{array}{l}\text { instrumental } \\
\text { everyday ac- } \\
\text { tivities }\end{array}$ & $\begin{array}{l}\text { A 15-item instrument to assess complex } \\
\text { functions of daily living, with a total score } \\
\text { from } 0 \text { to } 45 \text {. Higher scores reflect worse } \\
\text { function. }\end{array}$ & An 2017 \\
\hline
\end{tabular}




\begin{tabular}{|c|c|c|c|c|c|c|c|c|}
\hline Trial & $\begin{array}{l}\text { dementia cri- } \\
\text { teria }\end{array}$ & depression criteria & $\begin{array}{l}\text { number of } \\
\text { patients }\end{array}$ & duration & intervention & mean age & $\begin{array}{l}\text { mean } \\
\text { MMSE }\end{array}$ & $\begin{array}{l}\text { mean de- } \\
\text { pression } \\
\text { rating scale } \\
\text { score }\end{array}$ \\
\hline An 2017 & $\begin{array}{l}\text { NINCDS-ADR- } \\
\text { DA for AD }\end{array}$ & $\begin{array}{l}\text { three or more from } \\
\text { Olin's criteria for de- } \\
\text { pression in } A D\end{array}$ & 84 & 8 weeks & $\begin{array}{l}5 \mathrm{mg} / \text { day of escitalopram, in- } \\
\text { creased } 5 \mathrm{mg} / \text { day every two } \\
\text { weeks, up to a maximum dosage } \\
\text { of } 15 \mathrm{mg} / \text { day }\end{array}$ & $75.2(6.9)$ & 18.85 & CSDD: 11.39 \\
\hline $\begin{array}{l}\text { Banerjee } \\
2011\end{array}$ & $\begin{array}{l}\text { NINCDS-ADR- } \\
\text { DA for proba- } \\
\text { ble or possi- } \\
\text { ble AD }\end{array}$ & $\begin{array}{l}\text { depression } \geq 4 \text { weeks's } \\
\text { duration potentially } \\
\text { needing antidepres- } \\
\text { sants; CSDD } \geq 8\end{array}$ & 326 & 39 weeks & $\begin{array}{l}\text { sertraline } 70 \mathrm{mg} / \mathrm{d} \text { (target dose: } \\
150 \mathrm{mg} / \mathrm{d} \text { ), mirtazapine } 24 \mathrm{mg} / \mathrm{d} \\
\text { (target dose: } 45 \mathrm{mg} / \mathrm{d} \text { ) }\end{array}$ & 79.3 & 18.1 & CSDD: 12.9 \\
\hline $\begin{array}{l}\text { de Vascon- } \\
\text { celos } 2007\end{array}$ & $\begin{array}{l}\text { DSM-IV for } \\
\text { dementia } \\
\text { (AD, VD, and } \\
\text { mixed) }\end{array}$ & $\begin{array}{l}\text { DSM-IV major depres- } \\
\text { sive disorder and CSDD }\end{array}$ & 31 & 6 weeks & $\begin{array}{l}\text { venlafaxine }(37.5-131.25 \mathrm{mg} / \mathrm{d} \text {, } \\
\text { mean }=75 \mathrm{mg} / \mathrm{d})\end{array}$ & $77.6(6.4)$ & $\begin{array}{l}\text { (range: } \\
10-24)\end{array}$ & $\begin{array}{l}\text { MADRS: } 24.5 \\
(7.1)\end{array}$ \\
\hline Fuchs 1993 & $\begin{array}{l}\text { DSM-III-R for } \\
\text { PDD }\end{array}$ & $\begin{array}{l}\text { DSM-III-R } 290.21 \text { (mild- } \\
\text { ly depressed) }\end{array}$ & 127 & 8 weeks & $\begin{array}{l}\text { maprotiline ( } 25 \mathrm{mg} \text { titrated to } 75 \\
\mathrm{mg} / \mathrm{d} \text {, mean max. dose } 59 \mathrm{mg} / \mathrm{d} \text { ) }\end{array}$ & $80(48-96)$ & $15.4(0-30)$ & $\begin{array}{l}\text { GDS (medi- } \\
\text { an): } 8\end{array}$ \\
\hline $\begin{array}{l}\text { Lyketsos } \\
2003\end{array}$ & $\begin{array}{l}\text { NINCDS-ADR- } \\
\text { DA for proba- } \\
\text { ble AD }\end{array}$ & $\begin{array}{l}\text { DSM-VI for major de- } \\
\text { pressive episode }\end{array}$ & 44 & 12 weeks & $\begin{array}{l}\text { sertraline ( } 25 \mathrm{mg} \text { titrated to } 150 \\
\mathrm{mg} / \mathrm{d} \text {, mean peak dose } 113 \mathrm{mg} \text { ) }\end{array}$ & 77.7 & 16.9 & $\begin{array}{l}\text { Ham-D: } \\
22.75\end{array}$ \\
\hline $\begin{array}{l}\text { Petracca } \\
1996\end{array}$ & $\begin{array}{l}\text { NINCDS-ADR- } \\
\text { DA for proba- } \\
\text { ble AD }\end{array}$ & $\begin{array}{l}\text { DSM-III-R for dys- } \\
\text { thymia or major de- } \\
\text { pression }\end{array}$ & 24 & $\begin{array}{l}6 \text { weeks }+6 \\
\text { weeks }\end{array}$ & $\begin{array}{l}\text { clomipramine ( } 25 \mathrm{mg} \text { titrated to } \\
100 \mathrm{mg} / \mathrm{d} \text { ) }\end{array}$ & $72(7.2)$ & $21.5(6.2)$ & $\begin{array}{l}\text { Ham-D:17.5 } \\
(6.0)\end{array}$ \\
\hline $\begin{array}{l}\text { Petracca } \\
2001\end{array}$ & $\begin{array}{l}\text { NINCDS-ADR- } \\
\text { DA for proba- } \\
\text { ble AD }\end{array}$ & $\begin{array}{l}\text { DSM-IV criteria for ei- } \\
\text { ther major or minor } \\
\text { depression }\end{array}$ & 41 & 6 weeks & $\begin{array}{l}\text { fluoxetine (10 } \mathrm{mg} \text { titrated to } 40 \\
\mathrm{mg} / \mathrm{d} \text { ) }\end{array}$ & 70.8 & 23.2 & Ham-D: 16.5 \\
\hline Reifler 1989 & $\begin{array}{l}\text { DSM-III for } \\
\text { PDD }\end{array}$ & $\begin{array}{l}\text { DSM-III (major depres- } \\
\text { sive disorder) }\end{array}$ & 28 & 8 weeks & imipramine (mean dose $83 \mathrm{mg} / \mathrm{d}$ ) & $72(8)$ & $17.5(5.1)$ & $\begin{array}{l}\text { Ham-D: } 18.9 \\
(3.8)\end{array}$ \\
\hline $\begin{array}{l}\text { Rosenberg } \\
2010\end{array}$ & DSM-IV for AD & $\begin{array}{l}\text { Criteria for depression } \\
\text { of } A D\end{array}$ & 131 & 12 weeks & $\begin{array}{l}\text { sertraline } 50 \mathrm{mg} / \mathrm{d} \text { increased to } \\
100 \mathrm{mg} / \mathrm{d}, \mathrm{mean}=93.1 \mathrm{mg} / \mathrm{d} \text { ) }\end{array}$ & $77.3(8.0)$ & $20.0(4.6)$ & $\begin{array}{l}\text { CSDD (me- } \\
\text { dian): } 13 \\
\text { (1st and 3rd } \\
\text { quartile: } 9 \text {, } \\
\text { 18) }\end{array}$ \\
\hline
\end{tabular}




\begin{tabular}{|c|c|c|c|c|c|c|c|c|}
\hline Roth 1996 & $\begin{array}{l}\text { DSM-III for de- } \\
\text { mentia }\end{array}$ & $\begin{array}{l}\text { DSM-III for major de- } \\
\text { pressive episode }\end{array}$ & 726 & 6 weeks & moclobemide $(400 \mathrm{mg} / \mathrm{d})$ & $74.4(8.5)$ & $20.2(4.8)$ & $24.5(5.3)$ \\
\hline $\begin{array}{l}\text { Weintraub } \\
2010 \\
\text { (extension } \\
\text { of Rosen- } \\
\text { berg 2010) }\end{array}$ & DSM-IV for AD & $\begin{array}{l}\text { Criteria for depression } \\
\text { of } A D\end{array}$ & 131 & 24 weeks & $\begin{array}{l}\text { randomised treatment with ser- } \\
\text { traline for at least partial respon- } \\
\text { ders after week } 12\end{array}$ & $77.3(8.0)$ & $20.0(4.6)$ & $\begin{array}{l}\text { CSDD (me- } \\
\text { dian): } 13 \\
\text { (1st and 3rd } \\
\text { quartile: } 9 \text {, } \\
\text { 18) }\end{array}$ \\
\hline
\end{tabular}




\section{APPEN DICES}

Appendix 1. Update Search covering time period from October 2008 to August 2017

\begin{tabular}{lll}
\hline Source & Strategy & Hits \\
\hline ALOIS & $\begin{array}{l}\text { Keyword search on tag given to studies in which antidepressant/s are the in- } \\
\text { tervention: ANT }\end{array}$ & Aug all dates $2017: 2$ \\
$\begin{array}{l}\text { www.medi- } \\
\text { cine.ox.ac.uk/alois }\end{array}$ & \\
$\begin{array}{l}\text { [Latest search 16 Au- } \\
\text { gust 2017] }\end{array}$ & & \\
\hline
\end{tabular}

MEDLINE In-process and other non-indexed citations and MEDLINE 1950-present (15 August 2017) (Ovid SP)

[Latest search $16 \mathrm{Au}$ gust 2017]
1. (anti-depres` or antidepres`).mp.

Nov 2010: 158

2. Antidepressive Agents/

3. citalopram.mp. or Citalopram/

4. escitalopram.mp.

May 2012: 123

Mar 2013: 124

Dec 2013: 83

5. paroxetine.mp. or Paroxetine/

Mar 2014:

6. fluoxetine.mp. or Fluoxetine/ 73

7. fluvoxamine.mp. or Fluvoxamine/ Nov 2014: 282

8. sertraline.mp. or Sertraline/ Oct 2015: 104

9. trazodone.mp. or Trazodone/ Jul 2016: 147

10. nefazodone.mp. Aug 2017: 181

11. venlafaxine.mp.

12. duloxetine.mp.

13. reboxetine.mp.

14. bupropion.mp. or Bupropion/

15. amoxapine.mp. or Amoxapine/

16. amitriptyline.mp. or Amitriptyline/

17. nortriptyline.mp. or Nortriptyline/

18. desipramine.mp. or Desipramine/

19. trimipramine.mp. or Trimipramine/

20. imipramine.mp. or Imipramine/

21. protriptyline.mp. or Protriptyline/

22. doxepin.mp. or Doxepin/

23. clomipramine.mp. or Clomipramine/

24. mirtazapine.mp.

25. mianserin.mp. or Mianserin/ 


\section{6. moclobemide.mp. or Moclobemide/}

27. phenelzine.mp. or Phenelzine/

28. tranylcypromine.mp. or Tranylcypromine/

29. $\left(\mathrm{SSRI}^{\star}\right.$ or "selective serotonin reuptake inhibitor" or TCA $\left.{ }^{\star}\right)$.mp.

30. or/1-29

31. Dementia/

32. Dementia, Multi-Infarct/

33. Dementia, Vascular/

34. Alzheimer Disease/

35. Lewy Body Disease/

36. Delirium/

37. Huntington Disease/

38. "Pick Disease of the Brain"/

39. Kluver-Bucy Syndrome/

40. Wernicke Encephalopathy/

41. Creutzfeldt-Jakob Syndrome/

42. Delirium, Dementia, Amnestic, Cognitive Disorders/

43. dement*.mp.

44. Alzheimer*.mp.

45. (lewy ${ }^{\star}$ and bod $\left.{ }^{\star}\right) \cdot m p$.

46. deliri ${ }^{\star} . \mathrm{mp}$.

47. ("organic brain disease" or "organic brain syndrome").mp.

48. "supra nuclear palsy".mp.

49. ("normal pressure hydrocephalus" and "shunt*").mp.

50. "benign senescent forgetfulness".mp.

51. (pick* and disease).mp.

52. (creutzfeldt or jcd or cjd).mp.

53. huntington ${ }^{\star} \cdot \mathrm{mp}$.

54. binswanger ${ }^{\star} \cdot \mathrm{mp}$.

55. korsako*.mp.

56. (mci or "subjective memory complaint" or "episodic memory").mp.

57. "pre-clinical ad".mp.

58. randomized controlled trial.pt.

59. controlled clinical trial.pt. 
(Continued)
60. random*.ab.
61. placebo.ab.
62. drug therapy.fs.
63. trial.ab.
64. or/58-63
65. (animals not (humans and animals)).sh.
66.64 not 65
67.35 or 33 or 32 or 53 or 48 or 42 or 46 or 44 or 55 or 50 or 39 or 57 or 36 or 40 or 51 or 41 or 47 or 52 or 38 or 34 or 56 or 49 or 37 or 45 or 43 or 31 or 54
68.67 and 66 and 30

\begin{tabular}{|c|c|c|}
\hline EMBASE & 1. (anti-depres* or antidepres $\left.{ }^{\star}\right) \cdot \mathrm{mp}$. & Nov 2010: 172 \\
\hline 1974-15 August 2017 & 2. Antidepressive Agents/ & May 2012: 397 \\
\hline & 3. citalopram.mp. or Citalopram/ & Mar 2013: 263 \\
\hline $\begin{array}{l}\text { [Latest search } 16 \text { Au- } \\
\text { gust 2017] }\end{array}$ & 4. escitalopram.mp. & Dec 2013: 207 \\
\hline & 5. paroxetine.mp. or Paroxetine/ & Mar 2014: \\
\hline & 6. fluoxetine.mp. or Fluoxetine/ & 165 \\
\hline & 7. fluvoxamine.mp. or Fluvoxamine/ & Nov 2014: 65 \\
\hline & 8. sertraline.mp. or Sertraline/ & Oct 2015: 162 \\
\hline & 9. trazodone.mp. or Trazodone/ & Jul 2016: 254 \\
\hline & 10. nefazodone.mp. & Aug 2017: 364 \\
\hline & 11. venlafaxine.mp. & \\
\hline & 12. duloxetine.mp. & \\
\hline & 13. reboxetine.mp. & \\
\hline & 14. bupropion.mp. or Bupropion/ & \\
\hline & 15. amoxapine.mp. or Amoxapine/ & \\
\hline & 16. amitriptyline.mp. or Amitriptyline/ & \\
\hline & 17. nortriptyline.mp. or Nortriptyline/ & \\
\hline & 18. desipramine.mp. or Desipramine/ & \\
\hline & 19. trimipramine.mp. or Trimipramine/ & \\
\hline & 20. imipramine.mp. or Imipramine/ & \\
\hline & 21. protriptyline.mp. or Protriptyline/ & \\
\hline & 22. doxepin.mp. or Doxepin/ & \\
\hline & 23. clomipramine.mp. or Clomipramine/ & \\
\hline & 24. mirtazapine.mp. & \\
\hline
\end{tabular}




\section{5. mianserin.mp. or Mianserin/}

26. moclobemide.mp. or Moclobemide/

27. phenelzine.mp. or Phenelzine/

28. tranylcypromine.mp. or Tranylcypromine/

29. $\left(\mathrm{SSRI}^{\star}\right.$ or "selective serotonin reuptake inhibitor" or TCA $\left.{ }^{\star}\right)$.mp.

30. or/1-29

31. Dementia/

32. Dementia, Multi-Infarct/

33. Dementia, Vascular/

34. Alzheimer Disease/

35. Lewy Body Disease/

36. Delirium/

37. Huntington Disease/

38. "Pick Disease of the Brain"/

39. Kluver-Bucy Syndrome/

40. Wernicke Encephalopathy/

41. Creutzfeldt-Jakob Syndrome/

42. Delirium, Dementia, Amnestic, Cognitive Disorders/

43. dement*.mp.

44. Alzheimer*.mp.

45. (lewy ${ }^{\star}$ and bod $\left.{ }^{\star}\right) \cdot \mathrm{mp}$.

46. deliri ${ }^{\star} . \mathrm{mp}$.

47. ("organic brain disease" or "organic brain syndrome").mp.

48. "supra nuclear palsy".mp.

49. ("normal pressure hydrocephalus" and "shunt*").mp.

50. "benign senescent forgetfulness".mp.

51. (pick ${ }^{\star}$ and disease).mp.

52. (creutzfeldt or jcd or cjd).mp.

53. huntington*.mp.

54. binswanger*.mp.

55. korsako*.mp.

56. (mci or "subjective memory complaint" or "episodic memory").mp.

57. "pre-clinical ad".mp.

58.35 or 33 or 32 or 53 or 48 or 42 or 46 or 44 or 55 or 50 or 39 or 57 or 36 or 40 or 51 or 41 or 47 or 52 or 38 or 34 or 56 or 49 or 37 or 45 or 43 or 31 or 54 
(Continued)
59. 30 and 58
60. randomized controlled trial/
61. random*.ab.
62. trial.ab.
63. placebo.ab.
64. controlled clinical trial/ or "control* trial*".mp.
65.60 or 63 or 64 or 61 or 62
66.59 and 65

\section{PsychINFO \\ 1806-August week 2 2017 (Ovid SP)}

[Latest search $16 \mathrm{Au}$ gust 2017]

$$
\text { 1. (anti-depres } \left.{ }^{\star} \text { or antidepres }{ }^{\star}\right) \cdot \mathrm{mp} \text {. }
$$

2. exp Antidepressant Drugs/

3. exp Citalopram/ or Citalopram.mp.

4. escitalopram.mp.

5. exp Paroxetine/ or Paroxetine.mp.

6. Fluoxetine.mp. or exp Fluoxetine/

7. exp Fluvoxamine/ or Fluvoxamine.mp.

8. Sertraline.mp. or exp Sertraline/

9. Trazodone.mp. or exp Trazodone/

10. nefazodone.mp. or exp Nefazodone/

11. venlafaxine.mp. or exp Venlafaxine/

12. duloxetine.mp.

13. reboxetine.mp.

14. exp Bupropion/ or Bupropion.mp.

15. Amoxapine.mp

16. amitriptyline.mp. or exp Amitriptyline/

17. exp Nortriptyline/ or nortriptyline.mp.

18. Desipramine.mp. or exp Desipramine/

19. Trimipramine.mp.

20. Imipramine.mp. or exp Imipramine/

21. Protriptyline.mp.

22. exp Doxepin/ or Doxepin.mp.

23. Clomipramine.mp. or exp Chlorimipramine/

24. mirtazapine.mp.

25. Mianserin.mp. or exp Mianserin/

26. exp Moclobemide/ or Moclobemide.mp.
Nov 2010: 45

May 2012: 51

Mar 2013: 34

Dec 2013: 21

Mar 2014:

22

Nov 2014: 73

Oct 2015: 38

Jul 2016: 54

Aug 2017: 48 


\section{Phenelzine.mp. or exp Phenelzine/}

28. Tranylcypromine.mp. or exp Tranylcypromine/

29. $\left(\mathrm{SSRI}^{\star}\right.$ or "selective serotonin reuptake inhibitor" or TCA $\left.{ }^{\star}\right)$.mp.

30. or/1-29

31. exp Dementia/

32. exp Vascular Dementia/

33. exp Dementia with Lewy Bodies/

34. exp Senile Dementia/

35. exp Presenile Dementia/

36. multi-infarct dementia.mp.

37. exp Alzheimers Disease/

38. exp Delirium/

39. exp Huntingtons Disease/

40. exp Picks Disease/

41. exp Kluver Bucy Syndrome/

42. exp Wernickes Syndrome/ or exp Korsakoffs Psychosis/

43. exp Creutzfeldt Jakob Syndrome/

44. exp Cognitive Impairment/

45. dement*.mp.

46. Alzheimer*.mp.

47. (lewy ${ }^{\star}$ and bod $\left.{ }^{\star}\right) \cdot \mathrm{mp}$.

48. deliri ${ }^{\star} . \mathrm{mp}$

49. ("organic brain disease" or "organic brain syndrome").mp.

50. "supra nuclear palsy".mp.

51. ("normal pressure hydrocephalus" and "shunt*").mp.

52. "benign senescent forgetfulness".mp.

53. (pick* and disease).mp.

54. (creutzfeldt or jcd or cjd).mp.

55. huntington*.mp.

56. binswanger*.mp.

57. korsako*.mp.

58. or/31-57

59. 30 and 58

60. random ${ }^{\star} \cdot a b$. 
(Continued)
61. trial.ab.
62. placebo.ab.
63. exp Clinical Trials/
64.60 or 63 or 61 or 62
65.59 and 64

CINAHL (EBSCOhost)

[Latest search $16 \mathrm{Au}$ gust 2017]
S1 TX (anti-depres* or antidepres*)

S2 TX Antidepressive

S3 (MH "Antidepressive Agents")

S4 TX paroxetine

S5 TX fluoxetine

S6 TX fluvoxamine

S7 TX sertraline

S8 TX trazodone

S9 TX nefazodone

S10 TX venlafaxine

S11 TX duloxetine

S12 TX reboxetine

S13 TX bupropion

S14 TX amoxapine

S15 TX amitriptyline

S16 TX nortriptyline

S17 TX trimipramine

S18 TX desipramine

S19 TX imipramine

S20 TX protriptyline

S21 TX doxepin

S22 TX clomipramine

S23 TX mirtazapine

S24 TX mianserin

S25 TX moclobemide

S26 TX phenelzine

S27 TX tranylcypromine

S28 TX escitalopram

S29 TX citalopram
Nov 2010: 29

May 2012: 34

Mar 2013: 11

Dec 2013: 4

Mar 2014:

9

Nov 2014: 21

Oct 2015: 5

Jul 2016: 8

Aug 2017: 6 
(Continued)

$\mathrm{S} 30 \mathrm{~S} 1$ or $\mathrm{S} 2$ or $\mathrm{S} 3$ or $\mathrm{S} 4$ or $\mathrm{S} 5$ or $\mathrm{S} 6$ or $\mathrm{S} 7$ or $\mathrm{S} 8$ or $\mathrm{S} 9$ or $\mathrm{S} 10$ or $\mathrm{S} 11$ or $\mathrm{S} 12$ or $\mathrm{S} 13$ or $\mathrm{S} 14$ or $\mathrm{S} 15$ or $\mathrm{S} 16$ or $\mathrm{S} 17$ or $\mathrm{S} 18$ or $\mathrm{S} 19$ or $\mathrm{S} 20$ or $\mathrm{S} 21$ or $\mathrm{S} 22$ or $\mathrm{S} 23$ or $\mathrm{S} 24$ or $\mathrm{S} 25$ or $\mathrm{S} 26$ or $\mathrm{S} 27$ or $\mathrm{S} 28$ or $\mathrm{S} 29$

S31 ("Dementia") or (MH "Dementia+") or (MH "Dementia, Vascular+") or (MH "Delirium, Dementia, Amnestic, Cognitive Disorders+") or (MH "Dementia, Multi-Infarct") or (MH "Dementia, Presenile+") or (MH "Dementia, Senile+")

S32 ("Alzheimer Disease") or (MH "Alzheimer's Disease")

S33 "Lewy Body Disease"

S34 S31 or S32 or S33

S35 S30 and S34

S36 ("clinical trial") or (MH "Clinical Trials+")

S37 AB placebo

S38 AB random*

S39 AB (double-blind ${ }^{\star}$ ) OR (singl*-blind*) OR (treble-blind*) OR (triple-blind*)

S40 S36 or S37 or S38 or S39

S41 S35 and S40

CENTRAL (The

Cochrane Library)

[Latest search $16 \mathrm{Au}$ gust 2017]

\section{\#1 MeSH descriptor Dementia explode all trees}

\#2 MeSH descriptor Delirium, this term only

\#3 MeSH descriptor Wernicke Encephalopathy, this term only

\#4 MeSH descriptor Delirium, Dementia, Amnestic, Cognitive Disorders, this term only

\#5 dement*

\#6 alzheimer*

\#7 "lewy* bod*"

\#8 deliri*

\#9 "chronic cerebrovascular"

\#10 "organic brain disease" or "organic brain syndrome"

\#11 "normal pressure hydrocephalus" and "shunt"

\#12 "benign senescent forgetfulness"

\#13 "cerebr* deteriorat*"

\#14 "cerebral* insufficient*"

\#15 "pick* disease"

\#16 creutzfeldt or jcd or cjd

\#17 huntington *

\#18 binswanger ${ }^{\star}$

\#19 korsako*
May 2012: 25

Mar 2013: 2

Dec 2013: 9

Mar 2014: 41

Nov 2014: 45

Oct 2015: 27

Jul 2016: 16

Aug 2017: 19 
\#20 (\#1 OR \#2 OR \#3 OR \#4 OR \#5 OR \#6 OR \#7 OR \#8 OR \#9 OR \#10 OR \#11 OR \#12 OR \#13 OR \#14 OR \#15 OR \#16 OR \#17 OR \#18 OR \#19)

\#21 paroxetine OR fluoxetine OR fluvoxamine OR sertraline OR trazodone OR nefazodone $O R$ venlafaxine $O R$ duloxetine $O R$ reboxetine $O R$ bupropion OR amoxapine OR amitriptyline OR nortriptyline OR trimipramine OR desipramine OR imipramine OR protriptyline OR doxepin OR clomipramine OR mirtazapine OR mianserin OR moclobemide OR phenelzine OR tranylcypromine OR escitalopram OR citalopram in Trials

\#22 (\#20 AND \#21), from 2015 to 2016 [latest date restriction shown]

\section{LILACS (BIREME)}

[Latest search $16 \mathrm{Au}$ gust 2017] antidepressant OR antidepressants OR paroxetine OR fluoxetine OR fluvoxamine OR sertraline OR trazodone OR nefazodone OR venlafaxine OR duloxetine OR reboxetine OR bupropion OR amoxapine OR amitriptyline OR nortriptyline OR trimipramine OR desipramine OR imipramine OR protriptyline OR doxepin OR clomipramine OR mirtazapine OR mianserin OR moclobemide OR phenelzine OR tranylcypromine OR escitalopram OR citalopram [Words] and dementia OR alzheimer OR demência OR demencia OR cognición OR cognição OR cognition OR cognitive OR MCI [Words]
Nov 2010: 34

May 2012: 16

Mar 2013: 7

Dec 2013: 0

Mar 2014: 0

Nov 2014: 0

Oct 2015: 0

Jul 2016: 10

Aug 2017: 5

Nov 2010: 332

May 2012: 400

Mar 2013: 205

Dec 2013: 161

Mar 2014: 271

Nov 2014: 132

Oct 2015: 172

Jul 2016: 350

Aug 2017: 353

Nov 2010: 24

May 2012: 9

Mar 2013: 6

Dec 2013: 9

Mar 2014: 5

Nov 2014: 0

Oct 2015: 4

Jul 2016: 18

Aug 2017: 14 
(Continued)

WHO Portal (ICTRP)

[Latest search $16 \mathrm{Au}$ gust 2017]
\#1 Interventional Studies | dementia OR alzheimers OR AD OR alzheimer's OR alzheimer OR lewy OR FTLD OR FLD OR MCI OR cognitive OR cognition | paroxetine OR fluoxetine OR fluvoxamine OR sertraline OR trazodone OR nefazodone OR venlafaxine OR duloxetine OR reboxetine OR bupropion OR amoxapine OR amitriptyline OR nortriptyline OR trimipramine OR desipramine OR imipramine OR protriptyline |

\#2 Interventional Studies | dementia OR alzheimers OR AD OR alzheimer's OR alzheimer OR lewy OR FTLD OR FLD OR MCI OR cognitive OR cognition | doxepin OR clomipramine OR mirtazapine OR mianserin OR moclobemide OR phenelzine OR tranylcypromine OR escitalopram OR citalopram
Nov 2010: 5

May 2012: 37

Mar 2013: 7

Dec 2013: 9

Mar 2014: 5

Nov 2014: 0

Oct 2015: 6

Jul 2016: 2

Aug 2017: 312

Nov 2010: 827

May 2012: 1233

Mar 2013: 456

Dec 2013: 495

Mar 2014:

599

Nov 2014: 620

Oct 2015: 520

Jul 2016: 859

Aug 2017: 1304

TOTAL: 6913

TOTAL after de-duplication and first assessment based on titles and abstracts by the CDCIG Information 308 Specialist

Appendix 2. Update Search covering time period from October 2007 to October 2008

\begin{tabular}{lll}
\hline Source & Date Range Searched & Hits Retrieved \\
\hline MEDLINE (pubmed) & Oct 07-oct 08 & 10 \\
\hline Embase (Ovid SP) & 2007 -oct 08 & 10 \\
\hline PsycINFO (Ovid SP) & 2007 -oct 08 & 9 \\
\hline CINAHL (Ovid SP) & 2007-oct 08 & 7 \\
\hline Lilacs (bireme) & $2007-08$ & 0 \\
\hline CDCIG SR* & $2007-08$ & 6 \\
\hline
\end{tabular}


(Continued)

CENTRAL (The Cochrane Library) issue 42008

\begin{tabular}{|c|c|c|}
\hline ISTP Conference Proceedings http://portal.isiknowledge.com/portal.cgi & 2007-08 & 2 \\
\hline Australian Digital Theses Program & & 0 \\
\hline
\end{tabular}

\section{Canadian Theses and Dissertations}

http://www.collectionscanada.ca/thesescanada/index-e.html

\section{DATAD}

http://www.aau.org/datad/backgrd.htm

\begin{tabular}{ll}
\hline Dissertation Abstract Online & Not done \\
http://wwwlib.umi.com/dissertations/gateway &
\end{tabular}

UK National Research Register (archive)

Done with CCT

http://www.update-software.com/projects/nrr/

Current Controlled trials: Meta Register of Controlled trials (mRCT)

all

8

http://www.controlled-trials.com/

\begin{tabular}{ll}
\hline ISRCTN Register $\quad$ Done together with CCT
\end{tabular}

\begin{tabular}{ll}
\hline Nederlands Trial Register http://www.trialregister.nl/trialreg/index.asp & 0 \\
\hline ClinicalTrials.gov & Done together with CCT \\
http://www.ClinicalTrials.gov & \\
\hline IPFMA Clinical Trials Register & 0 \\
www.ifpma.org/clinicaltrials.html & Not done \\
\hline Lundbeck Clinical Trial Registry http://www.lundbecktrials.com & Not done \\
\hline Forest Clinical trial Registry http://www.forestclinicaltrials.com/ & 0 \\
\hline UMIN Japan Trial Register & \\
http://www.umin.ac.jp/ctr/ & \\
\hline
\end{tabular}

\section{WHAT'S NEW}




\begin{tabular}{lll}
\hline Date & Event & Description \\
\hline 16 August 2017 & $\begin{array}{l}\text { New citation required and conclusions } \\
\text { have changed }\end{array}$ & $\begin{array}{l}\text { New studies included. Background and methods were updated } \\
\text { in line with MECIR standards, and GRADE incorporated. Conclu- } \\
\text { sions changed. }\end{array}$ \\
\hline 16 August 2017 & New search has been performed & $\begin{array}{l}\text { The most recent search for this review was performed on 16 Au- } \\
\text { gust 2017. }\end{array}$ \\
\hline
\end{tabular}

\section{HISTORY}

Protocol first published: Issue 2, 1998

Review first published: Issue 4, 2002

\begin{tabular}{|c|c|c|}
\hline Date & Event & Description \\
\hline 22 July 2016 & New search has been performed & $\begin{array}{l}\text { A top-up search was performed for this review on } 22 \text { July } 2016 . \\
\text { No new studies were identified for inclusion from this search. }\end{array}$ \\
\hline 12 November 2014 & New search has been performed & A new literature search has been carried out. \\
\hline 1 December 2013 & New search has been performed & $\begin{array}{l}\text { A pre-publication search was performed for this review on } 1 \text { De- } \\
\text { cember } 2013 \text {. }\end{array}$ \\
\hline 17 May 2012 & New search has been performed & $\begin{array}{l}\text { A new search was performed for this review in May 2012. The } \\
\text { new search retrieved new studies for consideration by the au- } \\
\text { thors. }\end{array}$ \\
\hline 29 November 2010 & Amended & $\begin{array}{l}\text { A new search was performed for this review on } 29 \text { November } \\
\text { 2010. The search retrieved new studies for consideration by the } \\
\text { authors }\end{array}$ \\
\hline 21 May 2009 & New search has been performed & $\begin{array}{l}\text { Update searches of December } 2007 \text { and October } 2008 \text { retrieved } \\
\text { new studies for consideration by the authors. } \\
52 \text { references were retrieved in a new search. We found only one } \\
\text { trial that met our inclusion criteria for this review (de Vasconce- } \\
\text { los 2007). There were three ongoing studies registered on Clin- } \\
\text { icaltrials.com Banerjee 2006, Lyketsos 2004a, Sverdlik 2005a. } \\
\text { There is no clear evidence that antidepressants are effective in } \\
\text { the treatment of depression in dementia. }\end{array}$ \\
\hline 21 May 2008 & Amended & Converted to new review format. \\
\hline 24 August 2005 & New search has been performed & $\begin{array}{l}\text { Update 2005: new searches in the } 2005 \text { edition of the British Na- } \\
\text { tional Formulary (BNF) used the following extra search terms: es- } \\
\text { citalopram or cipralex or dosulepin or dothapex or prepadine. }\end{array}$ \\
\hline 17 July 2002 & $\begin{array}{l}\text { New citation required and conclusions } \\
\text { have changed }\end{array}$ & Substantive amendment \\
\hline
\end{tabular}

\section{CONTRIBUTIONS OF AUTHORS}

\section{Original review (2002/2005)}


-All correspondence: Jatinder Bains (JB)

-Drafting review versions: Jatinder B, Jacqueline S Birks (JSB), Tom Dening (TD)

-Selections of studies: JB and JSB

-Data into RevMan: JB

-Interpretation of data analyses: JB and JSB

-Contact editor: Gordon Wilcock

-Consumer editor: Brian Draper

-This review was peer reviewed by members of the Cochrane Depression Anxiety and Neurosis Group

\section{8 update}

-All correspondence: Robert Dudas (RD)

-Drafting review versions: RD, JM

-Selection of studies: RD, TD, RM

-Data extraction and into RevMan: RM, RD

-Interpretation of data analyses: RD, RM, TD, JM

\section{DECLARATIONS OF INTEREST}

Robert Dudas: none known

Reem Malouf: none known

Jenny McCleery: none known

Tom Dening: none known

\section{SOURCES OF SUPPORT}

\section{Internal sources}

- Cambridgeshire and Peterborough NHS Foundation Trust, UK.

- Cochrane Dementia and Cognitive Improvement Group, Nuffield Department of Medicine, Oxford University, UK.

- Department of Psychiatry, University of Cambridge, UK.

- Division of Psychiatry and Applied Psychology, School of Medicine, University of Nottingham, UK.

- Norfolk and Suffolk NHS Foundation Trust, UK.

\section{External sources}

- Collaborations for Leadership in Applied Health Research and Care (CLAHRC), UK.

- NIHR, UK.

This update was supported by the National Institute for Health Research (NIHR), via Cochrane Infrastructure funding to the Cochrane Dementia and Cognitive Improvement group. The views and opinions expressed therein are those of the authors and do not necessarily reflect those of the Systematic Reviews Programme, NIHR, National Health Service or the Department of Health

\section{DIFFERENCES BETWEEN PROTOCOLANDREVIEW}

The original wording of the description of the Types of studies has been changed by removing the word "unconfounded" and its explanation ("i.e. where any differences in the outcome measures between the treatment and control group were likely the result of the intervention and not that of a confounding factor, e.g. difference in age)".

\section{N O T E S}

None.

\section{N DEX TERMS}

\section{Medical Subject Headings (MeSH)}

Activities of Daily Living; Antidepressive Agents [*therapeutic use]; Cognition; Dementia [ ${ }^{*}$ psychology]; Depression [ ${ }^{\star}$ drug therapy]; Patient Dropouts [statistics \& numerical data]; Randomized Controlled Trials as Topic; Remission Induction; Time Factors; Treatment Outcome

\section{MeSH check words}

Humans 